\title{
The mechanism mediating fast neurotransmitter release at the calyx of Held synapse
}

\author{
PhD Thesis \\ in partial fulfillment of the requirements \\ for the degree 'Dr. rer. nat.' \\ in the Neuroscience Program \\ at the Georg-August-University Göttingen, \\ Faculty of Biology
}

submitted by

Kristian Wadel

born in

Friedberg, Germany 


\section{Declaration}

I hereby declare that my $\mathrm{PhD}$ thesis 'The mechanism mediating fast neurotransmitter release at the calyx of Held synapse' has been written independently with no other aids or sources than quoted.

Göttingen, September $16^{\text {th }} 2008$ 



\section{Contents}

1 Introduction 1

1.1 Neurotransmitter release - exemplified at the calyx of Held synapse . . 1

1.1.1 Morphology . . . . . . . . . . . . . . . . . 1

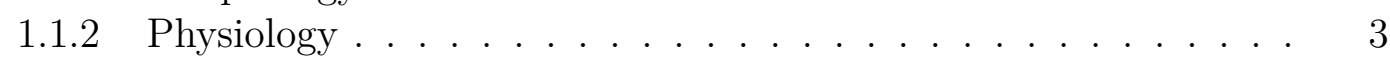

1.2 Motivation . . . . . . . . . . . . . . . . . . . . . . 14

2 Material and Methods 17

2.1 Slice preparation . . . . . . . . . . . . . . . . . . 17

2.2 Solutions . . . . . . . . . . . . . . . . . . . . . . . . . . . . . . . . . 19

2.2.1 Extracellular solution . . . . . . . . . . . . . . . . 19

2.2 .2 Intracellular solutions . . . . . . . . . . . . . . . . . 20

2.3 Electrophysiological recordings, calcium uncaging and calcium imaging 22

2.3.1 Experimental setup . . . . . . . . . . . . . . . 22

2.3.2 Measurements of intracellular calcium . . . . . . . . . . . . . 24

2.4 Data analysis . . . . . . . . . . . . . . . . . . 27

2.4 Deconvolution . . . . . . . . . . . . . . . 28

2.4 .2 Kinetic release models . . . . . . . . . . . . . . . . 28

3 Results 32

3.1 Heterogeneity in release probability at the calyx of Held . . . . . . . . 32

3.2 The role of synaptobrevin in release at the calyx of Held . . . . . . . . 41

3.3 Cleavage of synaptobrevin alters the kinetics of fast neurotransmitter release ........................... 43

3.4 Rabphilin3a as a potential modulator of release at the calyx of Held . . 50

4 Discussion $\quad 54$

5 Summary 62

$\begin{array}{ll}\text { Bibliography } & 64\end{array}$ 
$\begin{array}{ll}\text { A Appendix } & 74\end{array}$

A.1 Abbreviations . . . . . . . . . . . . . . . . . . . 74

$\begin{array}{ll}\text { Acknowledgment } & 76\end{array}$

$\begin{array}{ll}\text { Curriculum Vitae } & 77\end{array}$

Publication list 


\section{Introduction}

\subsection{Neurotransmitter release - exemplified at the calyx of Held synapse}

The calyx of Held synapse was first described in 1893 by the German anatomist Hans Held. Its rather unique features have established it as a model system early on and throughout the conceptional and technological advances in the field of neuroscience. This introduction is meant to reflect this development, to present our knowledge of the model synapse that the calyx of Held has become in relation to our general understanding of synaptic function.

\subsubsection{Morphology}

The first description of the calycial terminals in the auditory brain stem of cats originated from Golgi staining experiments conducted by the German anatomist Hans Held in 1893. This discovery was made at a time when the nature of connectivity within the brain was heavily disputed. Held, in support of the reticular brain theory, proposed that the axons giving rise to the calyx cross midline during development to eventually fuse onto the principle cells of the medial nucleus of the trapezoid body (MNTB). Ramon y Cajal however viewed the calyx of Held as an example to disprove the reticularists.

Further studies employing staining techniques (Harrison and Irving, 1966), electron microscopy (EM) (Lenn and Reese, 1966; Nakajima, 1971) and intraaxonal recordings combined with horseradish peroxidase staining (Friauf and Ostwald, 1988) investigated 
(a)

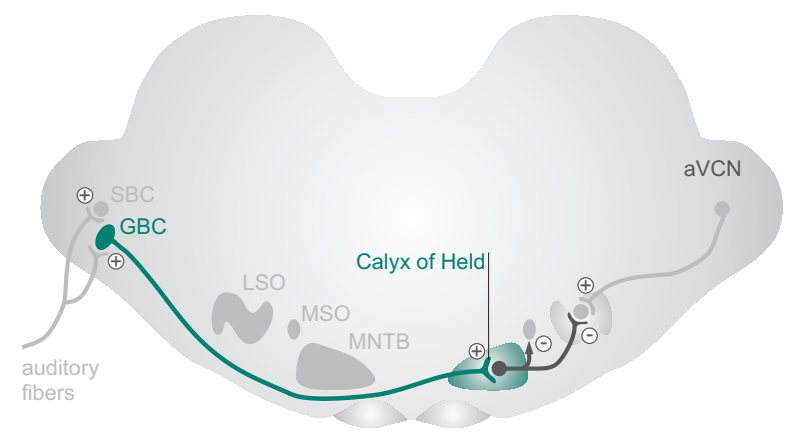

(b)

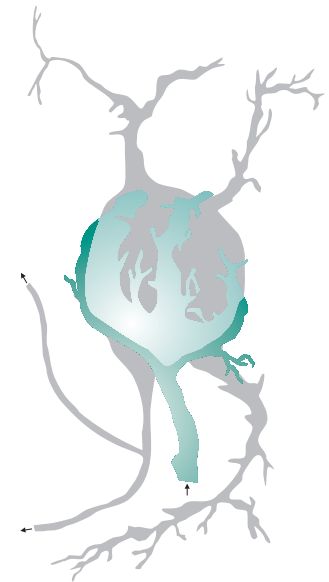

Figure 1.1: (a) Diagram of the superior olivary complex circuitry. Auditory fibers form synapses onto globular (GBC) and spherical bushy cells (SBC) in the anterior ventral cochlear nucleus (aVCN). GBC axons cross midline and give rise to the calyx of Held terminal in the medial nucleus of the trapezoid body (MNTB). Its target, the glycinergic principle cell of the MNTB, projects to the lateral superior olive (LSO) which is thought to serve as a coincidence detector for auditory signals. Plus and minus signs indicate excitatory and inhibitory synapses. (b) Illustration of the calyx of Held (green) and its corresponding principle cell (gray). Adapted from von Gersdorff and Borst (2002)

the connectivity in the auditory pathway that the calyx of Held is part of. The calycial axons are formed by globular bushy cells (GBCs) in the anterior ventral cochlear nucleus (aVCN). Consistent across mammalian species such as cat, bat and rodents, these projections form a direct connection arising in the aVCN, through the trapezoid body, across midline to branch of at the contralateral MNTB where they form large terminals, the calyx of Held, onto a principal cell (Fig. 1.1(a)). These afferents present the main input to the MNTB, however the principle cells also receive small inputs. In younger animals, axons forming two calyx terminals have been described (Kuwabara et al, 1991).

A detailed study of the morphology of a single postnatal day 9 (p9) rat calyx of Held terminal and its connecting principle cell by serial reconstruction of ultra thin sections imaged with electron microscopy was conducted by Sätzler et al. The calyx terminal had a thickness of $<1 \mu \mathrm{m}$ covering $\sim 40 \%$ of the principle cell that was $22 \mu \mathrm{m}$ and $18 \mu \mathrm{m}$ 
in its longer and shorter diameter. They identified 554 active zones (AZs) with a mean distance of $590 \mathrm{~nm}$. On average, two synaptic vesicles were docked at the active zone whereas 2800 vesicles were found within $20 \mathrm{~nm}$ from the active zone. By extrapolation, the total number of vesicles within the terminal was estimated to be higher than 70000 (Sätzler et al, 2002).

The calyx of Held has also been a model system for the study of synapse formation. Experiments using the established Golgi staining technique could show the developmental stages from the growth-cone bearing migrating axon to a cup-shaped terminal (around postnatal day 5) and the mature calyx terminal with its digit-like structures (seen around postnatal day 14) (Morest, 1968; Kandler and Friauf, 1993). With development, the calyx of Held also shows subcellular specializations. Rowland et al reported the atypical structural organization of puncta adherentia and mitochondria which they named mitochondria-associated adherens complex, thought to play a role in vesicle and energy supply, calcium homeostasis and synaptic stability to support high frequency transmission at this synapse (Rowland et al, 2000). Wimmer et al have shown a 'donut'like assembly of synaptic vesicles and active zones arranged around mitochondria by confocal microscopy and electron microscopy that forms after the onset of hearing at p11-p12 (Wimmer et al, 2006).

\subsubsection{Physiology}

Studies that have investigated the morphology of the calyx of Held synapse by electron microscopy already proposed that is glutamatergic (Lenn and Reese, 1966; Nakajima, 1971). More direct evidence was provided by experiments mapping glutamate-like immunoreactivity in the MNTB which was most prominently found at the calyx of Held (Grandes and Streit, 1989).

Intraaxonal recordings could show that GBCs present peristimulus time histogram responses much like the primary afferents, in a first attempt to correlate electrophysiological characteristics and the morphology of cell types found in the aVCN (Friauf and Ostwald, 1988). Intracellular recordings from MNTB principle cells showed that excitatory postsynaptic potentials (EPSPs) could be blocked by the AMPA/ kainate receptor antagonists CNQX and DNQX (Banks and Smith, 1992). This was confirmed by the first whole-cell voltage clamp recordings which described the excitatory postsy- 
naptic currents (EPSCs) to be mediated by AMPA and NMDA receptors with distinct kinetics (Forsythe and Barnes-Davies, 1993a). Additionally MNTB principle cells receive small excitatory and inhibitory inputs. It has been shown that inhibitory postsynaptic currents (IPSCs) are initially mediated by GABA receptors, but are driven by glycine receptors later in development (Banks and Smith, 1992; Awatramani et al, 2004).

The presynaptic channels mediating action potential (AP) firing have been characterized both electrophysiologically as well as immunohistochemically. Excitation of GBCs passes through a myelinated axon via saltatory conduction. AP generation can be completely blocked by application of the sodium channel blocker tetrodotoxin (TTX). Voltage-gated sodium channels are found in high density at nodes of Ranvier and the heminode (the unmyelinated last segment of the axon) but only a low density is found at the terminal. It has been shown that there is a developmental increase in $\mathrm{Na}_{\mathrm{v}} 1.6$ $\alpha$-subunit expression at the calyx heminode. This increase, combined with the apparent absence of sodium channels in the terminal, leads to a shortening of the AP and avoids changes in the sodium gradient that is needed to drive $\mathrm{Ca}^{2+}$ extrusion mechanisms. The variable expression of $\mathrm{Na}^{+}$channels could therefore serve as one of the properties that enable high-frequency transmission at the calyx of Held (Leão et al, 2005).

Forsythe and Barnes-Davies have also studied the conductances mediating AP generation and identified an inward sodium current and a low- and a high-voltage activated potassium current $\left(\mathrm{I}_{\mathrm{K}, \mathrm{LV}}, \mathrm{I}_{\mathrm{K}, \mathrm{HV}}\right)$ as well as a hyperpolarization-activated current $\left(\mathrm{I}_{\mathrm{H}}\right)$ (Forsythe and Barnes-Davies, 1993b). $\mathrm{I}_{\mathrm{K}, \mathrm{LV}}$ is attributed to the $\mathrm{K}_{\mathrm{v}} 1$ family of potassium channels, $\mathrm{I}_{\mathrm{K}, \mathrm{HV}}$ to the $\mathrm{K}_{\mathrm{v}} 3$ family. Again, expression is differential between the heminode and the terminal. $\mathrm{K}_{\mathrm{v}} 1$ channels colocalize with the $\mathrm{Na}_{\mathrm{v}} 1.6$ channels in the heminode at the light microscopic level and are absent from the terminal. $\mathrm{K}_{\mathrm{v}} 1$ channels are only found in the terminal. Apart from these delayed rectifiers, $\mathrm{I}_{\mathrm{H}}$ and $\mathrm{Ca}^{2+}$-activated $\mathrm{K}^{+}$ channels (BK) have been described presynaptically. Their physiological role at the calyx of Held, however, remains unclear.

Various other receptors have also been found in the presynaptic terminal: mGluRs, $\mathrm{GABA}_{\mathrm{B}}$, noradrenergic $\alpha 2$ and adenosine receptors, all of which can modulate transmitter release at the calyx of Held (reviewed in Schneggenburger and Forsythe, 2006). 


\section{Calcium channels, cytosolic calcium and neurotransmitter release}

Wu et al studied the contribution of $\mathrm{Ca}^{2+}$ channel subtypes to neurotransmitter release at the calyx of Held. Subtype specific toxins were used to identify the high-voltage activated P/Q-, N- and R-type channels $\left(\mathrm{Ca}_{\mathrm{v}} 2.1, \mathrm{Ca}_{\mathrm{v}} 2.2, \mathrm{Ca}_{\mathrm{v}} 2.3\right)$ as mediators of the presynaptic $\mathrm{Ca}^{2+}$ current in animals younger than p10. In response to a single AP, $\mathrm{P} / \mathrm{Q}$-type channels account for $\sim 50 \%$ of the measured $\mathrm{Ca}^{2+}$-current $\left(\mathrm{I}_{\mathrm{Ca}}\right), \mathrm{N}$ - and R-type for $\sim 25 \%$ each. Immunocytochemical analysis of the channel distribution hinted at a differential distribution of these subtypes, with $\mathrm{N}$ - and R-type channels being predominantly located more distant from the release sites (Wu et al, 1999). The fraction of the $\mathrm{Ca}^{2+}$ current attributed to $\mathrm{N}$ - and R-type channels is reduced from $\mathrm{p} 7$ on and diminished by p10, leaving P/Q-type channels as the predominant subtype (Iwasaki and Takahashi, 1998; Iwasaki et al, 2000). Studies performed with $\alpha_{1 \mathrm{~A}}$-subtype-deficient mice, which lack P/Q-type currents, showed that the upregulation of N-type channel expression can partially compensate for the lack of $\mathrm{P} / \mathrm{Q}$ channels. Interestingly, $\mathrm{Ca}^{2+}$ current facilitation was absent in these KO mice (Inchauspe et al, 2004; Ishikawa et al, 2005).

With its unusually large size, the calyx of Held serves as a good model system to study the intracellular calcium concentration $\left(\left[\mathrm{Ca}^{2+}\right]_{\mathrm{i}}\right)$, especially its spatial and temporal characteristics after AP induced calcium influx, the calcium sensitivity of neurotransmitter release and the cell's mechanisms to control $\left[\mathrm{Ca}^{2+}\right]_{\mathrm{i}}$.

Borst and Sakmann measured the $\mathrm{I}_{\mathrm{Ca}}$ induced by an AP waveform in whole-cell voltage clamp experiments. The recorded $\mathrm{I}_{\mathrm{Ca}}$ had a Gaussian-like shape with a full width of half maximum (FWHM) of $0.36 \mathrm{~ms}$ with a peak of $2.5 \mathrm{nA}$ and a charge integral of $0.92 \mathrm{pC}$ on average at room temperature $(\mathrm{RT})$. The $\mathrm{I}_{\mathrm{Ca}}$ increased in amplitude and got briefer at physiological temperature $\left(36^{\circ} \mathrm{C}\right)$ (Borst and Sakmann, 1998).

Although single $\mathrm{Ca}^{2+}$-channel conductances have not been obtained from the calyx of Held, about $25000 \mathrm{Ca}^{2+}$-channels would have to open to account for an $\mathrm{I}_{\mathrm{Ca}}$ of $2.5 \mathrm{nA}$ (assuming a maximal channel conductance of $0.1 \mathrm{pA}$ as found for L-type channels). However, the open probability for P/Q-type channels is low and likely even lower when channel opening is governed by an AP. The total number of $\mathrm{Ca}^{2+}$-channels is therefore expected to be much higher. 
Direct access to the presynaptic terminal allows for dialysis of controlled amounts of $\mathrm{Ca}^{2+}$-sensitive fluorescent dyes in order to measure the $\mathrm{Ca}^{2+}$ signal underlying release. Helmchen et al measured the resting $\left[\mathrm{Ca}^{2+}\right]$ at the calyx of Held to be $40 \mathrm{nM}$ at RT and estimated a calcium binding ratio $\left(\kappa_{\mathrm{s}}\right)$ of 40 . This implies that $2.5 \%$ of the $\mathrm{Ca}^{2+}$ ions entering the terminal after AP induced channel opening remain free after buffer equilibrium is reached. The volume averaged $\mathrm{Ca}^{2+}$ concentration will therefore only increase by $300 \mathrm{nM}$ rather than $12 \mu \mathrm{M}(0.96 \mathrm{pC}$ charge entering the terminal with a volume of $\left.\sim 400 \mu \mathrm{m}^{3}\right)$. The decay time constant of the volume averaged $\left[\mathrm{Ca}^{2+}\right]_{\mathrm{i}}$ was measured to be $\sim 106 \mathrm{~ms}$, which represents the sum of clearance of $\mathrm{Ca}^{2+}$ from the cytosol (extrusion via the plasma membrane, uptake into organelles i.e. mitochondria) and unbinding from the buffer(s) (Helmchen et al, 1997). A recent study has highlighted the importance of the endogenous mobile $\mathrm{Ca}^{2+}$ buffer parvalbumine in shaping the $\left[\mathrm{Ca}^{2+}\right]_{\mathrm{i}}$ decay and estimated the decay time constant to be $\sim 30 \mathrm{~ms}$ in unperturbed calyces (Müller et al, 2007).

However, volume averaged $\mathrm{Ca}^{2+}$ measurements cannot reflect the complex $\mathrm{Ca}^{2+}$ transients that arise in the vicinity of $\mathrm{Ca}^{2+}$ channels. In order to probe the coupling of $\mathrm{Ca}^{2+}$ influx and vesicular release, exogenous buffers such as EGTA and BAPTA have been used as an assay for the diffusional distance of $\mathrm{Ca}^{2+}$. These chelators can effectively reduce the diffusion of $\mathrm{Ca}^{2+}$ ions from the channel pore into the terminal. The mean distance an ion travels before being captured by the buffer depends on its on-binding rate (Neher, 1998). The on-binding rate of EGTA is $\sim 160$-fold smaller than BAPTA's, so that differential effects of the two buffers on transmitter release can infer information on channel-release-coupling (Naraghi and Neher, 1997). It has to be noted that $\mathrm{Ca}^{2+}$ indicator dyes also act as exogenous buffers. Their contribution, especially that of high affinity ones, to $\mathrm{Ca}^{2+}$ buffering within the cell cannot be neglected (see Neher, 2008).

Borst and Sakmann studied the effect of EGTA on neurotransmitter release at the calyx of Held. EPSC amplitudes were reduced by low millimolar concentrations of EGTA and up to $50 \%$ in $10 \mathrm{mM}$ (Borst and Sakmann, 1996). The effectiveness of EGTA has previously been shown in chromaffin cells (Neher and Marty, 1982), whereas it is ineffective in the squid giant synapse where a very tight coupling of vesicles with single $\mathrm{Ca}^{2+}$ channels has been postulated (Adler et al, 1991; Augustine et al, 1991). 
Cell attached recordings of the release face of the calyx-type synapse of the chick ciliary ganglion showed large $\mathrm{Ca}^{2+}$ conductances which were attributed to $\mathrm{Ca}^{2+}$ channel clusters (Stanley, 1991). Borst and Sakmann implicated that at the calyx of Held multiple $\mathrm{Ca}^{2+}$ channels govern the release of a single vesicle (channel domain overlap) (Borst and Sakmann, 1996). The measured EPSC amplitudes show a supralinear relationship to both peak $\mathrm{I}_{\mathrm{Ca}}$ and its integral which supports the concept of overlapping domains (Borst and Sakmann, 1999). At the squid giant axon terminal, the recruitment of additional $\mathrm{Ca}^{2+}$ channels only leads to a linear increase in release, again illustrating the tight coupling of single channels and vesicles (Augustine et al, 1991).

There is another marked difference between the calyx and the squid giant axon. At the calyx of Held, it has been found that $1 \mathrm{mM}$ BAPTA and $10 \mathrm{mM}$ EGTA are similarly effective in blocking neurotransmitter release (Borst et al, 1995; Borst and Sakmann, 1996). This result cannot be explained by models that assume a homogeneous vesicle population (Naraghi and Neher, 1997), but is in line with models that assume a variable channel-vesicle distance among release sites within a single calyx (Meinrenken et al, 2002).

Transient and localized 'hot spots' of $\mathrm{Ca}^{2+}$ entry have been measured using $n$ aequorin-J, which emits blue light after binding $\mathrm{Ca}^{2+}$, in squid (Llinás et al, 1992) and by using total internal reflection fluorescence microscopy (TIRFM) in retinal bipolar cells, saccular haircells (Zenisek et al, 2003) and chromaffin cells (Becherer et al, 2003). Although microscopy techniques have improved in both spatial and time resolution, there is, as of now, still no technique that would allow the exact measurement of an AP invoked $\left[\mathrm{Ca}^{2+}\right]_{\mathrm{i}}$ transient considering that it has a microdomain nature and fast kinetics (which would ideally be measured at the membrane/ site of $\mathrm{Ca}^{2+}$ entry alone).

Facing the difficulties in measuring the $\left[\mathrm{Ca}^{2+}\right]_{\mathrm{i}}$ transients directly, Heidelberger et al have relied on uniform elevations of $\left[\mathrm{Ca}^{2+}\right]_{\mathrm{i}}$ by flash photolysis of the $\mathrm{Ca}^{2+}$ chelator DMnitrophen (DMn). The uniform and relatively long lived elevation of $\left[\mathrm{Ca}^{2+}\right]_{\mathrm{i}}$ simplifies its detection with fluorescent indicator dyes and allows to determine vesicular release rates in dependence of intracellular $\mathrm{Ca}^{2+}$. The so-called 'reverse approach' can then be used to estimate the $\mathrm{Ca}^{2+}$ concentration that an average vesicle 'sees' before fusion by fitting the $\mathrm{Ca}^{2+}$ dependence of release with a kinetic model. The derived parameters of the model can then be used to infer the local $\left[\mathrm{Ca}^{2+}\right]_{\mathrm{i}}$ transient that drives an average vesicle to fuse after AP induced channel opening. Bollmann et al and Schneggenburger 
and Neher have used this approach at the calyx of Held and estimated $\left[\mathrm{Ca}^{2+}\right]_{\mathrm{i}}$ to rise to $10-25 \mu \mathrm{M}$ with a half-width of $\sim 0.5 \mathrm{~ms}$ (Bollmann et al, 2000; Schneggenburger and Neher, 2000). These numbers are much lower than the 200-300 $\mu \mathrm{M}$ indicated for the squid giant axon (Llinás et al, 1992).

Bollmann and Sakmann combined flash photolysis of DMn with the use of exogenous $\mathrm{Ca}^{2+}$ buffers and were able to create a uniform, but transient, elevation of $\left[\mathrm{Ca}^{2+}\right]_{\mathrm{i}}$ $($ FWHM $<0.5 \mathrm{~ms})$ in the terminal that could evoke a postsynaptic response similar to that of an AP, further emphasizing the role of $\left[\mathrm{Ca}^{2+}\right]_{\mathrm{i}}$ in controlling the dynamics of release and the fidelity of synaptic strength (Bollmann and Sakmann, 2005).

Although the exact topology of $\mathrm{Ca}^{2+}$ channels and vesicles remains to be shown, multiple lines of evidence support that multiple channels contribute to the local elevations of $\left[\mathrm{Ca}^{2+}\right]_{\mathrm{i}}$ that drive fusion of a vesicle at the calyx of Held. The channel-vesicle distance is variable and can extent hundreds of nanometers (as opposed to the squid giant synapse). However, comparably low levels of $\left[\mathrm{Ca}^{2+}\right]_{\mathrm{i}}$ at the transmitter release site can support a high rate of release at the calyx of Held. This is due to the highly non-linear relationship between release and the $\mathrm{Ca}^{2+}$ signal driving it, so that two orders of magnitude increase in $\left[\mathrm{Ca}^{2+}\right]_{\mathrm{i}}$ from resting levels can support five orders of magnitude increase in the release rate (Lou et al, 2005).

\section{Parameters determining synaptic strength}

The first paired recording of a principle cell and its corresponding calyx terminal by Borst et al opened the possibility to tightly control and describe the parameters governing synaptic strength at the calyx of Held synapse (Borst et al, 1995). Synaptic strength can be described quantitatively with

$$
P S C=N \cdot p \cdot q
$$

which describes the amplitude of the postsynaptic current $(P S C)$ as the product of the quantal size $(q)$, the number of release sites $(N)$ and the probability that release occurs at such a site $(p)$ (del Castillo and Katz, 1954; Zucker, 1973). The parameter $N$ of the binomial model is fixed, whereas the probability $p$ can be interpreted as the joint probability for fusion of a synaptic vesicle $\left(p_{\text {rel. }}\right)$ and the availability of a synaptic vesicle at the release site $\left(p_{\text {avail. }}\right)$ 
This model opens the ability to separate the pre- and postsynaptic contributions to synaptic strength which can change dramatically in response to repetitive activity. This synaptic plasticity can manifest itself by an increase (facilitation) or decrease (depression) of subsequent release on various time scales, short- and long-term (reviewed in von Gersdorff and Borst, 2002). When the calyx of Held is stimulated by trains of APs at high frequency the EPSC is dominated by short-term depression (STD). Facilitation is observed under conditions of lowered release probability. These short-term changes, a characteristic attributed to all synapses, play an important role in relaying information in the nervous system. The quantitative description of $N, p$ and $q$ at the calyx of Held might help to provide a conceptional understanding of synaptic function when faithful transmission at high frequencies is required. All three parameters can contribute to the STD observed at the calyx of Held. Postsynaptic receptor desensitization and saturation would result in reduction in $q$. A reduction in $\mathrm{Ca}^{2+}$-influx would cause a reduction in $p_{\text {rel. }}$, whereas the depletion of releasable vesicles would lower $p_{\text {avail. }}$ (reviewed in Schneggenburger et al, 2002).

It is important to note that the definition of 'release site' in the binomial model is ambiguous, their number $N$ is estimated to lie between two numbers that can be determined experimentally: the number of morphological active zone $\left(N_{a z}\right)$ with a corresponding $p_{a z}$ that release occurs at such a site. On the other hand, $N_{\text {ves }}$ describes the number of releasable vesicles with the probability $p_{\text {ves }}$ that a given vesicle is released.

Using EPSC variance-mean analysis, an upper limit of $\sim 600$ active zones was estimated for the calyx of Held (Meyer et al, 2001; Scheuss et al, 2002). This number is comparable to the $\sim 550$ active zones that were identified by the EM study mentioned above (Sätzler et al, 2002). Trains of APs have also been used to estimate the number of releasable vesicles in the terminal. However, postsynaptic effects such as AMPA receptor desensitization and saturation manifest in a reduction of $q$ during the train and will lead to an underestimation of $N_{\text {ves }}$. These postsynaptic effects can be controlled pharmacologically by adding cyclothiazide (CTZ) and kynurenic acid (Kyn) which lead to an estimate of $~ 900$ releasable vesicles by EPSC variance-mean analysis (Scheuss et al, 2002). A single active zone is therefore, on average, used only once or twice during short trains of AP.

Pool sizes $\left(N_{\text {ves }}\right)$ can also be estimated by non-physiological stimulations, either long lasting depolarizations (i.e. $50 \mathrm{~ms}$ ) or flash photolysis of caged $\mathrm{Ca}^{2+}$. Flash-induced 
elevations of $\left[\mathrm{Ca}^{2+}\right]_{\mathrm{i}}$ to levels above $12 \mu \mathrm{M}$ gave a pool estimate of $\sim 1800$ vesicles when analyzing cumulative release on a $10 \mathrm{~ms}$ interval (Schneggenburger and Neher, 2000). Studies employing long depolarizations of the terminal to deplete the readily releasable pool (RRP) of vesicles combined with deconvolution analysis of the obtained EPSCs found $N_{\text {ves }}$ to be 2300 (Sakaba and Neher, 2001a,b). Even higher numbers, 33005200 , were obtained by measurements of increases in cell capacitance in response to depolarizing stimuli of varied length (Sun and Wu, 2001). Additionally, the analysis of the covariance of EPSCs following AP trains also estimated $N_{\text {ves }}$ to be $\sim 2000$ (Scheuss et al, 2002). The release of thousands of vesicles within a few milliseconds implies that multiple vesicles fuse at each active zone.

The quantal content (the number of quanta released in response to an AP) was estimated to be 210, 140 and 157 on average in three studies (Borst and Sakmann, 1996; Schneggenburger et al, 1999; Meyer et al, 2001). With the high number of release ready vesicles at the calyx of Held, a very low release probability $p_{\text {ves }}$ would result which cannot explain the depression pattern observed at the calyx. Accordingly, simple depletion models fail to properly predict the experimental data (Weis et al, 1999). The model assumes a high release probability and that an invariable fraction of the releasable pool is consumed per AP. However, the decay in EPSC amplitudes during a train of APs observed at the calyx of Held is shallower than predicted by the model.

This inconsistency can be revoked if heterogeneity in the release probability is considered. Indeed, $\mathrm{Wu}$ and Borst and subsequently Sakaba and Neher showed that at the calyx of Held release probability is heterogeneous and that two subpools contribute equally to the pool of releasable vesicles (Wu and Borst, 1999; Sakaba and Neher, 2001a). $50 \%$ of vesicles released rapidly within a few milliseconds. Both pools possess distinct kinetic properties which allow their separation when analyzing the cumulative release in response to a sustained depolarization of the terminal. The release kinetics of the fast releasing pool of vesicles (FRP) are about 10 times faster than those of the slow releasing pool of vesicles (SRP).

Sakaba and Neher also showed that the recovery of the SRP is quick $(\tau=200 \mathrm{~ms})$ whereas the FRP recovers slowly. The latter is $\mathrm{Ca}^{2+} /$ calmodulin dependent and can be blocked by infusing a calmodulin binding domain peptide (Fig. 1.2). Heterogeneity of release probability has been reported in various other systems by either uncaging induced $\left[\mathrm{Ca}^{2+}\right]_{\mathrm{i}}$ elevations in tonic and phasic crustacean neuromuscular junctions 
Slow-release pool

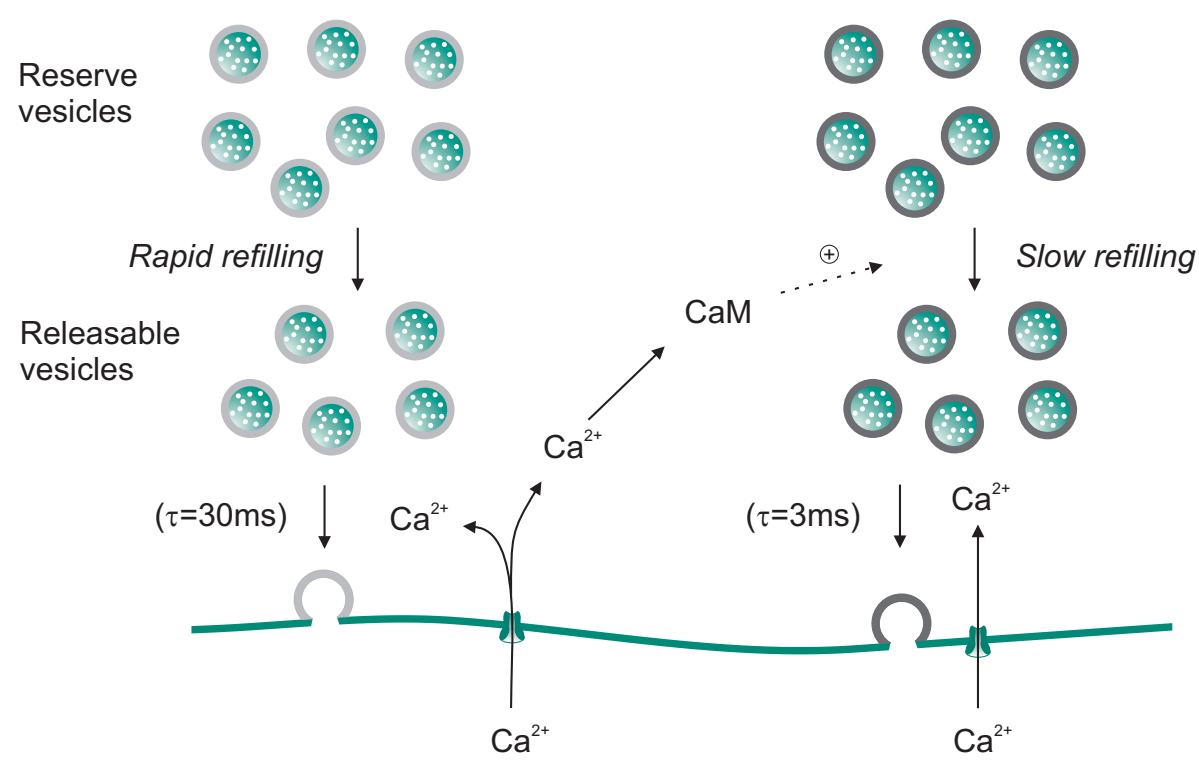

Figure 1.2: Vesicle pool dynamics at the calyx of Held. Two kinetically distinct pools can be identified at the calyx of Held when neurotransmitter release is stimulated by long depolarizations of the synaptic terminal. Vesicles from the slow releasing pool are rapidly refilled but release with a time constant $\sim 10$-fold slower than those from the fast releasing pool. Refilling of the latter is slow, but is accelerated by $\mathrm{Ca}^{2+} /$ calmodulin $(\mathrm{CaM})$. Adapted from Matthews (2001).

(Millar et al, 2005), brief depolarizing steps in cultured autaptic hippocampal neurons (Rosenmund et al, 1993) and minimum stimulation in hippocampal CA1 cells (Dobrunz and Stevens, 1997).

Multiple mechanistic concepts could serve as an explanation for an apparent heterogeneity in $p$. Assuming that postsynaptic effects such as receptor desensitization and saturation are counteracted pharmacologically as described by Neher and Sakaba, all remaining causes should have a presynaptic origin (Neher and Sakaba, 2001). A variable $\mathrm{Ca}^{2+}$ channel/ vesicle topology as described above could explain this phenomenon.

\section{Calcium-secretion coupling on a molecular level}

Multiple proteins involved in neurotransmitter release have been identified in the last 30 years. Among them and attributed as key players for exocytosis are the plasma 
membrane proteins syntaxin-1 and SNAP-25 as well as the vesicle protein synaptobrevin2/ VAMP (vesicle associated membrane protein). All three are members of the SNARE family of proteins (SNAREs are SNAP receptors, SNAPs are soluble NSF attachment proteins and NSF stands for N-ethylmaleimide sensitive factor).

Synaptobrevin, syntaxin and SNAP-25 form tight complexes that are generally accepted as being essential for membrane fusion. Neuronal SNARE complexes are formed by the parallel alignment of four helical SNARE motifs, one of which is contributed by synaptobrevin-2, one by syntaxin-1 and two by SNAP-25. According to the 'zippering hypothesis', the assembly is initiated by the interaction of synaptobrevin with heterodimers of syntaxin and SNAP-25, N-terminal to the SNARE motifs. The 'zippering' will then proceed towards the C-terminus. After fusion of the membranes, SNAPs-NSF serves to disassemble the SNARE complexes (reviewed in Jahn and Scheller, 2006). In this context, complexes that bring the vesicle membrane in apposition to the plasma membrane are referred to as trans complexes, whereas a cis complex resides in only one membrane.

In vitro studies employing liposome fusion assays have shown that synaptic vesicles are constitutively active fusion machines (Holt et al, 2008). Interestingly, the kinetics of fusion were solely influenced by the number of 1:1 acceptor heterodimers of syntaxin and SNAP-25 but no $\mathrm{Ca}^{2+}$ dependence was observed. Synaptotagmin-1, -2 and -9 are thought to present the $\mathrm{Ca}^{2+}$ sensors for synchronous neurotransmitter release observed in neurons (Xu et al, 2007). However, no additional increase in fusion kinetics mediated by synaptotagmin/ $\mathrm{Ca}^{2+}$ could be observed in in vitro assays (Stein et al, 2007).

This discrepancy can be attributed to multiple regulatory proteins that have been identified, in addition to the ones mentioned so far, as part of the active zone or direct interaction partners with the fusion machinery:

Munc13 (mammalian unc13) is an active zone protein thought to be essential for vesicle priming. Munc18 is a member of the Sec1/ Munc18 (SM) family of proteins which are important for membrane trafficking and secretion. Although its precise role remains to be shown, Munc18 is essential for neurotransmitter release. Mice lacking Munc18-1 show normal brain development and synapse morphology, yet no transmitter release could be observed (Verhage et al, 2000). $\alpha$ RIMs (Rab3 interaction molecules) are Rab3 effectors in the active zone that bind Munc13 and also play a role in priming. Rab3s 
are members of the Rab family, small monomeric GTPases, and exclusively found on synaptic vesicles.

Synaptotagmin is thought to be the $\mathrm{Ca}^{2+}$ sensor for release. It has been proposed that synaptotagmin is able to replace complexin from the SNARE complex after binding $\mathrm{Ca}^{2+}$. Complexin in turn is thought to act as a 'fusion clamp' that is able to stabilize a SNARE complex intermediate (reviewed in Rizo and Rosenmund, 2008).

The large number of regulatory proteins that have been identified so far illustrates that $\mathrm{Ca}^{2+}$ triggered exocytosis in nerve terminals critically depends on the timed interplay of multiple proteins at the active zone. As of now, this configuration cannot be reconstructed in vitro.

The molecular basis of vesicle fusion can, though to a limited extent, be studied at the calyx of Held as an accessible and hence well characterized model synapse. Specifically, the impact of molecular perturbations on the $\mathrm{Ca}^{2+}$ sensitivity of release can be studied.

Lou et al used the phorbol ester PDBu (which mimics diacylglycerols) to enhance the activity of presynaptic protein kinase $\mathrm{C}$. Mapping $\left[\mathrm{Ca}^{2+}\right]_{\mathrm{i}}$ and release rates showed a potentiation of release. The increased $\mathrm{Ca}^{2+}$ sensitivity was interpreted as an increased 'fusion willingness' of synaptic vesicles.

Studying neurotransmitter release in genetically modified animals is difficult at the calyx of Held. Since the synapse only forms after birth, electrophysiological studies can only be done from postnatal day 6 on, an age that is not reached by many animals in which presynaptic proteins have been deleted. Synaptotagmin-2 KO animals are viable at p8-p10 and have been studied by Sun et al. The studied calyces lacked the stereotypical supralinear dependence of release on $\left[\mathrm{Ca}^{2+}\right]_{\mathrm{i}}$, but release at basal levels $(<1 \mu \mathrm{M})$ was intact and slightly elevated. The remaining release was attributed to a second $\mathrm{Ca}^{2+}$ sensor for asynchronous release which exhibits a smaller cooperativity towards $\mathrm{Ca}^{2+}$ binding (Sun et al, 2007).

The accessibility of the calyx of Held for recording pipettes allows the perturbation of release by infusing peptides, antibodies and toxins into the terminal. Sakaba et al have done the latter to study the specific effect of clostridial neurotoxins onto release. Clostridial neurotoxins are zinc-endopeptidases that selectively cleave synaptobrevin, SNAP-25 and syntaxin. Seven serotypes of botulinum neurotoxin (BoNT) secreted by Clostridium botulinum have been identified (BoNT A-G) whereas C. tetani produces tetanus neurotoxin (TeNT). The BoNTs and TeNT are composed of a heavy ( 100 kDa) 
and a light chain $(\sim 50 \mathrm{kDa})$ with the latter conferring the peptidase activity. The toxins cause severe to complete reduction in postsynaptic responses and severe reduction in spontaneous release at vertebrate and invertebrate synapses (reviewed in Humeau et al, 2000; Schiavo et al, 2000).

When the recombinant light-chains of either BoNT/C (which cleaves syntaxin) or TeNT (which cleaves synaptobrevin) were introduced into the terminal, an all-or-none block of release was observed. For these two toxins, no significant changes in the efficiency of $\mathrm{Ca}^{2+}$ to trigger release were found. BoNT/A infusion (which cleaves SNAP-25), however, lead to a 4 -fold reduction in the $\mathrm{Ca}^{2+}$ sensitivity of release. The kinetics of release under BoNT/C are unchanged when release is triggered by long depolarizations. This is in marked contrast to TeNT, under which a preferential loss of the fast component of release could be shown. It was therefore postulated that cleavage of synaptobrevin might interfere with a 'maturation' step during which vesicles are incorporated in the vicinity of $\mathrm{Ca}^{2+}$ channel clusters to enable fast neurotransmitter release (Sakaba et al, 2005).

\subsection{Motivation}

Synapses in neural circuitry are not merely relay stations to pass on information coded in action potentials innervating their terminals. They themselves serve as modulators of information, processing units that can effectively filter or amplify the incoming signals. This modulation can be mediated on multiple time scales and the short-term effects were of key interest in the work that will be presented here. Accordingly, the strength of a synapse critically depends on the mechanisms governing this short-term plasticity during sustained high-frequency firing. How robust synapses can sustain activity will critically depend on the number of available vesicles, their release probability and the rate at which they are recruited to the plasma membrane.

Neurotransmitter release at the calyx of Held synapse, which was studied here, depresses in response to high-frequency stimulation which is attributed to the depletion of vesicles in the RRP (Rosenmund and Stevens, 1996; Dittman and Regehr, 1998). Interestingly, the vesicles found in the RRP are not released with equal probability when an AP innervates the terminal. In glutamatergic synapses, such as the calyx of 
Held and hippocampal synapses, a number of studies identified 'reluctant' or 'slow' vesicles (Wu and Borst, 1999; Hallermann et al, 2003; Moulder and Mennerick, 2005). Also, the presence of asynchronous release in response to an AP was taken as evidence for 'reluctant' vesicles (Sun et al, 2007). Multiple mechanisms could account for the apparent reluctance of vesicles to be released by an AP, two of which have gained much attention:

First, reluctant vesicles could be intrinsically different from fast releasing vesicles. This could be mechanistically attributed to i.e. a different $\mathrm{Ca}^{2+}$ sensor for release or an incomplete formation of the release apparatus (or in other words, a lack of fusion competence). For example, synaptotagmin-1, -2 and -9 have been proposed as mediators for fast and synchronous release, whereas an, as of now, unidentified second sensor is thought the mediate slow neurotransmitter release (Sun et al, 2007; Xu et al, 2007).

On the other hand, the coupling of vesicles to the source of the $\mathrm{Ca}^{2+}$ influx that triggers release, the $\mathrm{Ca}^{2+}$ channels, may be variable between populations of vesicles. Variable distances between $\mathrm{Ca}^{2+}$ channels and synaptic vesicles have been predicted for the calyx of Held in a modeling study (Meinrenken et al, 2002). In the scheme of a microdomain elevation of $\left[\mathrm{Ca}^{2+}\right]_{\mathrm{i}}$ around the channel pore, vesicles that are more distant from the channels would release only when sustained activity had led to an increase in global $\left[\mathrm{Ca}^{2+}\right]_{\mathrm{i}}$ and therefore release much slower (due to the supralinear relationship of release to $\mathrm{Ca}^{2+}$ ).

These two hypothesis can be discerned when the increase of $\left[\mathrm{Ca}^{2+}\right]_{\mathrm{i}}$ is obtained by uniform uncaging of $\mathrm{Ca}^{2+}$ from a caged compound rather than being mediated by $\mathrm{Ca}^{2+}$ influx through $\mathrm{Ca}^{2+}$ channels in the plasma membrane. By making use of the differential recovery paradigm of the fast and slow component of release at the calyx of Held (Sakaba and Neher (2001a), also see Fig. 1.2), the fast releasing vesicles can be depleted so that the response of reluctant vesicles to strong depolarizations and flash uncaging can be studied in isolation and in contrast to each other.

Investigating this issue provides important implications for the study of synaptic transmission. If the former hypothesis is correct, one would expect that the choice of the $\mathrm{Ca}^{2+}$ sensor will determine the kinetics of transmitter release. The presence of a fast $\mathrm{Ca}^{2+}$ sensor would then allow for rapid release to occur, whereas a slow $\mathrm{Ca}^{2+}$ sensor would cause slower release of synaptic vesicles. 
If the latter hypothesis is correct, then 'molecular priming' of synaptic vesicles will not be the rate limiting step for fast neurotransmitter release, but rather the association of synaptic vesicles with $\mathrm{Ca}^{2+}$ channel clusters at the active zone. The degree of association would then govern the kinetics of release at different synapses.

Additionally, it has been shown that the recovery of fast releasing vesicles can be modulated in multiple ways, one of which being the differential block of this component mediated by introducing TeNT into the terminal. In this work, the implicated role of synaptobrevin in recovery of the fast component of release was studied further. The use of additional toxins and peptides served as a valuable tool to bridge the wealth of information on proteins involved in $\mathrm{Ca}^{2+}$-dependent exocytosis with the vesicle pool definitions that are based on the kinetic analysis of neurotransmitter release, in an attempt to identify the critical steps in vesicle fusion that mediate rapid neurotransmitter release at the calyx of Held. 


\section{Material and Methods}

\subsection{Slice preparation}

The preparation of acute brain slices for electrophysiological recordings followed the general guidelines provided by Edwards et al (1989) and their specific application to obtain recordings from the medial nucleus of the trapezoid body (MNTB) as described by Forsythe and Barnes-Davies (1993b) and Borst et al (1995).

Postnatal day 8 to 10 (p8-10) Wistar rats were decapitated and the head was transferred into a dish containing ice cold artificial cerebrospinal fluid (aCSF) containing (in mM): $125 \mathrm{NaCl}, 2.5 \mathrm{KCl}, 25 \mathrm{NaHCO}_{3}, 1.25 \mathrm{NaH}_{2} \mathrm{PO}_{4}, 25$ glucose, $3 \mathrm{MgCl}_{2}, 0.1$ $\mathrm{CaCl}_{2}, 0.4$ L-ascorbic acid, 3 myo-inositol, 2 sodium pyruvate (according to von Gersdorff et al (1997), modified from Borst et al (1995)). Using this cold, low $\mathrm{Ca}^{2+}$, saline was meant to prevent anoxia and should reduce the metabolic activity of cells.

The skull was opened by carefully cutting along the midline from the neck to the eye line. Cuts along the mediolateral axis exposed the cerebrum and the cerebellum. Using a scalpel, two cuts (one coronal and close to the eyeline, the second slightly tilted close to the rostral-dorsal base of the cerebellum, see Fig. 2.1) allowed to remove the entire cerebrum. The remaining brainstem and cerebellum could then carefully be pushed caudally and out of the skull. Any fibers still connected to the brain stem were severed with forceps. In order to facilitate the slicing, fine forceps were used to remove the pia mater and the arachnoid mater. The location of the MNTB region could be estimated upon careful inspection of the ventral brainstem surface where the 


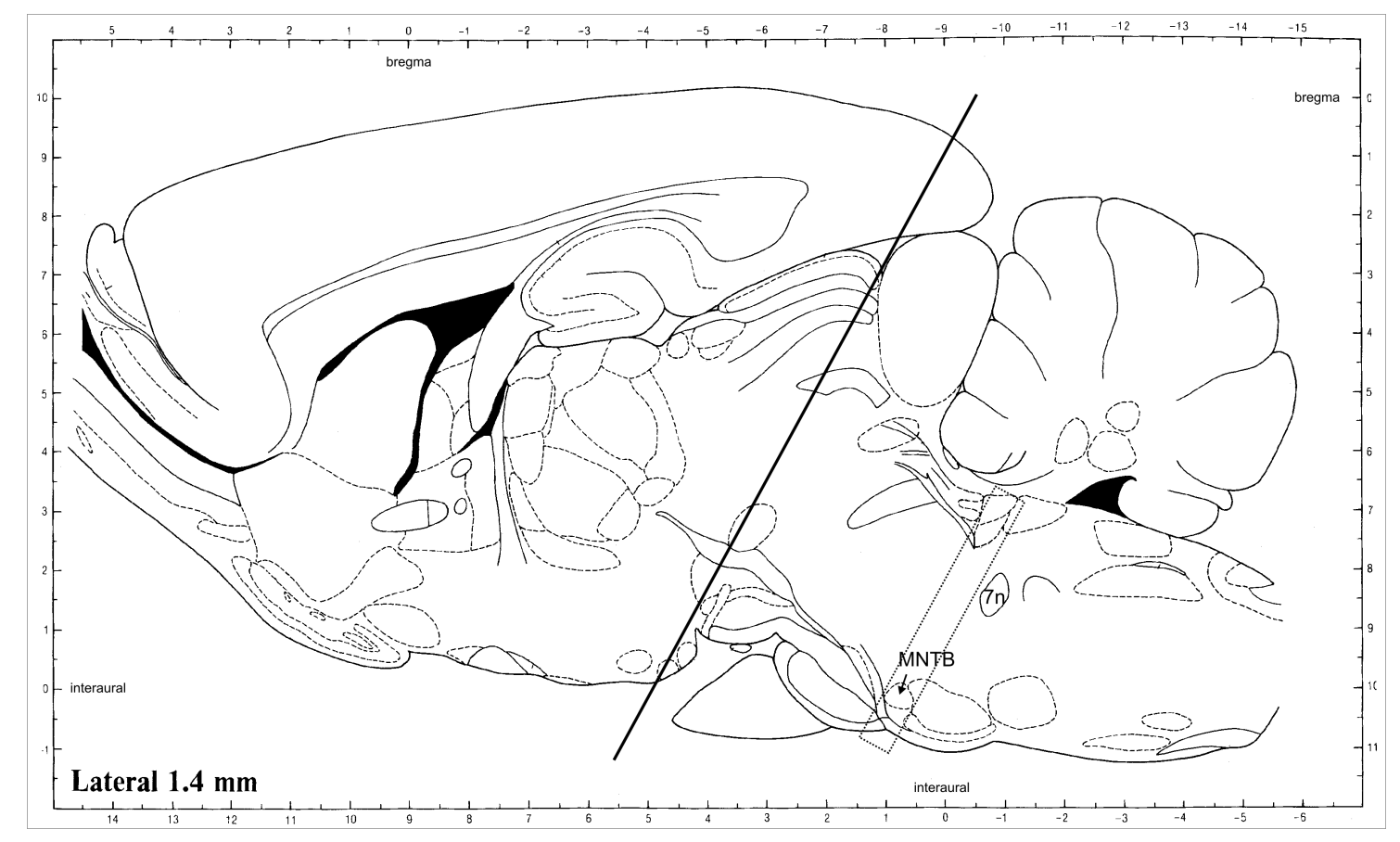

Figure 2.1: Lateral view of the adult rat brain. The diagonal line indicates the cut that was performed to separate the cerebrum from the brainstem. The latter was then mounted for slicing. The region of interest is highlighted by the dashed box and contains the medial nucleus of the trapezoid body (MNTB). While slicing, the seventh cranial nerve $(7 \mathrm{n})$ served as a landmark that indicated the beginning of the region of interest. Modified from Paxinos and Watson (1982).

crossing fiber bundles leave a white band which becomes more prominent with age (and increased myelination).

The preparation, containing the brain stem and the cerebellum, was then glued onto the Teflon base of a slicing chamber using cyanoacrylate glue, oriented so that the caudal side faced up and the ventral side of the brainstem faced the slicer's blade.

Transverse brain slices were made using a vibratome slicer (Integraslice $7550 \mathrm{MM}$, Campden Instruments, Leicester, UK) with the horizontal vibration set at $70 \mathrm{~Hz}$ and advancing $0.18 \mathrm{~mm} / \mathrm{s}$. Initial slicing was performed at higher speed and thicker than the final desired slices since they did not contain the MNTB region. The $7^{\text {th }}$ cranial nerve (facial nerve) served as a landmark to the experimenter and was usually visible unilaterally. A slight tilt in the mounted preparation could be corrected by rotating the Teflon base. Once the $7^{\text {th }}$ nerve was visible, $200 \mu \mathrm{m}$ thick slices were collected. The 
MNTB region was usually contained in the $2^{\text {nd }}$ to $5^{\text {th }}$ slice (Fig. 2.1). The exact number of slices critically depended on the size and age of the animal.

Slices containing the MNTB were transferred to an incubation chamber containing aCSF at $37^{\circ} \mathrm{C}$ using a glass suction pipette and placed onto a nylon mesh. The aCSF solution was identical to the one mentioned above except that $2 \mathrm{mM} \mathrm{CaCl} 2$ and $1 \mathrm{mM}$ $\mathrm{MgCl}_{2}$ were used. The solution was continuously bubbled with carbogen gas $\left(95 \% \mathrm{O}_{2}\right.$, $\left.5 \% \mathrm{CO}_{2}\right)$. At $37^{\circ} \mathrm{C}$, slices were viable for 3-4 hours.

\subsection{Solutions}

\subsubsection{Extracellular solution}

The extracellular solution for electrophysiological recordings was the same as the solution used for incubation (in mM): $125 \mathrm{NaCl}, 2.5 \mathrm{KCl}, 25 \mathrm{NaHCO}_{3}, 1.25 \mathrm{NaH}_{2} \mathrm{PO}_{4}, 25$ glucose, $1 \mathrm{MgCl}_{2}, 2 \mathrm{CaCl}_{2}, 0.4$ L-ascorbic acid, 3 myo-inositol, 2 sodium pyruvate $(\mathrm{NaCl}, \mathrm{KCl}$, $\mathrm{NaHCO}_{3}, \mathrm{MgCl}_{2}$ and $\mathrm{CaCl}_{2}$ from Merck (Darmstadt, Germany), all others from Sigma (Steinheim, Germany)). This aCSF had an osmolarity of $\sim 310$ mOsm with a $\mathrm{pH}$ of 7.4 when bubbled with carbogen. Depending on the type of experiment, additional chemicals were added. All experiments utilized $10 \mathrm{mM}$ tetraethylammonium (TEA) chloride to block potassium channels and $1 \mu \mathrm{M}$ of the sodium channel blocker tetrodotoxin (TTX). Non-AMPA type glutamate channels were blocked with $50 \mu \mathrm{M}$ of the competitive NMDA antagonist D(-)-2-amino-5-phosphonopentanoic acid (D-AP5), effectively isolating postsynaptic AMPA receptor mediated excitatory postsynaptic currents (EPSCs).

Strong non-physiological stimulations, such as sustained depolarizations of the terminal or flash uncaging, lead to massive neurotransmitter release. $100 \mu \mathrm{M}$ cyclothiazide (CTZ) was therefore used to prevent AMPA receptor desensitization in all experiments (Neher and Sakaba, 2001). To prevent AMPA receptor saturation, the competitive receptor antagonists $\boldsymbol{\gamma}$-D-glutamylglycine (gDGG) or kynurenic acid (Kyn) were used. $1 \mathrm{mM}$ Kyn reduces the mean miniature excitatory postsynaptic current (mEPSC) amplitude by $50 \%$. Since Kyn absorbs ultraviolet (UV) light and therefore interferes with flash experiments, $2 \mathrm{mM}$ gDGG was used in these cases which reduces the mean mEPSC amplitude to $30 \%$. To detect mEPSC faithfully, neither Kyn nor gDGG were used when $\mathrm{mEPSC}$ were recorded. In the latter type of experiments, excitatory mEPSC were 
isolated by adding $30 \mu \mathrm{M}$ bicuculline (to block $\mathrm{GABA}_{\mathrm{A}}$ receptors) and $5 \mu \mathrm{M}$ strychnine (as antagonist for glycine receptors) to the extracellular solution. TEA was purchased from Sigma, TTX from Alamone Labs (Jerusalem, Israel). D-AP5, CTZ, gDGG, Kyn, bicuculline and strychnine came from Tocris (Bristol, UK).

\subsubsection{Intracellular solutions}

The principle composition of the pipette solutions was taken from Schneggenburger and Neher (2000) and Sakaba and Neher (2001a). The stock solution used for postsynaptic recordings and presynaptic recordings that did not involve $\mathrm{Ca}^{2+}$ measurements contained (final concentration in $\mathrm{mM}$ ): 100 Cs-gluconate, $10 \mathrm{HEPES}, 5 \mathrm{Na}_{2}$-phosphocreatine, 4 MgATP, 0.3 NaGTP, 20 TEA-Cl and was prepared as a $4 \mathrm{x}$ stock. The $\mathrm{pH}$ was adjusted to 7.2 using $\mathrm{CsOH}$ (Cs-gluconate was custom-made, all others from Sigma). Additional substances could be added to this stock solution and the final volume was established by adding purified water (Milli-Q Plus, Millipore, Billerica, USA) as with all other solutions presented herein. For postsynaptic recordings, 5 mM Cs-EGTA (from Sigma, $\mathrm{pH}$ adjusted with $\mathrm{CsOH}$ ) and $40 \mathrm{mM}$ Cs-gluconate were added to adjust the osmolarity to $\sim 320$ Osm prior to experiments.

The presynaptic pipette solution contained (final concentration in $\mathrm{mM}$ ): 100 Csgluconate, $20 \mathrm{HEPES}, 5 \mathrm{Na}_{2} \mathrm{ATP}, 0.5 \mathrm{NaGTP}, 0.5 \mathrm{MgCl}_{2}$ and $20 \mathrm{TEA}-\mathrm{Cl}$, also prepared as a $4 \mathrm{x}, \mathrm{pH}$ adjusted, stock solution. For experiments in which transient elevations of $\left[\mathrm{Ca}^{2+}\right]_{\mathrm{i}}$ were desired, $2 \mathrm{mM}$ DM-nitrophen (DMn) (Calbiochem, La Jolla, CA, USA), $1.7 \mathrm{mM} \mathrm{CaCl}_{2}, 1 \mathrm{mM}$ Cs-EGTA and $0.5 \mathrm{mM}$ Oregon Green BAPTA-5N (OGB-5N) (Molecular Probes, Eugene, Oregon, USA) were added. An additional 35 mM Csgluconate raised the osmolarity to $\sim 320$ Osm.

Step-like elevations of $\left[\mathrm{Ca}^{2+}\right]_{\mathrm{i}}$ were achieved by adding $1-3 \mathrm{mM} \mathrm{DMn}, 0.8-2.7 \mathrm{mM}$ $\mathrm{CaCl}_{2}, 0.2 \mathrm{mM}$ fura-2FF (Teflabs, Austin, TX, USA) and $30 \mathrm{mM}$ Cs-gluconate.

For mEPSC measurements, fura-2FF was substituted with fura-4F (Molecular Probes) to be able to determine $\left[\mathrm{Ca}^{2+}\right]_{\mathrm{i}}$ around resting levels and $<1 \mu \mathrm{M}$. For some experiments, free $\mathrm{Ca}^{2+}$ in the pipette solution was 'clamped' to an estimated $100 \mathrm{nM}$ by adding $10 \mathrm{mM}$ EGTA and $4 \mathrm{mM} \mathrm{CaCl}_{2}$.

The free $\mathrm{Ca}^{2+}$ concentration in solution was estimated by a computational routine kindly provided by Dr. Sørensen (Xu et al, 1997). 
Peptides and toxins: Recombinantly produced light chain botulinum neurotoxin serotype B (BoNT/B) was kindly provided by Dr. Stein and stored as a $59 \mu \mathrm{M}(3 \mathrm{mg} / \mathrm{ml})$ stock solution containing (in $\mathrm{mM}$ ): $130 \mathrm{CsCl}, 10$ HEPES and 1 DTT at $\mathrm{pH}$ 7.2.

Table 2.1: Synthetic peptides

\begin{tabular}{lll} 
Peptide & Sequence & Notes \\
\hline Rp3a(650-669) & AKGERLKHWYECLKNKDKKI & $\begin{array}{l}\text { amino acids 650-669 of rat } \\
\text { rabphilin3a }\end{array}$ \\
Rp3a(s650-669) & KERDKIKWECKHLLKNYGAK & $\begin{array}{l}\text { scrambled version of } \\
\text { Rp3a(650-669) }\end{array}$ \\
Syt2(383-401) & ATGTELRHWSDMLANPRRP & $\begin{array}{l}\text { homologue of Rp3a(650-669) } \\
\text { in rat synaptotagmin-2 }\end{array}$ \\
\hline
\end{tabular}

All synthetic peptides were obtained from Biosyntan (Berlin, Germany) and delivered as lyophilized TFA salts. Desalting was performed on a short column packed with Sephadex G-10 (GE Healthcare, Chalfont St. Giles, UK). The Sephadex media was swelled in $165 \mathrm{mM} \mathrm{CsCl}, 10 \mathrm{mM}$ HEPES and $1 \mathrm{mM}$ DTT according to the manufacturer's guidelines. A $20 \mathrm{~cm} \cdot 1 \mathrm{~cm}$ column was packed with $\sim 10 \mathrm{~cm}$ of medium. Packing and sample application followed the guidelines provided in the Amersham Biosciences gel filtration handbook. $10 \mathrm{mg}$ peptide were dissolved in $500 \mu \mathrm{l}$ buffer and eluted at the void volume of the column, collecting $500 \mu \mathrm{l}$ fractions. The protein concentration was determined using 1:20 dilutions of the sample in $8 \mathrm{M}$ guanidinium hydrochloride in a UV spectrometer by measuring the absorption spectrum from 250-320 $\mathrm{nm}$. The measured absorption was then correlated to the predicted one as calculated by the ExPASy tool ProtParam to determine the peptide concentration in a given fraction. Fractions were pooled if possible and resulted in stock concentrations of $4.58 \mathrm{mg} / \mathrm{ml}(1.83 \mathrm{mM})$ for Rp3a(650-669), $6.88 \mathrm{mg} / \mathrm{ml}(2.76 \mathrm{mM})$ for Rp3a(s650-669) and $7.3 \mathrm{mg} / \mathrm{ml}(3.31 \mathrm{mM})$ for Syt2(383-401).

Control experiments for both peptide and toxin experiments were performed by adding equivalent amounts of their respective buffer solutions to the intracellular solution. 


\subsection{Electrophysiological recordings, calcium uncaging and calcium imaging}

After 40-60 min incubation time, slices were transferred to a custom build recording chamber with a glass base. A U-shaped platinum wire with parallel Nylon threads spanned across it was used to hold the slice in place. The recording chamber connected to a gravity driven perfusion system with adjustable flow rate which contained both plain extracellular solution and extracellular solution supplemented with the drugs listed in 2.2.1. After establishing a whole-cell patch clamp configuration on a postsynaptic principle cell, the bath solution was exchanged within 3-4 min for the latter solution.

Recording pipettes were made from borosilicate glass filaments $(2 \mathrm{~mm}$ outer- and $1.4 \mathrm{~mm}$ inner diameter from Hilgenberg, Malsfeld, Germany) using a temperature controlled two-step vertical pipette puller (PIP 5 from HEKA, Lambrecht/Pfalz, Germany). Whole-cell voltage clamp recordings were performed at room temperature (RT) using either EPC9/2 or EPC10/2 amplifiers controlled by Patchmaster (v. 2.20, HEKA). Pipette- and other stray capacitances as well as cell capacitance were compensated using the built-in compensation mechanisms. The series resistance $\left(R_{s}\right)$ for postsynaptic recordings was generally $5-10 \mathrm{M} \Omega$ and $8-20 \mathrm{M} \Omega$ for presynaptic patches. The series resistance was also compensated electronically by setting the fractional compensation such that the remaining resistance was $2.5-3 \mathrm{M} \Omega$ for post- and $8 \mathrm{M} \Omega$ for presynaptic recordings. The remaining $R_{s}$ was corrected offline (see 2.4). Data were sampled at $20-50 \mathrm{kHz}$ and low-pass filtered (Bessel, $6 \mathrm{kHz}$ corner frequency).

\subsubsection{Experimental setup}

Two electrophysiological setups were used: One consisted of an Axioskop FS (Carl Zeiss, Jena, Germany) equipped with an infrared (IR) differential interference contrast (DIC) system. The slice was centered around the midline crossing point of the trapezoid body using a Zeiss PlanNEOFLUAR air objective with $2.5 \mathrm{x}$ magnification. Cell pairs were selected and imaged using a $60 \mathrm{x}$ water immersion objective (LUMPlan FI/IR, 0.9 N.A. from Olympus, Tokyo, Japan). 


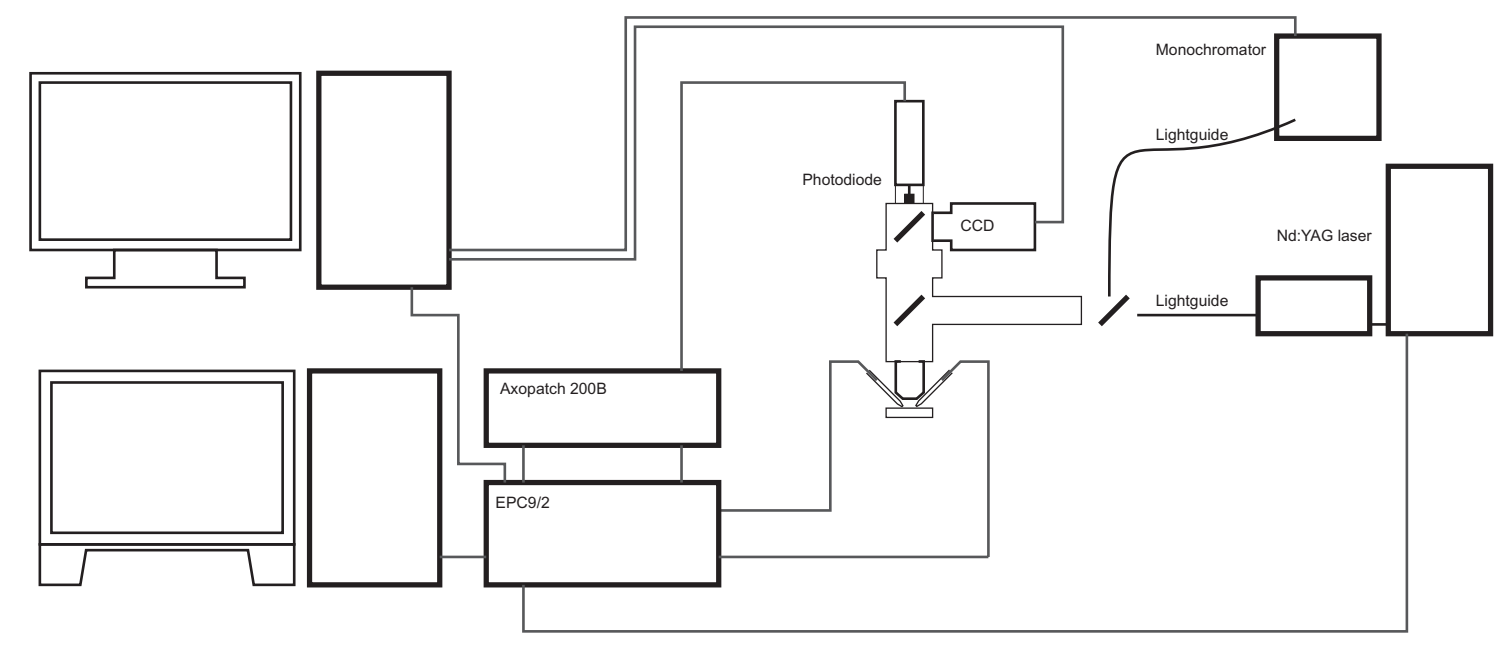

Figure 2.2: Experimental setup for UV-laser uncaging: A setup for slice electrophysiology was equipped with a photodiode for fast $\mathrm{Ca}^{2+}$ measurements as described by Bollmann (2001). The fluorescence signal was sampled by a computer which also controlled the UV-laser and the patch clamp amplifier. Both light sources were coupled into the epifluorescence port of the microscope via light guides. A CCD camera was employed for visual control of the electrophysiological recordings.

The second setup followed the principle design outlined above. It consists of an Olympus BX51WI microscope equipped with IR Dodt gradient contrast (DGC) illumination (Luigs \& Neumann, Ratingen, Germany) and the UPlanFL N 4x and LUMPlan FI/IR $60 \mathrm{x}$ objectives (both Olympus).

Both setups were equipped with fluorescence imaging systems consisting of a monochromator (Polychrome V) and a 2-port condenser that coupled the light coming from the monochromator into the epifluorescence port of the microscope. Images were acquired by a CCD camera (Imago VGA). Both camera and monochromator were software controlled by TILLvisIO (all from TILL Photonics, Gräfelfing, Germany). Calcium uncaging was achieved via Xenon flash lamps that produced a brief (1-1.5 ms) flash of UV light (DP-10 or JML-C2 by Rapp OptoElectronic, Hamburg, Germany). The flash lamp was coupled into the second port of the epifluorescence condenser via a light guide. Quartz glass was used to couple both light paths into the microscope. Its reflective properties result in an attenuation of the monochromator light (passing $8 \%$ into to microscope), but $92 \%$ of the UV flash light are transmitted. 
The photometric system used to measure transient elevations of $\left[\mathrm{Ca}^{2+}\right]_{\mathrm{i}}$ was adapted from Bollmann (2001). The fluorescence signal was detected using a low-noise, high sensitivity PIN photodiode (S5973-02, Hamamatsu, Hamamatsu, Japan) mounted into a Viewfinder III (TILL Photonics). The viewfinder passes $95 \%$ of the $400-590 \mathrm{~nm}$ light onto the detector whereas red and IR light is directed towards the CCD camera to visualize the preparation. A rectangular aperture allowed one to limit the window from which the fluorescence signal was collected and was adjusted to match the size of the calyx of Held under investigation. An Axopatch 200B patch-clamp amplifier (Molecular Devices, Sunnyvale, CA, USA) served as a current-to-voltage converter and signal amplifier. Its signal was then fed into the EPC9/2 for data acquisition. For these experiments, a frequency-tripled Nd:YAG laser (Continuum, Santa Clara, CA, USA) was used. The peak laser output of $2 \mathrm{~mJ}$ was attenuated by the built-in adjustable energy attenuator and the components in the optical path so that peak amplitudes $<100 \mu \mathrm{J}$ were measured in the focal plane of the objective. Additional control of the laser output could be achieved by altering the timing of the quality switch (Q-switch). A shorter Q-switching time leads to reduced charging of the laser medium and therefore a decreased laser output.

\subsubsection{Measurements of intracellular calcium}

\section{$\mathrm{Ca}^{2+}$ uncaging}

Homogeneous elevations of cytosolic $\left[\mathrm{Ca}^{2+}\right]$ were achieved by photolyzing the $\mathrm{Ca}^{2+}$ cage DMn (Kaplan and Ellis-Davies, 1988). The cell-impermeant form of DMn was dialyzed into the terminal via the patch pipette. Due to its high affinity for $\mathrm{Ca}^{2+}\left(\mathrm{K}_{\mathrm{D}}=5 \mathrm{nM}\right)$, DMn can be loaded with $\mathrm{Ca}^{2+}$ to a high degree while still maintaining low levels of free $\mathrm{Ca}^{2+}(\sim 100 \mathrm{nM})$. The product of extinction coefficient $(\varepsilon)$ and quantum yield $(\Phi)$ of DMn is comparatively high. Consequentially, the use of UV flash lamps allows one to elevate $\left[\mathrm{Ca}^{2+}\right]_{\mathrm{i}}$ to levels of $30 \mu \mathrm{M}$ and higher. DMn shows a 600000 -fold reduced affinity to $\mathrm{Ca}^{2+}$ after photolysis $\left(\mathrm{K}_{\mathrm{D}}=3 \mathrm{mM}\right)$ (reviewed in Ellis-Davies, 2007, 2008). These properties make DMn the prime candidate for uncaging studies at the calyx of Held. However, it has to be noted that DMn has a relatively high affinity for $\mathrm{Mg}^{2+}$ $\left(\mathrm{K}_{\mathrm{D}}=2.5 \mu \mathrm{M}\right)$. The presynaptic pipette solution used here contained only $0.5 \mathrm{mM}$ 
$\mathrm{MgCl}_{2}$ which effectively results in lowered levels of MgATP available to the cell. DMn is therefore not suitable in environments where $\left[\mathrm{Mg}^{2+}\right]$ cannot be tightly controlled (see Ellis-Davies, 2006) or when physiological levels of MgATP are required.

To determine the purity of the DMn stock solution, a titration series with increasing levels of $\mathrm{Ca}^{2+}$ was made. The $\mathrm{Ca}^{2+}$ indicator fura- $4 \mathrm{~F}$ was used to determine the amount of $\mathrm{Ca}^{2+}$ that saturated the available fraction of chelating DMn by measuring the fluorescence ratio in microcuvettes. The purity was determined for each batch of DMn and varied among lot numbers from 70-80\%. The error introduced by impure DMn was compensated by using proportionally more of the stock solution. All concentrations of DMn given herein reflect the effective concentration of DMn in the pipette solution.

\section{Single wavelength dye}

Experiments in which fast-decaying $\mathrm{Ca}^{2+}$ transients were recorded made use of the $\mathrm{Ca}^{2+}$ indicator dye OGB-5N which was perfused into the presynaptic terminal via the patch pipette. OGB-5N is a low affinity dye $\left(K_{\mathrm{D}}=20 \mu \mathrm{M}\right)$ with an excitation/ emission spectra like fluorescein (excitation maximum at $492 \mathrm{~nm}$, emission maximum at $517 \mathrm{~nm}$ ) according to the manufacturer. Faas et al measured $k_{\text {on }}$ to be $\sim 2.5 \times 10^{8} \mathrm{M}^{-1} \mathrm{~s}^{-1}$ and a $k_{\text {off }}$ around $8 \times 10^{3} \mathrm{~s}^{-1}$ (Faas et al, 2005).

Fluorescence traces collected via the photodiode were expressed as $\Delta F / F$ and corrected for both the dark-current of the photodiode and the background fluorescence of the preparation. The latter was determined by retracting both pipettes (excised patch configuration) after recordings were completed and placing them onto the slice in a nearby location from which a fluorescence signal was then recorded.

\section{Dual wavelength dyes}

The ratiometric $\mathrm{Ca}^{2+}$ indicator dyes used in this study all belong to the fura-2 family (reviewed in Takahashi et al, 1999). Fura-2 is an UV excited indicator that shifts its absorption maximum upon $\mathrm{Ca}^{2+}$ binding. Peak absorption for $\mathrm{Ca}^{2+}$ free solution is $362 \mathrm{~nm}$ and $335 \mathrm{~nm}$ at maximal $\left[\mathrm{Ca}^{2+}\right.$ ] with an emission peak at $\sim 510 \mathrm{~nm}$ (Grynkiewicz et al, 1985). This feature can be used to derive $\left[\mathrm{Ca}^{2+}\right]$ from ratiometric measurements rather than relying on the increased fluorescence signal that single wavelength dyes emit 
upon binding of $\mathrm{Ca}^{2+}$. By measuring the dye signal at two wavelengths, $\left[\mathrm{Ca}^{2+}\right]$ values can be derived from their ratio which is essentially independent of dye concentration.

Grynkiewicz et al described the calibration equation as

$$
\left[\mathrm{Ca}^{2+}\right]=K_{\mathrm{D}} \frac{R-R_{\min }}{R_{\max }-R}\left(\frac{S_{\mathrm{f} 2}}{S_{\mathrm{b} 2}}\right)
$$

The ratio $R$ signifies the fluorescence signal measured at two wavelengths $\lambda_{1}$ and $\lambda_{2}$ : $R=F_{\lambda 1} / F_{\lambda 2}$. S indicates a proportionality coefficient that depends on dye properties and properties of the measurement system (i.e. excitation intensity, extinction coefficient and quantum efficiency). Four constants $S_{\mathrm{f} 1}, S_{\mathrm{f} 2}, S_{\mathrm{b} 1}, S_{\mathrm{b} 1}$ describe both $\mathrm{Ca}^{2+}$ free and $\mathrm{Ca}^{2+}$ bound states at the two wavelengths.

Experimentally, values for $R_{\min }, R_{\max }$ and $K_{\text {eff }}$ are determined by performing ratiometric measurements in solutions for which the free $\left[\mathrm{Ca}^{2+}\right]$ is known. Taking $K_{\mathrm{eff}}=K_{\mathrm{D}} \cdot \frac{S_{\mathrm{f} 2}}{S_{\mathrm{b} 2}}$ simplifies the above equation to:

$$
\left[\mathrm{Ca}^{2+}\right]=K_{\mathrm{eff}} \frac{R-R_{\min }}{R_{\max }-R}
$$

The cytosolic $\left[\mathrm{Ca}^{2+}\right]$ can therefore be inferred by measuring fluorescence ratios $R=$ $F_{350 \mathrm{~nm}} / F_{380 \mathrm{~nm}}$ after the calibration parameters have been determined. The experiments presented herein made use of two derivatives of fura-2. As a rule of thumb, the affinity of a given dye to $\mathrm{Ca}^{2+}$ should relate to the $\left[\mathrm{Ca}^{2+}\right]$ in question such that $0.1 \cdot K_{\mathrm{D}} \leq\left[\mathrm{Ca}^{2+}\right] \leq 10 \cdot K_{\mathrm{D}}$ is satisfied. Fura- $4 \mathrm{~F}\left(K_{\mathrm{D}}=800 \mathrm{nM}\right)$ was therefore used as a high affinity dye to measure $\left[\mathrm{Ca}^{2+}\right]_{\mathrm{i}}$ around resting levels and in experiments that employed weak uncaging flashes (Gee et al, 2000). Fura-2FF (originally described as fura-F by London et al and also marketed as fura-FF) is a low affinity derivative of fura-2 with two added fluorines on the BAPTA moiety (London et al, 1994). A $K_{\mathrm{D}}$ of $\sim 6-10 \mu \mathrm{M}$ makes it the ideal dye to measure flash induced elevations of cytosolic $\mathrm{Ca}^{2+}$.

In vitro calibration: The in vitro calibration was performed according to Schneggenburger (2005, chap. 53). The solutions used are based on the intracellular solution for fluorescence measurements (see 2.2.2) and were measured in microcuvettes. Since DMn absorbs UV light, it was included in the calibrations solutions to mimic the solution used for actual experiments. The composition of the solutions used for calibration of 
fura- $2 \mathrm{FF}$ is shown in Table 2.2. The calibration of fura- $4 \mathrm{~F}$ was performed according to the same principle.

Table 2.2: Solutions for in vitro calibration of fura-2FF. EGTA, DPTA (Fluka, Buchs, Switzerland) and DPTA $/ \mathrm{Ca}^{2+}$ was taken from stock solutions with $\mathrm{pH} 7.2$ (adjusted with $\mathrm{CsOH})$. The osmolarity was elevated to $320 \mathrm{mOsm}$ with Cs-gluconate. The free $\left[\mathrm{Ca}^{2+}\right]$ of the solution to measure $\mathrm{R}_{\mathrm{i}}$ was calculated to be $10.5 \mu \mathrm{M}$.

\begin{tabular}{ll}
\hline Substance & Final concentration [mM] \\
\hline $\mathbf{R}_{\text {min }}$ & \\
\hline intracellular solution & \\
\hline Fura-2FF & 0.05 \\
\hline DM-nitrophen & 1 \\
\hline EGTA & 10 \\
\hline $\mathbf{R}_{\mathbf{i}}$ & \\
\hline intracellular solution & \\
\hline Fura-2FF & 0.05 \\
\hline DM-nitrophen & 1 \\
\hline DPTA, $50 \%$ loaded with $\mathrm{CaCl}_{2}$ & 5 \\
\hline DPTA & 5 \\
\hline $\mathbf{R}_{\text {max }}$ & \\
\hline intracellular solution & \\
\hline Fura-2FF & 0.05 \\
\hline DM-nitrophen & 1 \\
\hline CaCl & 10 \\
\hline
\end{tabular}

\subsection{Data analysis}

Electrophysiological data were analyzed using Igor Pro (v. 5.0.5.7, Wavemetrics, Lake Oswego, OR, USA). Recordings were imported into Igor via the patcher's powertools routines kindly provided by Mr. Würriehausen. Remaining $\mathrm{R}_{\mathrm{s}}$ after online correction (see 2.3) was compensated according to Traynelis (1998). In order to assess mEPSCs, a template matching algorithm as described in Clements and Bekkers (1997), kindly provided by Dr. Taschenberger, was used. Average data are presented as mean \pm standard error of the mean (SEM). 


\subsubsection{Deconvolution}

For the experiments presented here, presynaptic release rates were inferred from EPSC recordings. This assay is only legitimate under the assumption that mEPSCs add up linearly to form the EPSC and that each measured mEPSC corresponds to a single presynaptic fusion event. As mentioned, postsynaptic receptor desensitization and saturation would violate this principle since both would lead to changes in mEPSCs during a prolonged stimulation and were therefore counteracted pharmacologically in this study. Additionally, such stimulations lead to excess glutamate in the synaptic cleft, which would be detected postsynaptically, yet does not represent additional release. This 'spill-over current' is caused by delayed clearance of glutamate and has to be subtracted from the compound EPSC prior to calculating the presynaptic release rate.

In order to derive release rates, the deconvolution method as described in Neher and Sakaba (2001); Sakaba and Neher (2001b) was used. The routine was implemented in Igor Pro and kindly provided by Dr. Neher and Mr. Würriehausen. A 'template recording' consisting of depolarizations to $0 \mathrm{mV}$ of varied length was used to invoke EPSCs of variable amplitudes. The parameters for mEPSC kinetics and spill-over current were then adjusted manually, so that the spill-over current accounted for the decay phases of the EPSCs. The resulting estimate for the spill-over current was then subtracted from the EPSC. Deconvolution with the mEPSC then yields the quantal release rate. The assumed underlying mEPSC distribution was scaled according to the means taken to reduce postsynaptic non-linearities. For CTZ alone, a mean mEPSC amplitude of $30 \mathrm{pA}$ was used, $15 \mathrm{pA}$ for CTZ and Kyn and $10 \mathrm{pA}$ for CTZ and gDGG.

The integral of the release rate derived from deconvolution yields the cumulative release of vesicles over time. For further analysis, the cumulative release was corrected for vesicles that had been recruited to the pool in the course of a given stimulus protocol (Sakaba and Neher, 2001b).

\subsubsection{Kinetic release models}

As mentioned in 1.1.2, kinetic models are a valuable tool to estimate release rates in response to the $\mathrm{Ca}^{2+}$ waveform driving vesicle fusion. Its reverse analogy allows to adjust the $\mathrm{Ca}^{2+}$ waveform so that the model prediction matches experimental release 
rates in order to determine amplitude and time course of the $\mathrm{Ca}^{2+}$ signal at the $\mathrm{Ca}^{2+}$ sensor (Bollmann et al, 2000; Schneggenburger and Neher, 2000).

$$
\mathbf{B}_{\mathbf{0}} \underset{k_{\mathrm{off}} \mathrm{b}^{0}}{\stackrel{5 k_{\mathrm{on}}\left[\mathrm{Ca}^{2+}\right]}{\rightleftharpoons}} \mathbf{B}_{\mathbf{1}} \cdots \mathbf{B}_{\mathbf{4}} \underset{5 k_{\mathrm{off}} \mathrm{b}^{4}}{\stackrel{k_{\mathrm{on}}\left[\mathrm{Ca}^{2+}\right]}{\rightleftharpoons}} \mathbf{B}_{\mathbf{5}} \stackrel{\gamma}{\longrightarrow} \text { fused }
$$

The model used by Schneggenburger and Neher represents a minimal sequential model describing the consecutive binding of $5 \mathrm{Ca}^{2+}$ ions. The occupancy of each binding state is governed by the rate constants $k_{\text {on }}$ and $k_{\text {off }}$ as well as a cooperativity factor $b$ which is necessary to account for the supralinear dependence of release on $\left[\mathrm{Ca}^{2+}\right]_{\mathrm{i}}$ (Heidelberger et al, 1994). Fusion occurs irreversible from the fully occupied state at rate $\gamma$ (see scheme 2.1). This kinetic model was translated into a set of rate equations that describe the occupancy of each binding site and implemented in Igor Pro and Matlab (v 7.6, Mathworks, Natick, MA, USA). It was solved numerically with a built-in algorithm for stiff problems available in both programs. The release rate per vesicle was determined by differentiation of the cumulative release (the 'fused' state in scheme 2.1).

Release rates predicted by a kinetic model can be compared to experimental data by either multiplying with an average pool size or by dividing the peak release rate obtained experimentally by the pool size estimate for the given cell (release rate per vesicle).

Although this sequential model is minimalistic in nature, it sufficiently describes the steep $\mathrm{Ca}^{2+}$ dependency of release identified at the calyx of Held. Lou et al (2005) showed however that the sequential model fails to predict release rates at $\left[\mathrm{Ca}^{2+}\right]_{\mathrm{i}}$ levels $<1 \mu \mathrm{M}$ which have been found to be several orders of magnitude higher than predicted. This is owed to the model assumption that fusion can only occur when all binding sites have successively been occupied in scheme 2.1.

Higher release rates at basal levels of $\left[\mathrm{Ca}^{2+}\right]_{\mathrm{i}}$ can be accounted for if one allows fusion to occur from a sensor that is not fully occupied. Changes between interconvertible 
(a)

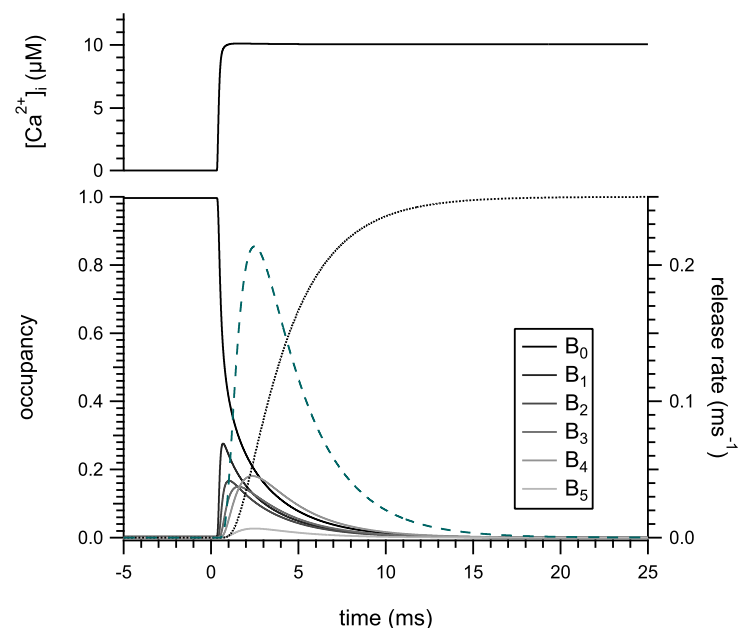

(b)

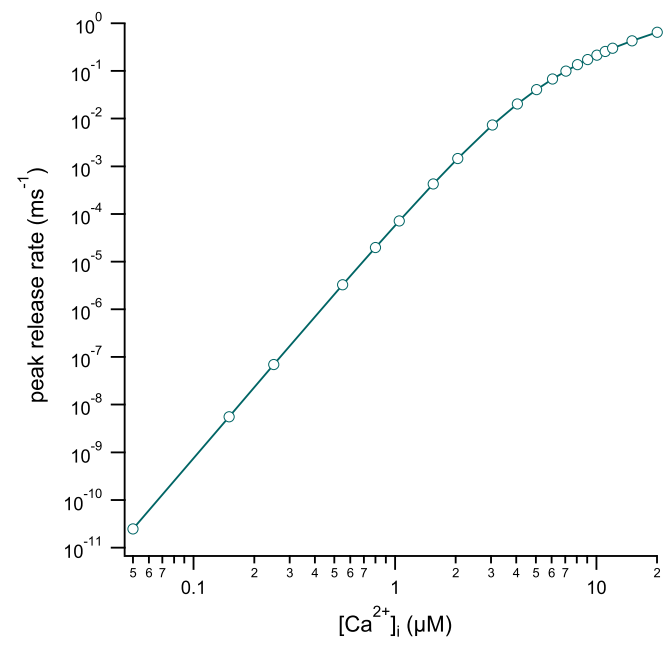

Figure 2.3: Example of the minimal kinetic release model described by Schneggenburger and Neher (2000). (a) shows the occupancy of each binding site in scheme 2.1 over time (bottom) in response to a simulated $\mathrm{Ca}^{2+}$ waveform after flash induced $\mathrm{Ca}^{2+}$ uncaging (top). The dotted line represents the 'fused' state (or cumulative release) whereas the superimposed dashed line shows its derivative, the release rate. (b): Dose-response-curve plotting peak release rates obtained from a simulation as in (a) against various levels of $\left[\mathrm{Ca}^{2+}\right]_{i}$ on a double logarithmic scale. The model parameters in this example were taken from Fig. 3.4(d).

states in the absence of a regulator are a feature of an allosteric model (also called MWC model, reviewed in Changeux and Edelstein (1998)).

$$
\begin{aligned}
& \mathbf{B}_{\mathbf{0}} \stackrel{5 k_{\mathrm{on}}\left[\mathrm{Ca}^{2+}\right]}{k_{\text {off }}} \mathbf{B}_{\mathbf{1}} \quad \ldots \quad \mathbf{B}_{\mathbf{4}} \stackrel{\frac{k_{\mathrm{on}}\left[\mathrm{Ca}^{2+}\right]}{5 k_{\text {off }}}}{\rightleftharpoons} \mathbf{B}_{\mathbf{5}}
\end{aligned}
$$

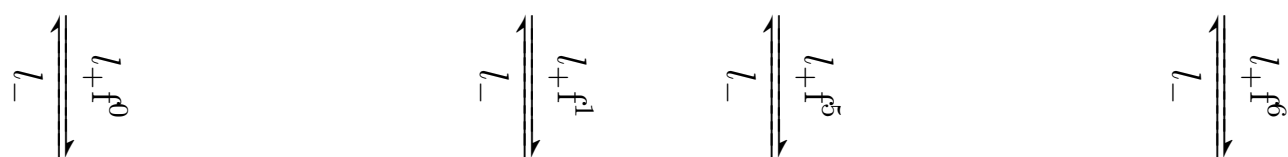

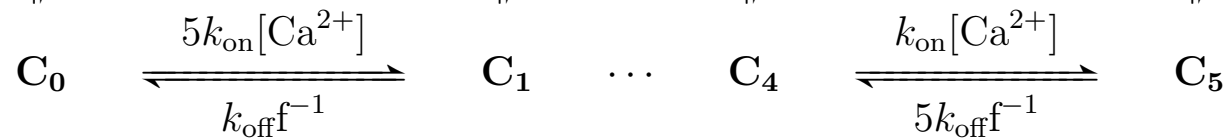

$$
\begin{aligned}
& \downarrow \gamma \\
& \downarrow \gamma \\
& \downarrow \gamma \\
& \text { fused fused }
\end{aligned}
$$


In scheme 2.2, the $\mathbf{B}$ and $\mathbf{C}$ states correspond to the 'tense' and 'relaxed' states in the MWC model. Fusion can only occur from the 'relaxed' states. All C states have a finite probability to lead to fusion, which can occur without binding $\mathrm{Ca}^{2+}\left(\mathbf{B}_{\mathbf{0}}\right)$, from partially filled states $\left(\mathbf{B}_{1 \ldots 4}\right)$ or a fully occupied one $\left(\mathbf{B}_{5}\right.$ in scheme 2.2$)$. The equilibrium constant of the reaction from states $\mathbf{B}$ to $\mathbf{C}$ increases by a factor $\mathbf{f}$ with each successive $\mathrm{Ca}^{2+}$ ion that is bound. Also, the binding affinity for $\mathrm{Ca}^{2+}$ is larger in the $\mathbf{C}$ states. A cyclic mechanism, without an energy input, has to conform to the demand for microscopic reversibility. The dissociation constant for agonist binding in the relaxed state is therefore multiplied by $\mathrm{f}^{-1}$. As a result, going from $\mathbf{B}_{\mathbf{0}}$ to $\mathbf{C}_{\mathbf{1}}$ clockwise or counterclockwise is energetically equivalent. Fusion is then promoted irreversibly from the $\mathbf{C}$ states and limited by rate $\gamma$ as in scheme 2.1 .

In Lou et al (2005), a simplified allosteric model was adopted for which scheme 2.1 was extended by allowing fusion to occur irreversible from each $\mathbf{B}$ state mediated by a single forward rate $l_{+}$and factor $\mathrm{f}$, as in scheme 2.2 . 


\section{Results}

\subsection{Heterogeneity in release probability at the calyx of Held}

Heterogeneity in release probability at the calyx of Held was first reported by $\mathrm{Wu}$ and Borst. They used voltage-clamp to depolarize the terminal via two action potential waveforms (APWs) with an interstimulus interval of $1 \mathrm{~s}$. Both APWs were followed by a $10 \mathrm{~ms}$ step depolarization meant to deplete the releasable vesicles. It was shown that the second APW can only trigger a small amount of release during recovery from the induced depression. The following step however elicited a substantial excitatory postsynaptic current (EPSC). Wu and Borst concluded that vesicles are rapidly replenished after depression of the releasable pool, yet are 'reluctant' and can therefore only be released by an increase in the global $\left[\mathrm{Ca}^{2+}\right]_{\mathrm{i}}$ (Wu and Borst, 1999).

This heterogeneity in $p_{\text {ves }}$ can also be revealed when the calyx of Held is exposed to a $50 \mathrm{~ms}$ step depolarization in the presence of $0.5 \mathrm{mM}$ EGTA which has been shown to effectively block overlapping facilitation of release (Sakaba and Neher, 2001a). Figure 3.1 shows an example for this type of stimulation. The resulting AMPA-receptor mediated EPSC was deconvolved as described in 2.4.1 to yield the vesicular release rate. Its integral gives the cumulative release over time. Figure 3.1(b) illustrates that this kind of stimulation depletes almost all available vesicles. Accordingly, the readily releasable pool (RRP) is defined herein as comprising vesicles that can be released by strong stimulations such as sustained depolarizations of the presynaptic terminal. When the cumulative release trace is fitted with a biexponential function after correction for pool refilling, two time constants of release can be obtained. They differ roughly by a 
(a)

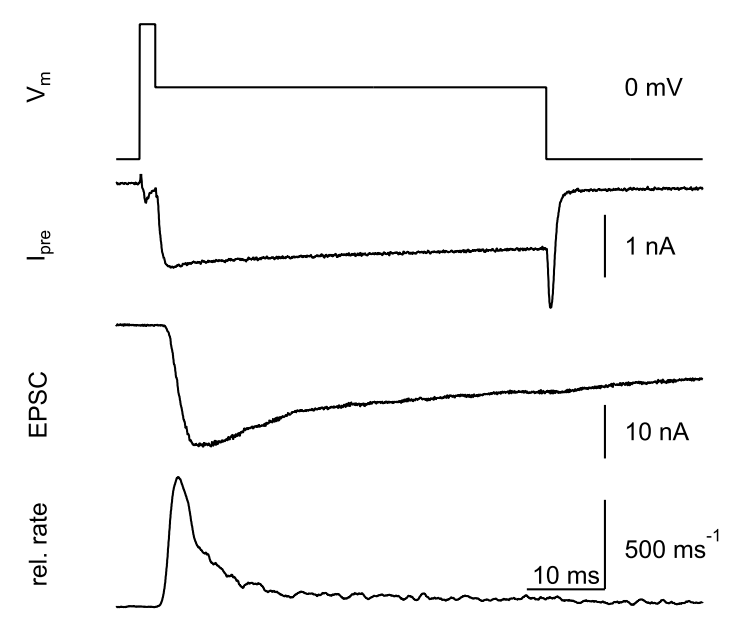

(b)

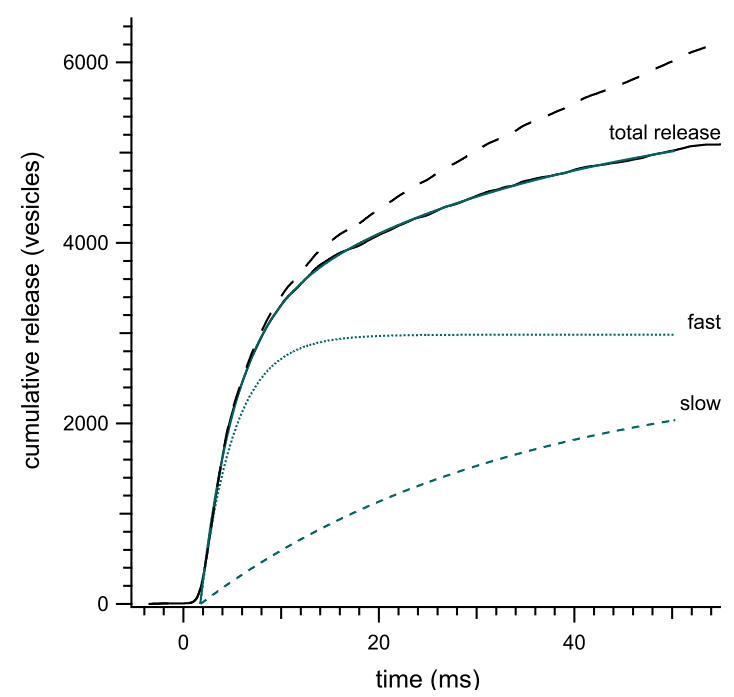

Figure 3.1: (a) A $50 \mathrm{~ms}$ step-depolarizations depletes the RRP at the calyx of Held. Traces shown are (from top to bottom): presynaptic membrane potential, presynaptic $\mathrm{Ca}^{2+}$ current, EPSC and vesicle release rate. The presynaptic terminal was depolarized to $+70 \mathrm{mV}$ for $2 \mathrm{~ms}$ and then to $0 \mathrm{mV}$ for $50 \mathrm{~ms}$ to deplete the readily releasable pool. A pre-depolarization to $+70 \mathrm{mV}$ maximizes $\mathrm{Ca}^{2+}$ channel opening without causing influx of $\mathrm{Ca}^{2+}$ ions. $0.5 \mathrm{mM}$ EGTA was added to the presynaptic pipette solution to facilitate the differentiation between fast and slow releasing vesicles. CTZ and Kyn were added to the presynaptic pipette solution to block postsynaptic AMPA receptor desensitization and saturation. (b) cumulative release in response to the $50 \mathrm{~ms}$ step-depolarization shown in (a) (dashed black line) obtained after integrating the vesicular release rate. The cumulative release was corrected for pool refilling as described in 2.4.1 (solid black line). The double exponential fit to the corrected cumulative release trace is shown in green and can be separated into the contributions of the fast releasing pool (dotted green line) and slow releasing pool of vesicles (dashed green line).

factor of 10 (2-3 ms and 20-30 ms respectively) and are attributed to the fast and slow component of release. The heterogeneity among vesicles of the RRP can therefore be ascribed to the presence of two subpools, the fast releasing pool of vesicles (FRP) and the slow releasing pool of vesicles (SRP).

Figure 3.2 shows an experiment similar to the one by $\mathrm{Wu}$ and Borst. A calyx terminal and its corresponding medial nucleus of the trapezoid body (MNTB) principle cell were double voltage-clamped at $-80 \mathrm{mV}$. A square pulse to $+40 \mathrm{mV}$ for $1.5 \mathrm{~ms}$ was used to mimic an action potential (AP). The subsequent $10 \mathrm{~ms}$ step depolarization to $0 \mathrm{mV}$ 


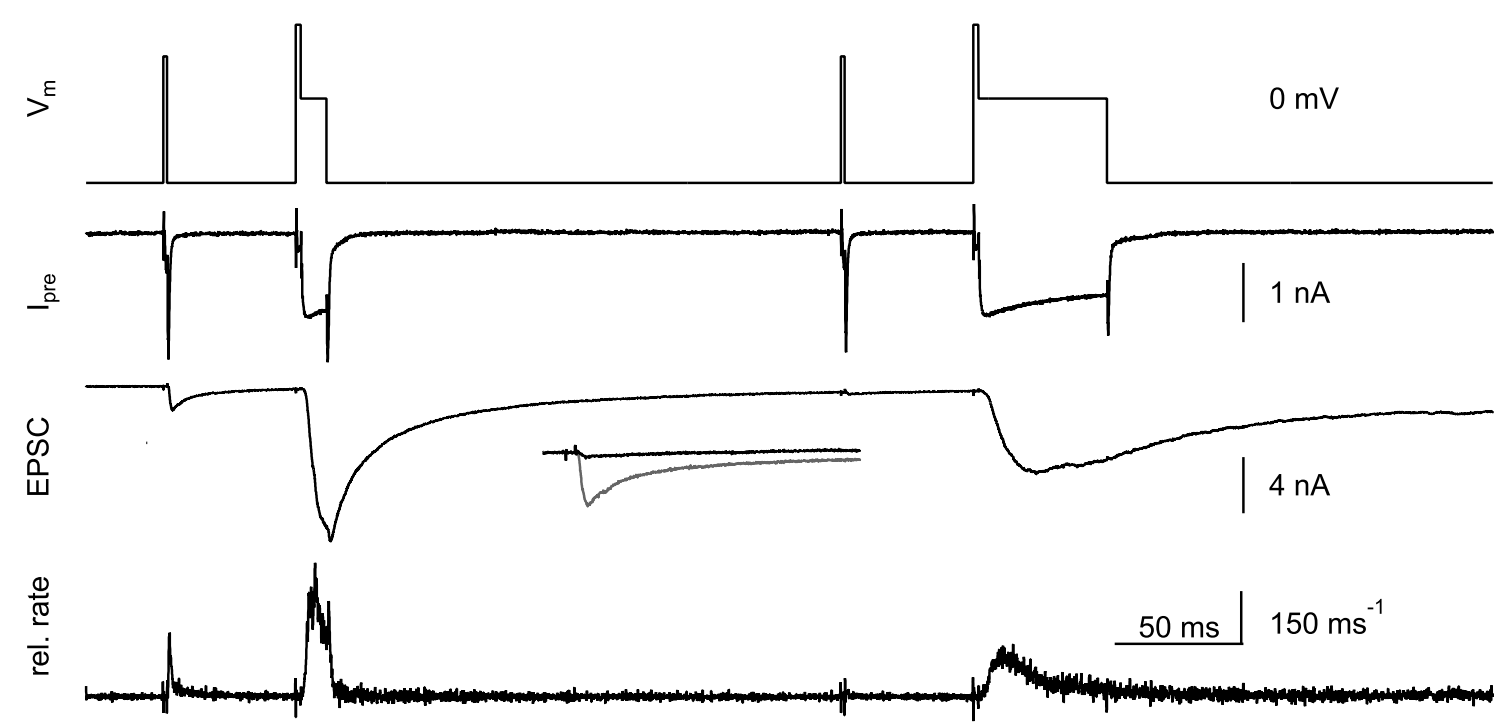

Figure 3.2: Release evoked by AP-like stimulation is blocked when the vesicles from the fast releasing pool of vesicles have been depleted. Traces shown are (from top to bottom): Presynaptic membrane potential, presynaptic $\mathrm{Ca}^{2+}$ current, excitatory postsynaptic current and vesicle release rate. The inset shows an overlay of the first (gray) and second (black) EPSC response to action potential-like stimulation.

(after a $2 \mathrm{~ms}$ prepulse to $+70 \mathrm{mV})$ released the fast releasing vesicles $\left(3 \times \tau_{\text {fast }} \approx 10 \mathrm{~ms}\right)$ corresponding to $\sim 50 \%$ of the RRP (Sakaba and Neher, 2001a). A second AP-like pulse followed after $200 \mathrm{~ms}$. This interval allowed for replenishment of the SRP but not the FRP owing to the differential recovery times of these pools. It has been shown previously that the SRP recovers fast whereas the FRP recovers more slowly (Sakaba and Neher, 2001a). A final $50 \mathrm{~ms}$ step depolarization was then used to release all remaining vesicles in order to obtain a faithful RRP size estimate.

Recordings were performed in the presence of the NMDA receptor blocker D-AP5, Kyn (or gDGG) and CTZ to prevent AMPA receptor saturation and desensitization. Presynaptic $\mathrm{Ca}^{2+}$ currents were pharmacologically isolated by TEA and TTX.

In the example given in Fig. 3.2, the first brief depolarization elicited an EPSC of $\sim 2 \mathrm{nA}$ whereas the second response to the AP-like stimulation was largely depressed (see inset). The lack of release in response to the second AP-like stimulus was not caused by inactivation of $\mathrm{Ca}^{2+}$ currents, because the $\mathrm{Ca}^{2+}$ charge integral of the first and second AP-like stimulus was not significantly different: the ratio of AP2/AP1 
(a)

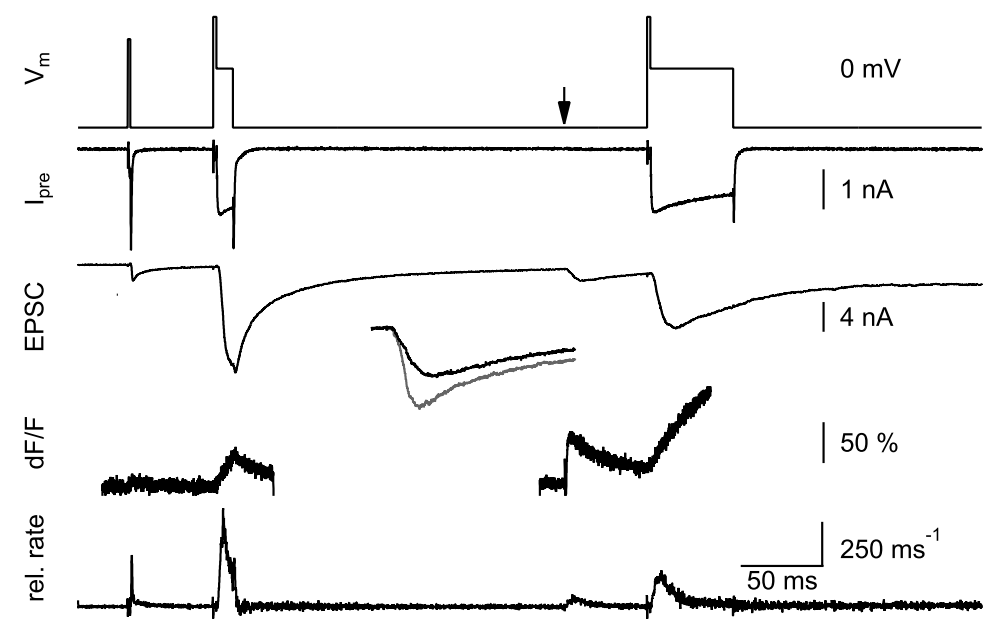

(b)

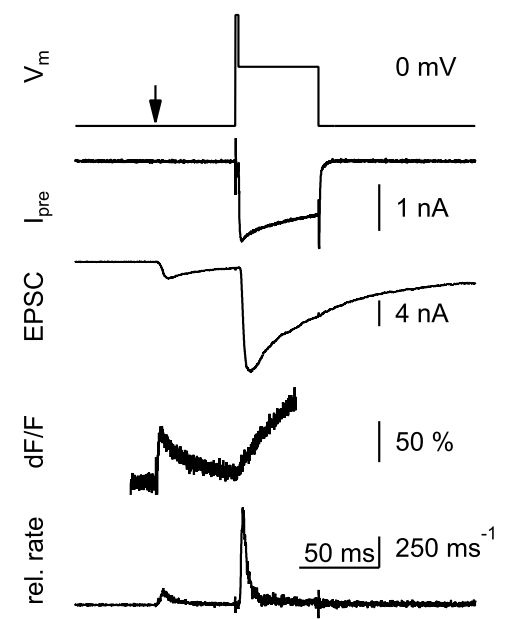

Figure 3.3: Release evoked by flash-induced transient elevations of $\left[\mathrm{Ca}^{2+}\right]_{\mathrm{i}}$ is intact after depletion of the rapidly releasing vesicles. Traces shown are (from top to bottom): Presynaptic membrane potential, presynaptic $\mathrm{Ca}^{2+}$ current, excitatory postsynaptic current, fluorescence signal of the $\mathrm{Ca}^{2+}$ indicator OGB-5N and vesicle release rate. OGB-5N is a single wavelength dye, $\mathrm{Ca}^{2+}$ binding to the dye is reported as the relative increase of fluorescence over the baseline fluorescence $(d F / F)$. (a) shows the same protocol as Fig. 3.2, but flash uncaging was used instead of the second AP-like depolarization (time point of the flash indicated by an arrow). (b) shows a flash response where the preceding prepulse was omitted. Both (a) and (b) were recorded in the same cell pair as Fig. 3.2.

was $94.7 \% \pm 1.5 \%$ (mean \pm standard error of the mean $(\mathrm{SEM})$ ). As reported by $\mathrm{Wu}$ and Borst, a subsequent long depolarization elevates $\left[\mathrm{Ca}^{2+}\right]_{\mathrm{i}}$ sufficiently to release the 'reluctant' vesicles.

To investigate the nature of these 'reluctant' vesicles and to see whether they are less sensitive to $\left[\mathrm{Ca}^{2+}\right]_{\mathrm{i}}$, the second stimulus was substituted with a laser-induced transient, but spatially uniform, elevation of $\left[\mathrm{Ca}^{2+}\right]_{\mathrm{i}}$. If vesicles are 'reluctant' because of a loose coupling between $\mathrm{Ca}^{2+}$ channels and the $\mathrm{Ca}^{2+}$ sensor of release, uniform elevations of $\left[\mathrm{Ca}^{2+}\right]_{\mathrm{i}}$ should elicit rapid release (hypothesis 1 ), while AP-induced release would be small. Alternatively, if vesicles are 'reluctant' because of a reduced $\mathrm{Ca}^{2+}$ sensitivity for fusion, uniform elevations of $\left[\mathrm{Ca}^{2+}\right]_{\mathrm{i}}$ would only trigger slow release (hypothesis 2). Bollmann and Sakmann revised the $\mathrm{Ca}^{2+}$ uncaging technique described in 1.1.2 by using a pulsed ultraviolet (UV) laser in combination with the low affinity $\mathrm{Ca}^{2+}$ indicator 
dye OGB-5N. High concentrations of endogenous buffers were used to evoke a uniform and rapidly decaying global elevation of $\left[\mathrm{Ca}^{2+}\right]_{\mathrm{i}}$ that can be measured at high sampling frequencies with a photo diode (Bollmann and Sakmann, 2005).

Figure 3.3 shows examples in which $1 \mathrm{mM}$ EGTA was added to the intracellular pipette solution to induce a faster decay of $\left[\mathrm{Ca}^{2+}\right]_{\mathrm{i}}$ after flash uncaging. It has to be noted that the transients reported here were not as short as the AP transients described in Bollmann and Sakmann (2005). However, the large amounts of EGTA and BAPTA used by Bollmann and Sakmann would make it impossible to obtain RRP size estimates in response to strong depolarizing pulses, as $\mathrm{Ca}^{2+}$ entering through channels would readily be buffered before inducing vesicle fusion. Still, the transient flashes shown here are closer to the physiological $\mathrm{Ca}^{2+}$ rise invoked by an AP since they do not cause the sustained neurotransmitter release seen in response to flash uncaging designed to produce a step-like elevation of $\left[\mathrm{Ca}^{2+}\right]_{\mathrm{i}}$ (see below).

In the stimulation protocol depicted in Fig. 3.3(a) the second AP-like stimulus of Fig. 3.2 was substituted with a laser flash. The spatially uniform elevation of $\left[\mathrm{Ca}^{2+}\right]_{\mathrm{i}}$ was able to trigger release (Fig. 3.3(a)) whereas a short depolarization was not (Fig. 3.2). This difference was not caused by an overly strong flash stimulus since the flash intensity was adjusted so that a stand-alone flash elicited an EPSC $(\sim 2 \mathrm{nA}$ in the example shown in Fig. 3.3(b)) comparable to one elicited by AP-like stimulation ( $1^{\text {st }}$ AP-like stimulus response in Fig. 3.2). Experiments as shown in Fig. 3.2 and Fig. 3.3 were performed in seven cell pairs $(n=7)$. Within a given pair, the laser intensity was adjusted such that stand-alone flashes without a depleting prepulse (control flash) evoked an EPSC of comparable amplitudes to AP-like triggered ones (Fig. 3.3(b)). The $\left[\mathrm{Ca}^{2+}\right]_{\mathrm{i}}$ elevations $(\Delta F / F)$ were similar between flashes with a prepulse and control flashes in a given cell and gave a mean ratio of $1.04 \pm 0.03$ across all cell pairs. In order to study the 'reluctant' vesicles alone, $10 \mathrm{~ms}$ prepulses were used which, on average, released $52.9 \% \pm 3.6 \%$ of the total RRP. The fast releasing vesicles should have been depleted by this prepulse since the contribution of fast releasing vesicles is $50 \%$ (as described in Sakaba and Neher (2001a)).

The EPSC amplitudes obtained by the double AP-like stimulation protocols like in Fig. 3.2 gave an average ratio of $\mathrm{AP}_{2} / \mathrm{AP}_{1}=0.12 \pm 0.05$. This ratio is much lower than the one given by flashes after a prepulse and control flashes which was $0.78 \pm 0.21$. Similar results were obtained when the comparison of the protocols of Fig. 3.2 and 
Fig. 3.3 was based on the analysis of vesicular release rates obtained after deconvolution. The peak release rates resulting from either flash or brief depolarizing stimulation were divided by the pool of available vesicles yielding the release rate per vesicle. For double pulse experiments, the release rate per vesicle for the first AP-stimulus was $0.093 \mathrm{~ms}^{-1} \pm 0.04 \mathrm{~ms}^{-1}$ and $0.028 \mathrm{~ms}^{-1} \pm 0.019 \mathrm{~ms}^{-1}$ for the second, giving a ratio $\mathrm{AP}_{2} / \mathrm{AP}_{1}$ of $29 \% \pm 9 \%$. The ratio of release rates per vesicle for flashes after a prepulse and stand-alone (control) flashes was $81 \% \pm 16 \%$. Release rates per vesicle were $0.035 \mathrm{~ms}^{-1} \pm 0.008 \mathrm{~ms}^{-1}$ for control flashes and $0.022 \mathrm{~ms}^{-1} \pm 0.004 \mathrm{~ms}^{-1}$ for flashes after the prepulse.

The experiment shown in Fig. 3.3 demonstrated that an intrinsic difference in the $\mathrm{Ca}^{2+}$ sensitivity among vesicles is not the major cause for the heterogeneity in $p_{\text {ves }}$ observed at the calyx of Held. Instead, the experiment indicated that reluctant vesicles are slow because of loose coupling between $\mathrm{Ca}^{2+}$ channels and vesicles in a qualitative manner. To study the kinetics of release quantitatively, step-like elevations of $\left[\mathrm{Ca}^{2+}\right]_{\mathrm{i}}$ were used to follow the time course of release. $\mathrm{Ca}^{2+}$ uncaging in combination with the ratiometric $\mathrm{Ca}^{2+}$ indicator dye fura- $2 \mathrm{FF}$ allows for the quantitative determination of $\left[\mathrm{Ca}^{2+}\right]_{\mathrm{i}}$. Using 1-2 mM DM-nitrophen (DMn) and a variable intensity of the UV flash, $\left[\mathrm{Ca}^{2+}\right]_{\mathrm{i}}$ could be elevated in a step-like manner ranging from $2-30 \mu \mathrm{M}$. Figure 3.4(a) shows a protocol analogous to Fig. 3.2 except that the two AP-like stimuli were omitted. A $15 \mathrm{~ms}$ prepulse is followed by a $50 \mathrm{~ms}$ pool depleting pulse with an interstimulus interval of $200 \mathrm{~ms}$. In order to completely rule out recovery of the fast releasing vesicles during this interval, $20 \mu \mathrm{M}$ of calmodulin binding domain peptide were added, which has been shown to eliminate the fast phase of FRP recovery (Sakaba and Neher, 2001a). Figure 3.4(a) shows the slow rise of the EPSC during the second stimulus which reflects the release of 'reluctant' vesicles. The EPSC rose much faster when a flash induced elevation of $\left[\mathrm{Ca}^{2+}\right]_{\mathrm{i}}$ was employed as shown in Fig. 3.4(b). In this example, intracellular $\mathrm{Ca}^{2+}$ was elevated to levels $>10 \mu \mathrm{M}$ which is comparable to $\left[\mathrm{Ca}^{2+}\right]_{\mathrm{i}}$ during an AP and sufficient to deplete the RRP. It can be seen that a subsequent $50 \mathrm{~ms}$ depolarization did not lead to additional release, indicating that the RRP had been depleted by the preceding flash. The increase in EPSC risetime indicated again that slow vesicles can in fact be released rapidly, but that the $\mathrm{Ca}^{2+}$ concentrations reached during depolarizations do not reach high enough levels to do so. 
As mentioned previously, the two components of release, fast and slow, can be separated based on their kinetic properties. The deconvolution of the EPSC with miniature excitatory postsynaptic currents (mEPSCs) yields the release rate of vesicles. Its integral describes the cumulative release of vesicles over time. The cumulative release was corrected for the recovery of slow vesicles which takes place at a rate of $\sim 10$ vesicles $/ \mathrm{ms}$ (see 2.4.1). Figure 3.4(c) shows an example of the cumulative release in response to a flash after prepulse (solid trace). The time course of release evoked by flash uncaging can be fitted with a double exponential function (gray trace) that shows the dominant fast component of release ( $>80 \%$ depleted within $2 \mathrm{~ms}$ ), whereas the slow rise of the $2^{\text {nd }}$ EPSC evoked by a $50 \mathrm{~ms}$ step depolarization in Fig. 3.4(a) could be fitted with a single exponential function. The lack of biexponential kinetics is indicative of the depletion of fast vesicles (dashed trace in Fig. 3.4(c)).

The dominating fast component of release was most pronounced at $\left[\mathrm{Ca}^{2+}\right]_{\mathrm{i}}>10 \mu \mathrm{M}$ and showed that the release probability amongst the RRP vesicles is more homogeneous when $\left[\mathrm{Ca}^{2+}\right]_{\mathrm{i}}$ is elevated uniformly around them. The kinetics of release were analyzed in 30 cell pairs by flash photolysis. The fast component of release accounted for $87 \% \pm 4 \%$ of the total release in control flashes and still $84 \% \pm 4 \%$ in flashes that followed a prepulse. This implies that when $\left[\mathrm{Ca}^{2+}\right]_{\mathrm{i}}$ is elevated sufficiently high $(>10 \mu \mathrm{M})$, most of the reluctant vesicles can be released rapidly.

It remains possible that the $\mathrm{Ca}^{2+}$ sensitivity of release differs at lower $\left[\mathrm{Ca}^{2+}\right]_{\mathrm{i}}$. It is therefore necessary to examine the $\left[\mathrm{Ca}^{2+}\right]_{\mathrm{i}}$-dependence of fast and slow vesicles. This was achieved by changing the UV-flash intensity which allows to achieve post-flash $\left[\mathrm{Ca}^{2+}\right]_{\mathrm{i}}$ levels of $2-30 \mu \mathrm{M}$. Figure $3.4(\mathrm{~d})$ shows the peak release rate per vesicle plotted against $\left[\mathrm{Ca}^{2+}\right]_{i}$. The data were fitted with the 5 -site secretion model described by Schneggenburger and Neher (2000) (also see 2.4.2). Only the on-binding rate of the model needed to be changed in order to describe both experimental conditions of control flashes and flashes following a prepulse respectively $\left(k_{\mathrm{on}}=1.2 \times 10^{8} \mathrm{M}^{-1} \mathrm{~s}^{-1}\right.$ for control and $k_{\text {on }}=0.9 \times 10^{8} \mathrm{M}^{-1} \mathrm{~s}^{-1}$ after prepulse, $\left.k_{\text {off }}=9000 \mathrm{~s}^{-1}, \mathrm{~b}=0.25, \gamma=8000 \mathrm{~s}^{-1}\right)$. Overall, a $\sim 2$-fold difference was observed. The same difference was observed when the time constants of the fast component in the cumulative release were compared (data not shown).

This 2-fold difference is much smaller than the 10-fold difference in release kinetics between FRP and SRP during a depolarizing pulse (Fig. 3.1) so that the spatial 
distribution of vesicles seems to be the predominant cause of heterogeneity in the release probability observed at the calyx of Held. This excludes the possibility that intrinsic differences in the $\mathrm{Ca}^{2+}$ sensitivity can cause fast and slow neurotransmitter release in wild-type animals (Sun et al, 2007). However, even when $\left[\mathrm{Ca}^{2+}\right]_{\mathrm{i}}$ was elevated uniformly by flash uncaging, some vesicles remained 'reluctant' to release. It is therefore not admissible to exclude the possibility of an additional, though smaller, intrinsic heterogeneity of vesicles. However, the protocols employed here do not allow to discern between an intrinsic heterogeneity that exists a priori of release (Sun et al, 2007) and heterogeneity that develops during release (Wölfel et al, 2007). 
(a)
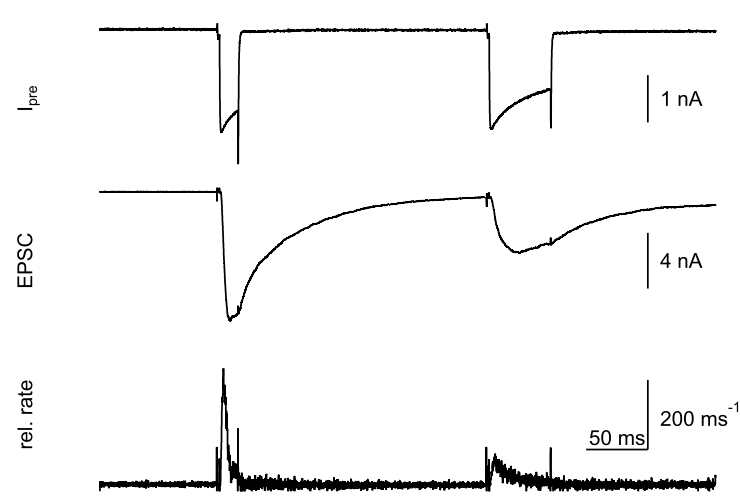

(c)

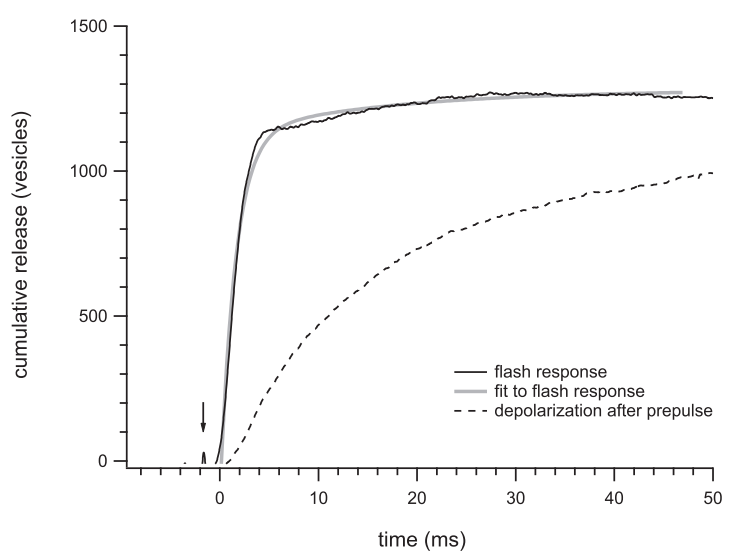

(b)

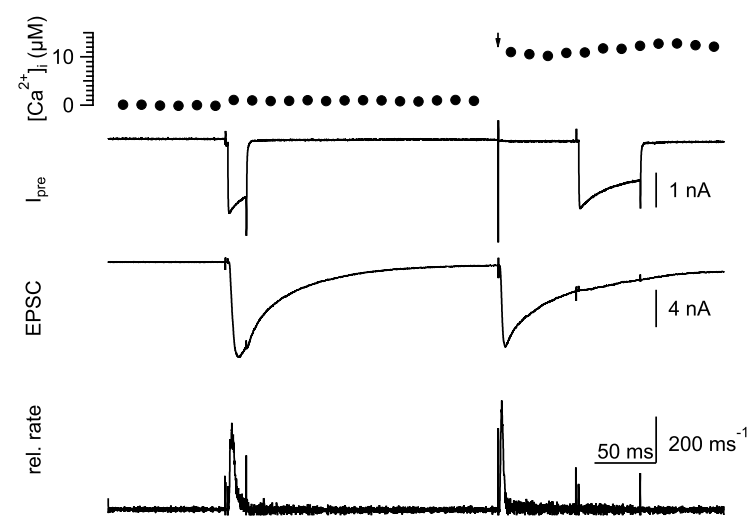

(d)

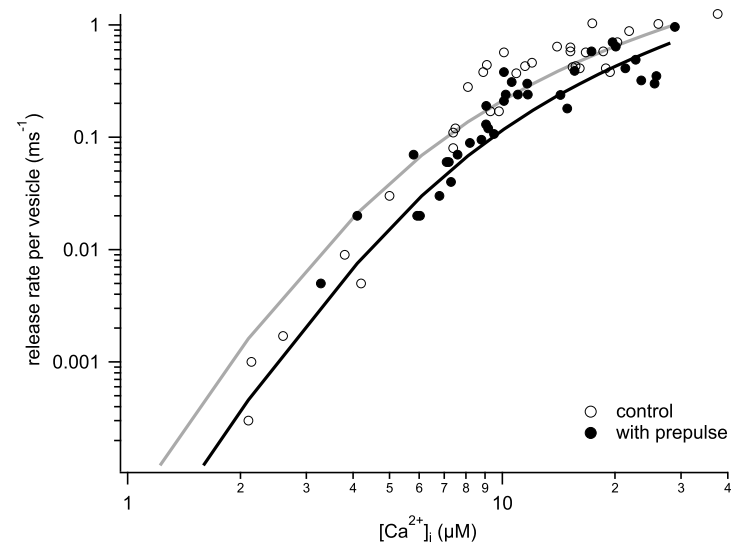

Figure 3.4: Quantitative comparison of neurotransmitter release evoked by either depolarization or flash uncaging after depletion of the fast releasing vesicles. (a) Traces shown are (from top to bottom): presynaptic $\mathrm{Ca}^{2+}$ current, excitatory postsynaptic current and vesicle release rate. The presynaptic terminal was depolarized to $+70 \mathrm{mV}$ for $2 \mathrm{~ms}$ and then to $0 \mathrm{mV}$ for $15 \mathrm{~ms}$ to deplete the fast releasing vesicles. The addition of calmodulin binding domain peptide and an inter stimulus interval of $200 \mathrm{~ms}$ allowed to study the slow releasing vesicles in isolation (Sakaba and Neher, 2001a). The following $50 \mathrm{~ms}$ depolarization elicited an EPSC with slow rise and decay (see release rate trace). (b) shows the same protocol as (a) except that flash uncaging was used as the second stimulus. A uniform elevation of $\left[\mathrm{Ca}^{2+}\right]_{\mathrm{i}}$ to $\sim 10 \mu \mathrm{M}$ (top trace) evoked an EPSC with fast risetime. (c) shows the cumulative release to illustrate the difference in the release kinetics in response to the second stimulus in (a) and (b). (d) Relationship between the release rate per vesicle and $\left[\mathrm{Ca}^{2+}\right]_{\mathrm{i}}$ for flash experiments with (black circles) and without (open circles) preceding prepulse. The data were fitted with the 5 -site binding model (see scheme 2.1). 


\subsection{The role of synaptobrevin in release at the calyx of Held}

The discrimination between fast and slow releasing vesicles at the calyx of Held is based on the observation of distinct kinetic differences (Wu and Borst, 1999; Sakaba and Neher, 2001a). In order to study the slow component of release, the protocols described so far exploited the slower recovery of fast releasing vesicles and their depletion by stimuli that trigger release of $\sim 50 \%$ of the RRP (the fraction attributed to be 'fast').

A selective effect on the fast releasing vesicles via a molecular perturbation of the release machinery using tetanus neurotoxin (TeNT) was described by Sakaba et al (2005). TeNT leads to a complete block of exocytosis at the calyx of Held with time, however the analysis of release kinetics revealed a preferential loss of the fast component of release when the time course of the toxin effect on release was tracked by multiple $50 \mathrm{~ms}$ depolarizations. It was shown that under the influence of TeNT, but not under BoNT/C, the cumulative release lost its biexponential characteristic and showed a slowing in the remaining single time constant describing the release kinetics. It was also shown, that the recovery of the fast component was slowed markedly when strong depolarizations were applied at various interstimulus intervals (ISIs), whereas recovery of the slow component was not. TeNT cleaves rat synaptobrevin-2 at the C-terminal end of the segment that participates in SNARE complex formation. However, it is not clear which region of synaptobrevin is responsible for the observed effects on release kinetics.

To further specify the role of synaptobrevin for fast release at the calyx of Held, $100 \mu \mathrm{M}$ of the N-terminal proline-rich domain of synaptobrevin (corresponding to amino acids 1-26) was perfused into the terminal (Cornille et al, 1995). To facilitate the discrimination of the fast and slow components of release, $0.5 \mathrm{mM}$ EGTA was also added (Sakaba and Neher, 2001a). As shown in Fig. 3.1, two kinetic components representing FRP and SRP can be discerned in this condition. The recovery of the two pools was probed by pairs of $50 \mathrm{~ms}$ depolarizations with varied interstimulus interval (Fig. 3.5). The peptide had no effect on the kinetics of release during the first depolarization (Fig. 3.5(b) and Fig. 3.5(a) black traces) whereas the release (and therefore recovery) was reduced under the influence of the peptide (gray traces). It has to be noted however that the peptide had no effect on the total amount of release whereas TeNT eventually blocks 
(a) control
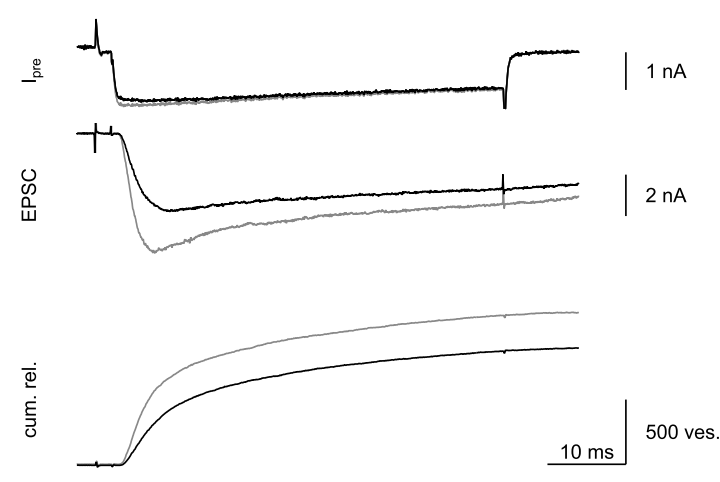

(c) fast component

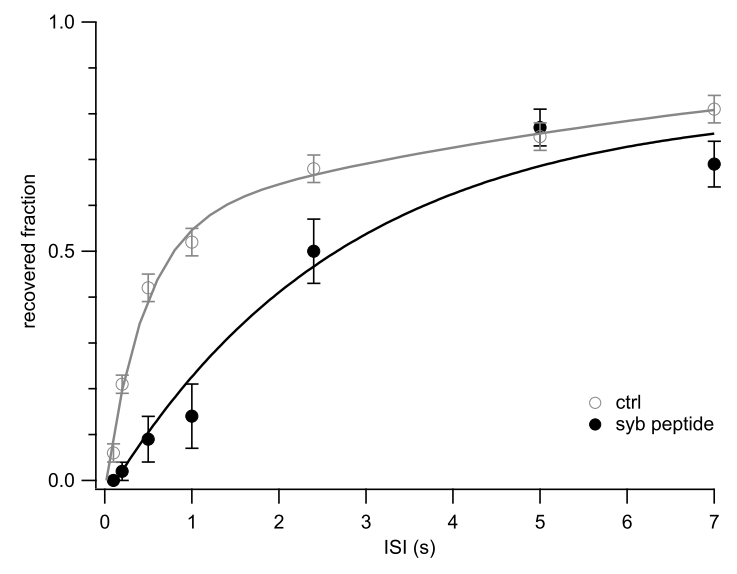

(b) synaptobrevin peptide

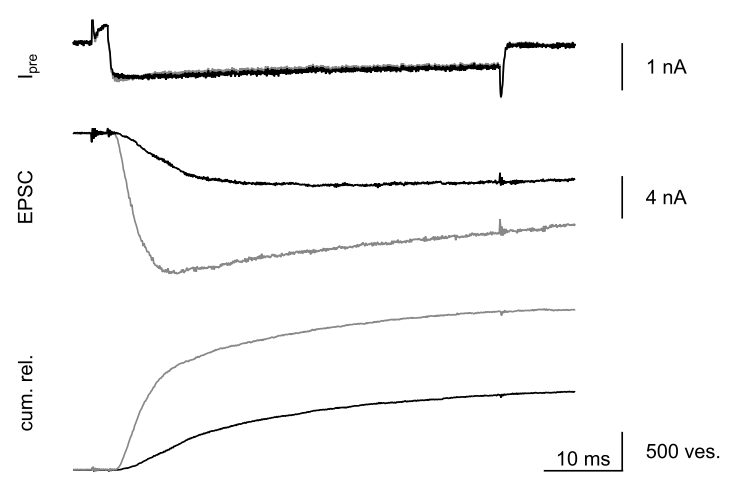

(d) slow component

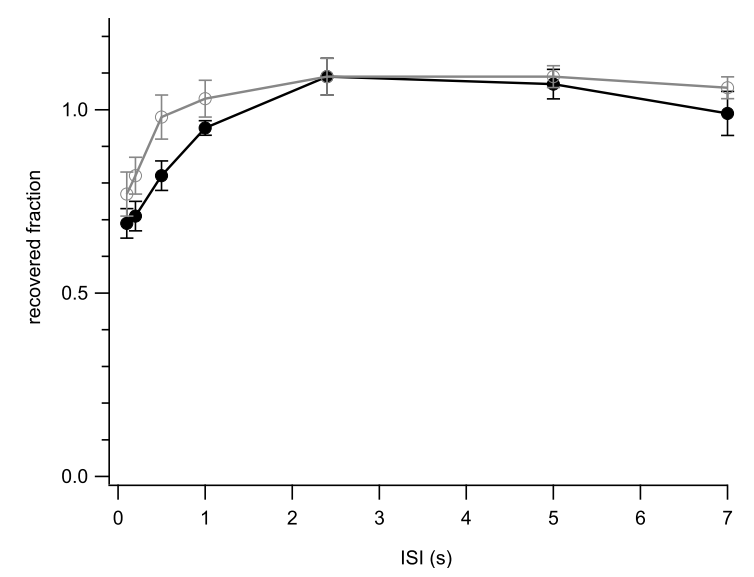

Figure 3.5: (a) \& (b) Traces shown are (from top to bottom): presynaptic $\mathrm{Ca}^{2+}$ current, EPSC and cumulative release under control conditions and in presence of synaptobrevin proline-rich domain peptide respectively. Two successive $50 \mathrm{~ms}$ depolarizations were given with an inter stimulus interval of $1 \mathrm{~s}$. Gray and black traces indicate the first and second stimulus. (c) \& (d) show the recovered fraction of the fast and slow component of release during the second depolarizing pulse plotted against the inter stimulus interval between the sustained depolarizations as exemplified in (a) \& (b). Open and filled circles indicate control and peptide experiments respectively.

release completely, indicating that the block of release is mediated at the N-terminal side of synaptobrevin but not by the proline-rich domain alone. Similar results were obtained when an antibody raised against amino acids 2-17 of synaptobrevin was used instead of the peptide. 
When the recovery was analyzed for the FRP and SRP selectively, it could be shown that the reduction of release during the second pulse stems from a reduction in the recovery of the fast releasing vesicles (Fig. 3.5(c) and (d)). Figure 3.5(c) shows that this reduction was most pronounced at an interstimulus interval of $1 \mathrm{~s}$. This opened the ability to study the $\mathrm{Ca}^{2+}$ sensitivity of release of the slow releasing vesicles again, yet under different circumstances. When the second of the $50 \mathrm{~ms}$ depolarizations was substituted with a flash, the vesicles released by $\mathrm{Ca}^{2+}$ uncaging were vesicles that were recovered within $1 \mathrm{~s}$ after the $1^{\text {st }}$ pool depleting $50 \mathrm{~ms}$ pulse. The slow vesicles studied in Fig. 3.3(b) and Fig. 3.4(b) were spared during the preceding stimulation. Still, even with the difference in experimental paradigm, only a $\sim 2$-fold difference in the $\mathrm{Ca}^{2+}$ sensitivity of release was found (data not shown). This supports the importance of the proline-rich domain of synaptobrevin in recruitment of fast releasing vesicles without affecting the apparent $\mathrm{Ca}^{2+}$ sensitivity.

\subsection{Cleavage of synaptobrevin alters the kinetics of fast neurotransmitter release}

To further the investigation of synaptobrevin's role in vesicle fusion at the calyx of Held, $3 \mu \mathrm{M}$ of the botulinum neurotoxin serotype B (BoNT/B) light-chain was infused into the presynaptic terminal. BoNT/B and TeNT share the same cleavage site on synaptobrevin, yet differ in their requirements for exerting their protease activity. Whereas TeNT requires the V1 copy of the SNARE motif in synaptobrevin, BoNT/B requires V2 (Foran et al (1994); Pellizzari et al (1996), also see Fig. 4.2). The difference in binding requirements was exploited in Hua and Charlton (1999) which showed that at the crayfish neuromuscular junction (NMJ), TeNT cleavage was greatly enhanced by stimulation of the terminal, whereas BoNT/B was effective even in the absence of stimulation.

The effect of various clostridial neurotoxins including TeNT at the calyx of Held was studied in Sakaba et al (2005). TeNT infusion showed a preferential loss of the fast component of release when strong depolarizing stimuli were used to assay the toxin effect. Figure 3.6 shows the effect of BoNT/B in the same experimental paradigm. The presynaptic terminal was depolarized to $0 \mathrm{mV}$ for $50 \mathrm{~ms}$ (after a prepulse to $+70 \mathrm{mV}$ 


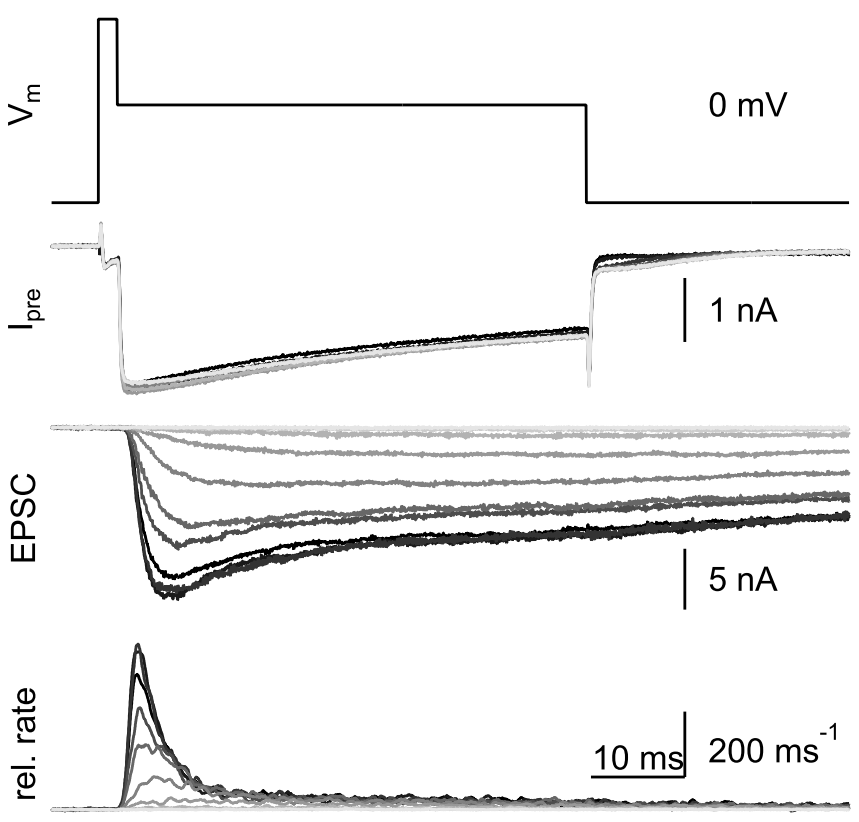

Figure 3.6: $\mathrm{BoNT} / \mathrm{B}$ causes a complete block of neurotransmitter release at the calyx of Held. Traces shown (from top to bottom): presynaptic membrane potential, presynaptic current, EPSC and release rate. Depolarizing pulses were applied every $\sim 60 \mathrm{sec}$, shades from dark to light show the toxin effect during the course of the experiment $(\sim 12 \mathrm{~min}$ in this case). The presynaptic pipette solution contained 0.5 mM EGTA.

for $2 \mathrm{~ms}$ ) roughly every $60 \mathrm{sec}$ to map the toxin effect over time. The presynaptic pipette contained $0.5 \mathrm{mM}$ EGTA to facilitate the differentiation between FRP and SRP. In the example shown in Fig. 3.7, neurotransmitter release was completely abolished within 12 min although the presynaptic $\mathrm{Ca}^{2+}$ currents were unchanged ( $\mathrm{I}_{\text {pre }}$ in Fig. 3.6). The cumulative release shown in Fig. 3.7(a) was obtained by integration of the release rate shown in Fig. 3.6. Normalizing to the end of the depolarizing pulse revealed the preferential loss of the fast component of release (see Fig. 3.7(b)) as described for TeNT at the calyx of Held. Early into toxin action, the cumulative release shown in Fig. 3.7(b) showed biexponential kinetics (dark gray) which were eventually lost with time (light gray).

Both TeNT and botulinum neurotoxins (BoNTs) have been shown to reduce spontaneous neurotransmitter release significantly in a number of systems and species (reviewed in Humeau et al, 2000). Both BoNT/B and TeNT block miniature endplate potentials (mEPPs) at the mouse NMJ (Gansel et al, 1987) whereas TeNT has been shown to block mEPSCs in organotypic hippocampal slice cultures even when $\left[\mathrm{Ca}^{2+}\right]_{\mathrm{i}}$ was elevated by ionomycin (Capogna et al, 1997). To determine the effect of BoNT/B on spontaneous release at the calyx of Held, mEPSCs were measured while keeping 
(a)

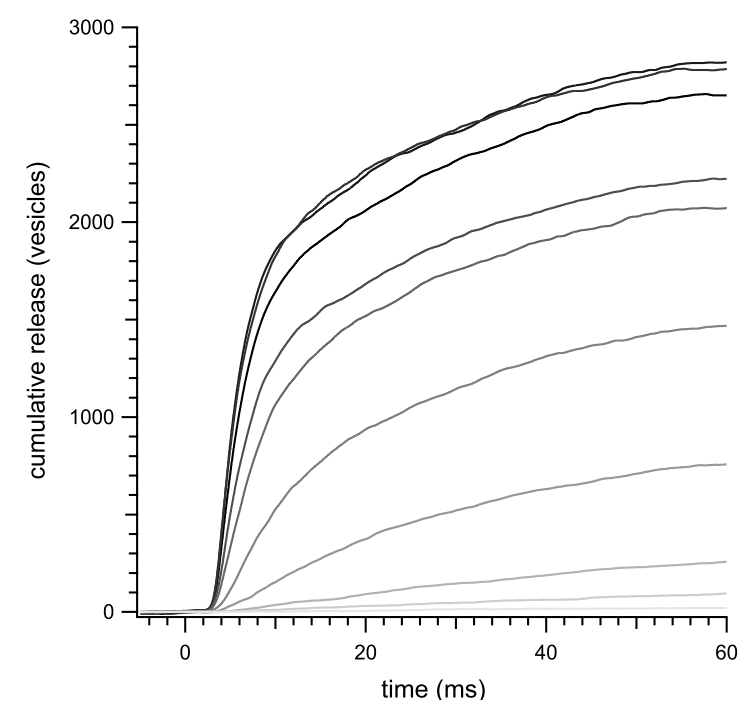

(b)

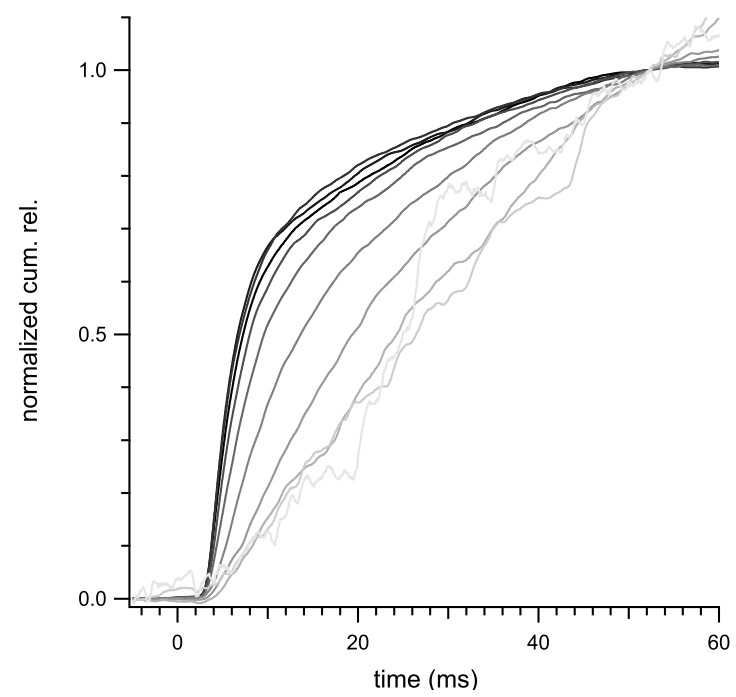

Figure 3.7: (a) Cumulative release of a BoNT/B-infused calyx of Held, obtained by integrating the release rate shown in Fig. 3.6. (b) same as (a) but normalized to the value at the end of the depolarizing pulse to illustrate the slowing of release over time. Shades from dark to light illustrate the toxin effect during the course of the experiment.

control of $\left[\mathrm{Ca}^{2+}\right]_{\mathrm{i}}$. mEPSC recordings were followed by strong depolarizing stimuli to obtain a RRP size estimate and to make sure that the toxin led to a full block of release by the end of the experiment (usually within $15 \mathrm{~min}$ ). To allow the synapse to recover, strong stimuli were followed by $\sim 60 \mathrm{sec}$ of waiting time before mEPSCs were recorded again. Control experiments that employed the same stimulation pattern but omitting the toxin showed that both mEPSCs and EPSCs could be recorded without significant run-down in the postsynaptic response for 15-20 min. Figure 3.8(a) shows an example of spontaneous release at a slightly elevated $\left[\mathrm{Ca}^{2+}\right]_{\mathrm{i}}$ compared to resting levels. When the RRP size was still $98 \%$ compared to the one found right after break-in into whole-cell configuration, the release rate was $7 \times 10^{-4} \mathrm{~ms}^{-1}$. The RRP was reduced to $20 \%$ of its initial size after 13:30 min and no mEPSCs could be detected anymore. The reduction in RRP size was therefore paralleled by a reduction in mEPSC frequency (see Fig. 3.8(b)). Recordings of mEPSCs were performed in five cell pairs in the presence of $\mathrm{BoNT} / \mathrm{B}$ and in three cell pairs in control conditions ( $n=5$ and $n=3$ respectively). 
(a)
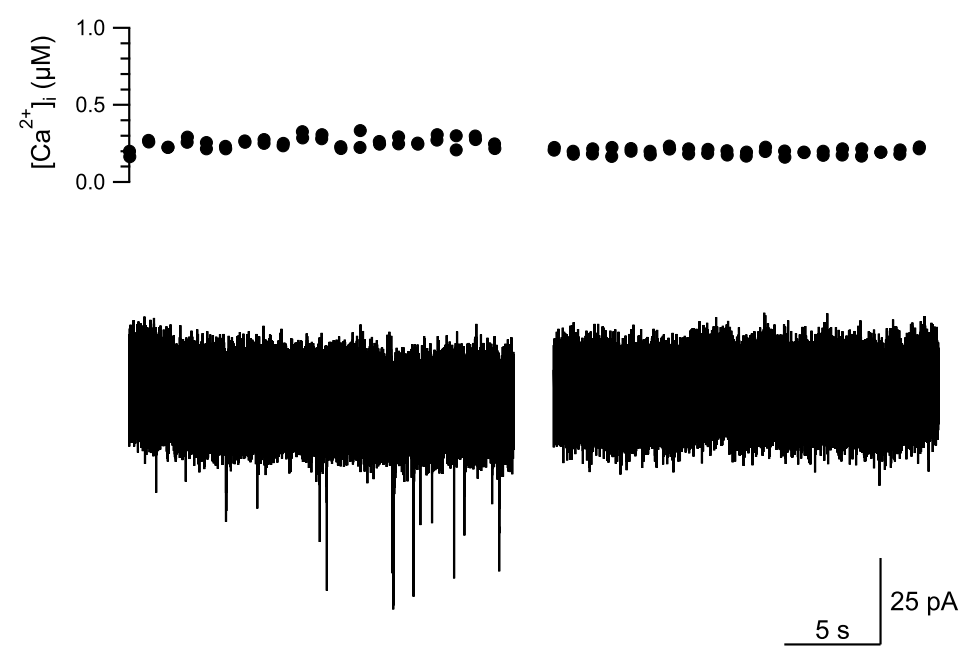

(b)

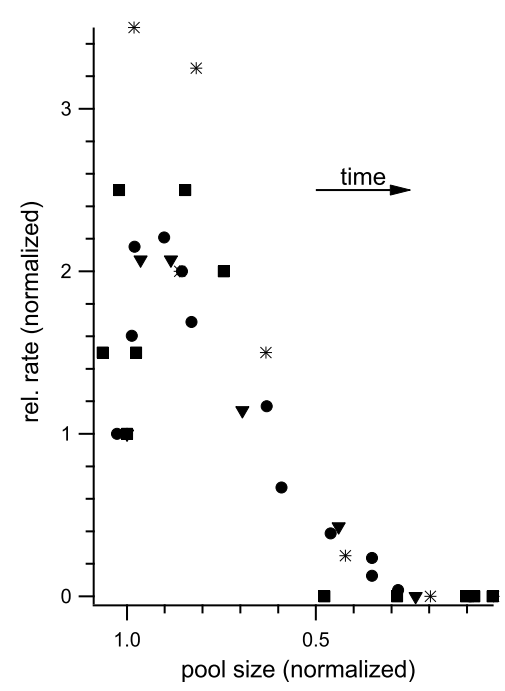

Figure 3.8: (a) Recordings of mEPSCs (bottom) with corresponding $\left[\mathrm{Ca}^{2+}\right]_{\mathrm{i}}$ (top). The presynaptic pipette solution contained $0.5 \mathrm{mM}$ EGTA and fura- $4 \mathrm{~F} .\left[\mathrm{Ca}^{2+}\right]_{\mathrm{i}}$ was $\sim 200 \mathrm{nM}$ in this example. Traces on the left side are 4:30 min after entering whole-cell configuration, traces on the right are after 13:30 min. (b) Plot of normalized mEPSC frequency against normalized pool size. Four cells are shown to indicate that the reduction in mEPSC frequency parallels the reduction in pool size assessed by pool depleting stimuli. It has to be noted that changes in $\left[\mathrm{Ca}^{2+}\right]_{\mathrm{i}}$ are not corrected for which explains the initial increase in the release rate observed in the early phase of the experiments.

Spontaneous quantal release could be studied in $\left[\mathrm{Ca}^{2+}\right]_{\mathrm{i}}$ ranges from $\sim 0.5-1.5 \mu \mathrm{M}$ by using minimal flash uncaging and measuring $\left[\mathrm{Ca}^{2+}\right]_{\mathrm{i}}$ with the $\mathrm{Ca}^{2+}$ indicator dye fura- $4 \mathrm{~F}$ (Lou et al, 2005). Uncaging to low levels of $\left[\mathrm{Ca}^{2+}\right]_{\mathrm{i}}$ is particularly challenging as stable concentrations can only be obtained by counterbalancing the terminal's $\mathrm{Ca}^{2+}$ binding and extrusion mechanisms (readily returning $\left[\mathrm{Ca}^{2+}\right]_{\mathrm{i}}$ to basal levels) by increasing either the exposure time or frequency of monochromator illumination so that the excitation by the imaging system itself leads to incremental uncaging of $\mathrm{Ca}^{2+}$. The analysis of mEPSCs frequency was therefore limited to a time window during which $\left[\mathrm{Ca}^{2+}\right]_{\mathrm{i}}$ was constant ( $n=4$ for both BoNT/B and control condition, summarized in Fig. 3.10(a)).

To further investigate the effect of BoNT/B on neurotransmitter release at the calyx of Held, stronger flash stimuli were used to elevate $\left[\mathrm{Ca}^{2+}\right]_{\mathrm{i}}$ to the levels indicated for AP-driven neurotransmitter release (10-20 $\mu \mathrm{M}$, Bollmann et al (2000); Schneggenburger 
(a) $\operatorname{BoNT} / \mathrm{B}$

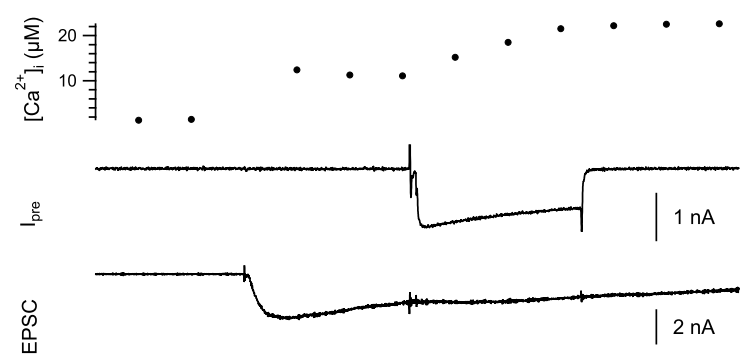

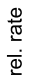

(b) Control

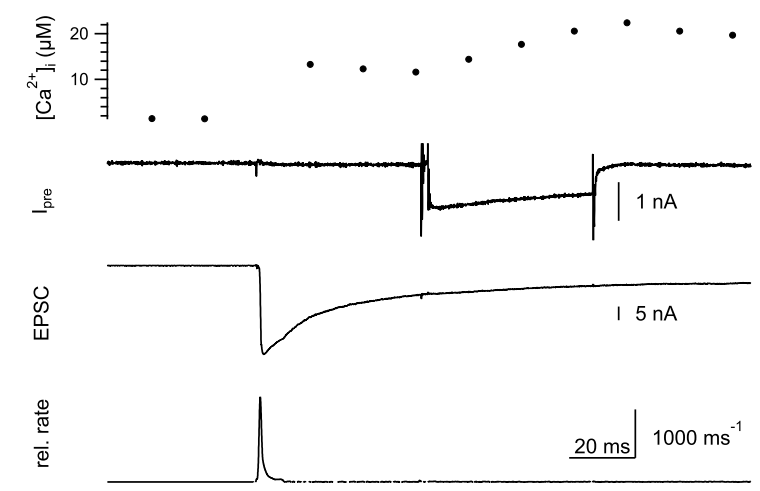

Figure 3.9: (a) shows a flash uncaging experiment in a calyx terminal infused with BoNT/BLC. Traces shown (from top to bottom): $\left[\mathrm{Ca}^{2+}\right]_{\mathrm{i}}$ derived from fura-2FF measurement, presynaptic current, postsynaptic EPSC and release rate. (b) is analogous to (a) but under control conditions.

and Neher (2000)) and to lower levels to completely map the release rate's dependence on $\left[\mathrm{Ca}^{2+}\right]_{\mathrm{i}}$ for both control and toxin condition. As mentioned before, time constraints limit the number of flash trials that can be performed in a given cell pair. Additionally, flashes to levels $>10 \mu \mathrm{M}$ can induce run-down of the postsynaptic response. For these reasons, only $1-3$ flash stimuli were given per cell pair $(n=19$ cell pairs for toxin and $n=9$ for control experiments).

Figure 3.9 (a) shows an example where $\left[\mathrm{Ca}^{2+}\right]_{\mathrm{i}}$ was elevated to $12.4 \mu \mathrm{M}$ which evoked a slowly rising EPSC of $\sim 2.5 \mathrm{nA}$. The subsequent depolarization for $50 \mathrm{~ms}$ did not elicit further release, indicating that the RRP had been emptied completely. A comparable flash in control conditions $(13.3 \mu \mathrm{M})$ led to a $\sim 30 \mathrm{nA}$ EPSC with fast rise time, again emptying the RRP completely. As with recordings of mEPSCs, BoNT/B flash experiments were done when the RRP was reduced to 5-50\% of its initial size. Notably, release was slowed down severely, indicating that the $\mathrm{Ca}^{2+}$ sensitivity of release was reduced by BoNT/B. Figure 3.10(a) shows the observed peak release rates per vesicle for $\left[\mathrm{Ca}^{2+}\right]_{\mathrm{i}}$ levels $<1 \mu \mathrm{M}$ which were found to be similar for both toxin and control data. As illustrated in Fig. 3.8, spontaneous release is gradually blocked by BoNT/B but the RRP size is reduced as well. Presenting the data as release rate per vesicle (release rate normalized to the RRP size) allows to compare the control experiments to 
(a)

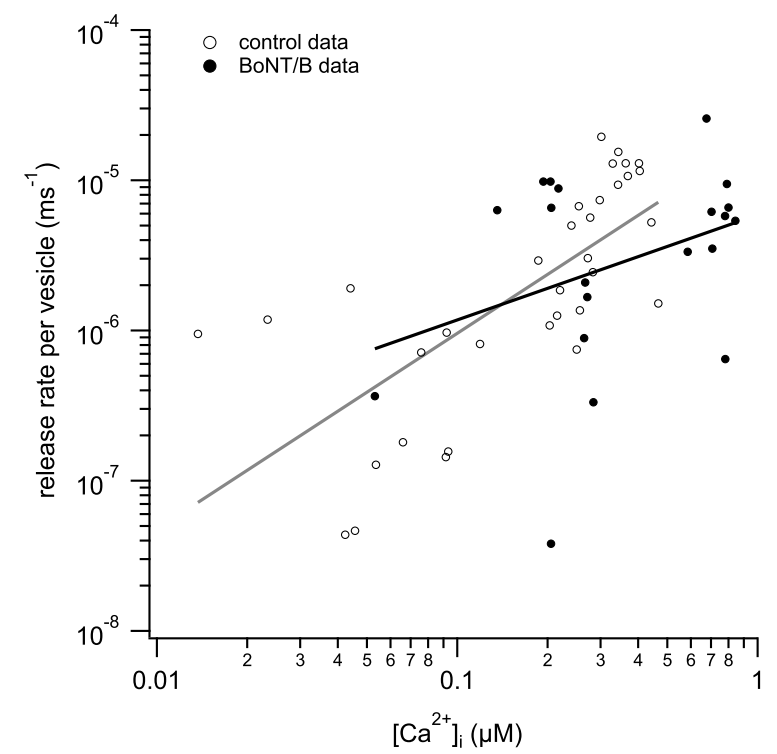

(b)

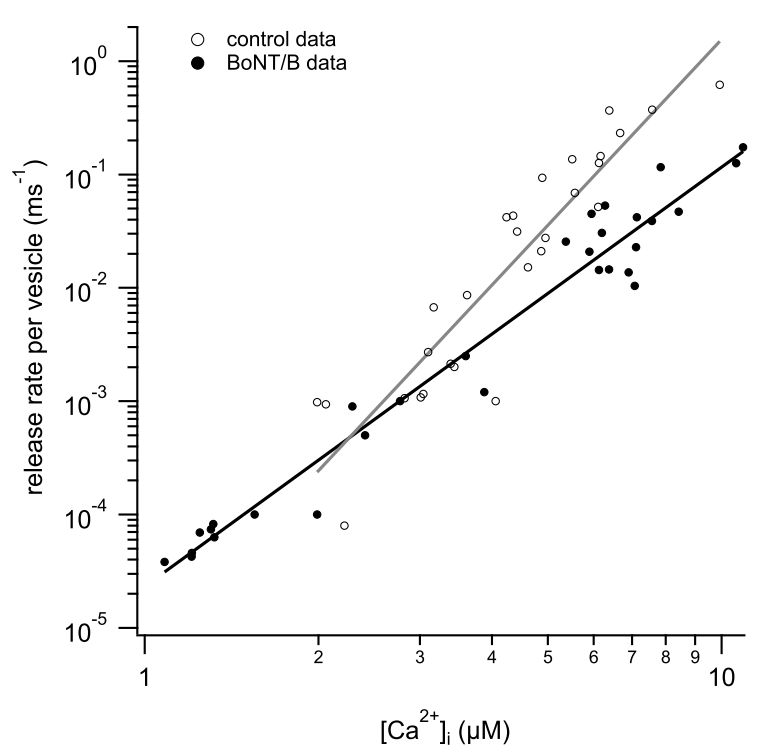

Figure 3.10: (a) Peak release rates per vesicle plotted against $\left[\mathrm{Ca}^{2+}\right]_{\mathrm{i}}$ for levels lower than $1 \mu \mathrm{M}$. Control and BoNT/B data were fitted with lines with slopes of 1.3 and 0.7 respectively, illustrating the shallow dependence of release on $\left[\mathrm{Ca}^{2+}\right]_{\mathrm{i}}$ at these levels. (b) Same as (a) but for $1-10 \mu \mathrm{M}\left[\mathrm{Ca}^{2+}\right]_{\mathrm{i}}$. Slopes were 5.4 and 3.7 for control and BoNT/B respectively.

the toxin ones even in the case of pronounced pool depression. Up to $5 \mu \mathrm{M}\left[\mathrm{Ca}^{2+}\right]_{\mathrm{i}}$ no clear separation between the two datasets could be revealed. The separation is seen however at levels $>5 \mu \mathrm{M}$, where an up to 10-fold difference could be observed. Also, the slope of the dose-response curve is shallower under BoNT/B (Fig. 3.10(b)).

Figure 3.11 summarizes the results of mEPSC recordings and flash uncaging experiments to low and high levels of $\left[\mathrm{Ca}^{2+}\right]_{\mathrm{i}}$ for both control and toxin experiments (filled circles, $n=28$ cells) and control data (open circles, $n=16$ cells). Since the spontaneous release rate per vesicle is similar for low $\left[\mathrm{Ca}^{2+}\right]_{\mathrm{i}}$ levels (Fig. 3.10(a)), BoNT/B does not seem to affect the energy barrier for fusion (parameter $l_{+}$in the allosteric model) as postulated for the effect of phorbol esters on release at the calyx of Held (Lou et al, 2005). The dashed lines in Fig. 3.11 show the predictions of the allosteric model outlined in 2.4.2. To account for the comparable release rates at low levels of $\left[\mathrm{Ca}^{2+}\right]_{\mathrm{i}}$ (Fig. 3.10(a)) but differential release rates at levels $>5 \mu \mathrm{M}$ (Fig. 3.10(b)), the number of binding steps had to be increased. The observed results could not be accounted for by changing the 


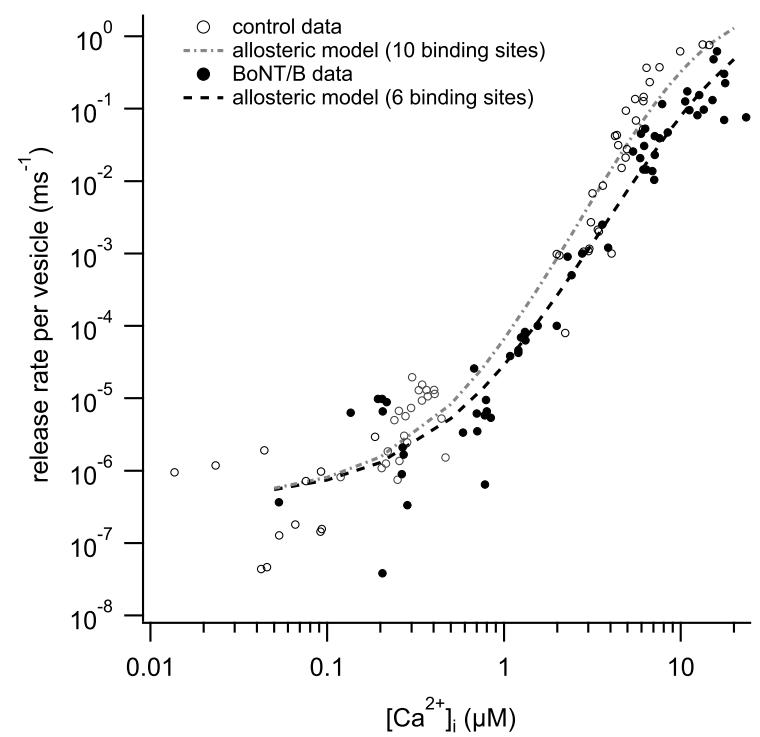

Figure 3.11: Summary plot of release rates per vesicle derived from $\mathrm{mEPSC}$ recordings and flash uncaging experiments plotted against intracellular calcium. Open circles show the data from recordings in cells that were infused with BoNT/B-LC and showed a $50-95 \%$ reduction in EPSC amplitude. Filled circles show recordings in control conditions. The overlaid curves show the predictions from an allosteric release model. To account for the divergent release rates between control and toxin experiments, the number of binding steps had to be altered.

parameters $l_{+/-}, k_{\text {on/off }}$ or $\gamma$ alone. A difference in $l_{+/-}$should manifest as a difference in the release rate per vesicle at low $\left[\mathrm{Ca}^{2+}\right]_{\mathrm{i}}$ between control and toxin recordings, which was not observed. Changes in $k_{\text {on/off }}$ shift the dose-response curve, whereas the parameter $\gamma$ becomes limiting only at high $\left[\mathrm{Ca}^{2+}\right]_{\mathrm{i}}(>30 \mu \mathrm{M})$. The number of $\mathrm{Ca}^{2+}$ binding steps governs the cooperativity of the kinetic release model and its reduction was necessary to account for the shallower dose-response curve of BoNT/B data (parameters for control data: $k_{\mathrm{on}}=3 \times 10^{8} \mathrm{M}^{-1} \mathrm{~s}^{-1}, k_{\text {off }}=1.2 \times 10^{4} \mathrm{~s}^{-1}, l_{+}=4 \times 10^{-4} \mathrm{M}^{-1} \mathrm{~s}^{-1}$, $l_{-}=4 \times 10^{-5} \mathrm{~s}^{-1}, \mathrm{f}=30, \gamma=5000 \mathrm{~s}^{-1}, 10$ binding sites; parameters for BoNT/B data: $k_{\text {on }}=4.5 \times 10^{8} \mathrm{M}^{-1} \mathrm{~s}^{-1}, k_{\text {off }}=1.2 \times 10^{4} \mathrm{~s}^{-1}, l_{+}=4 \times 10^{-4} \mathrm{M}^{-1} \mathrm{~s}^{-1}, l_{-}=4 \times 10^{-5} \mathrm{~s}^{-1}$, $\mathrm{f}=30, \gamma=5000 \mathrm{~s}^{-1}, 6$ binding sites).

In conclusion, BoNT/B diminishes the fast component of release similarly to TeNT when the release is evoked by a step depolarization. The underlying mechanism is different, however, as TeNT blocks the coupling of vesicles to $\mathrm{Ca}^{2+}$ channels whereas BoNT/B reduces the $\mathrm{Ca}^{2+}$ sensitivity. Although the $\mathrm{Ca}^{2+}$ sensitivity is changed, the mechanism of action is different than the one described in Lou et al (2005), where the effect of phorbol esters was ascribed to an increased 'fusion willingness' for release governed by the parameter $l_{+}$in a simplified allosteric model. 


\subsection{Rabphilin3a as a potential modulator of release at the calyx of Held}

The toxins that have been shown to effect the fast component of release at the calyx of Held selectively cleave synaptobrevin. Toxins that cleave other members of the SNARE family of proteins, though mediating severe block of neurotransmitter release, did not share the differential effects on the kinetics of release. To investigate whether the fast component of release can be perturbed by other means, a peptide taken from rabphilin3a that showed a marked reduction in chromaffin cell secretion was perfused into the calyx terminal via the patch pipette. Chung et al could show that the basic COOH-terminal peptide from the $\mathrm{C}_{2} \mathrm{~B}$ domain of bovine rabphilin3a (amino acids 676-695, corresponding to amino acids 650-669 in rat rabphilin3a (Rp3a(650-669))) reduced release whereas its scrambled version and homologous peptides taken from synaptotagmin did not (Chung et al, 1998). It has also been shown that the bottom surface of the $\mathrm{C}_{2} \mathrm{~B}$ in rabphilin3a, which contains a long $\alpha$-helix (Ubach et al, 1999), mediates binding to SNAP-25 (Deák et al, 2006).

Figure 3.12 illustrates the effect of $\mathrm{Rp} 3 \mathrm{a}(650-669)$ and its homologue from synaptotagmin-2 (Syt2(383-401)) at the calyx of Held. Synthetic peptides dissolved in cesiumbased solution were added to the presynaptic solution. Rp3a(650-669) was effective in blocking release at the calyx of Held at concentrations as low as $100 \mu \mathrm{M}$. However, $400 \mu \mathrm{M}$ were used so that release could be blocked completely within 10-15 min even when the access resistances obtained in the presence of peptide were close to $20 \mathrm{M} \Omega$. Within this timeframe, the contribution of run-down of release should be minimal, so that the observed block of release could solely be attributed to be a peptide effect. Figures 3.12(a), (c) and (e) show that, much like TeNT and BoNT/B, Rp3a(650-669) blocks synaptic release completely (within $\sim 13$ min in this example). Again, the fast component of release was lost early into peptide action.

The interpretation of data derived from experiments in which peptides were used as competitive antagonists is ambiguous as the concentrations used experimentally should greatly exceed those of the natively found protein they are derived from. Also, it cannot be ruled out that peptides yield secondary effects due to differential folding, dimerization or the ability to diffuse freely within the cytosol. As one control for the 
(a) Rp3a(650-669)

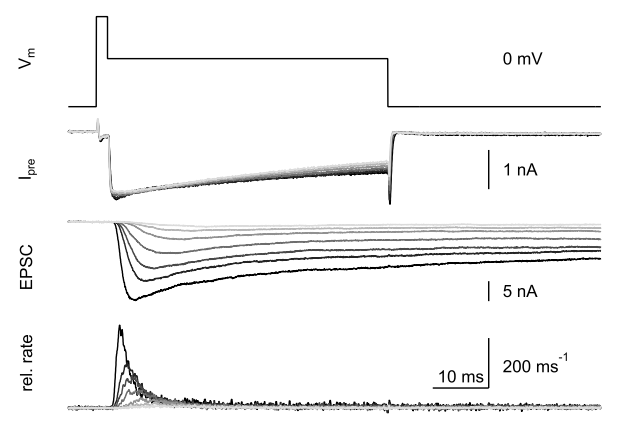

(c) Rp3a(650-669)

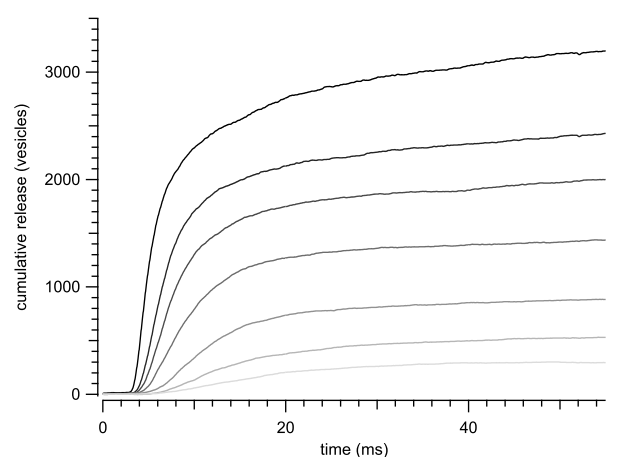

(e) Rp3a(650-669)

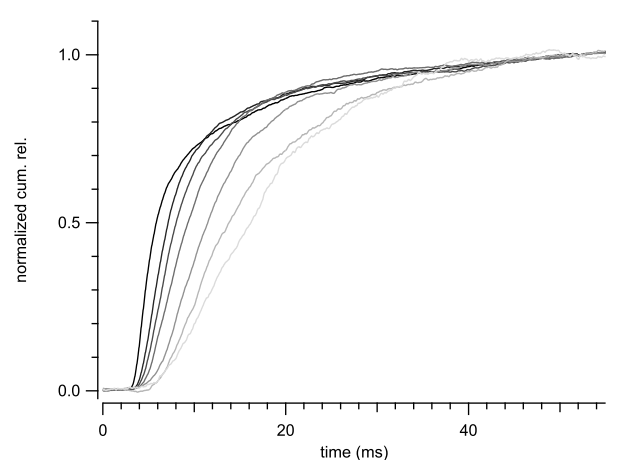

(b) Syt2(383-401)

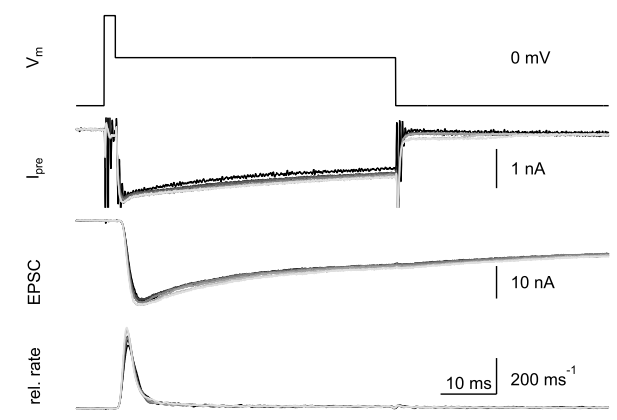

(d) Syt2(383-401)

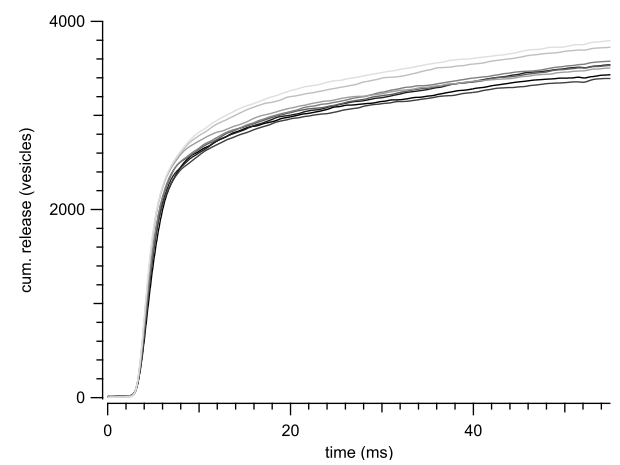

(f) $\operatorname{Syt} 2(383-401)$

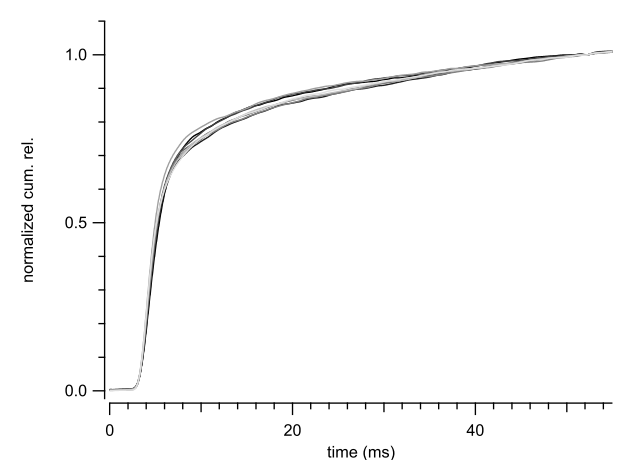

Figure 3.12: (a) \& (b) Traces shown (from top to bottom): presynaptic membrane potential, presynaptic current, EPSC and release rate. Depolarizing pulses were applied every $\sim 60 \mathrm{sec}$, shades from dark to light show the EPSCs during the course of the experiment. The presynaptic pipette solution contained $0.5 \mathrm{mM}$ EGTA. (c) \& (d) Cumulative release obtained by integrating the release rate shown in (a) and (b) respectively. (e) \& (f): same as (c) \& (d) but normalized to the value at the end of the depolarizing pulse. 
(a) $\operatorname{Rp} 3 \mathrm{a}(650-669)$

(b) Control

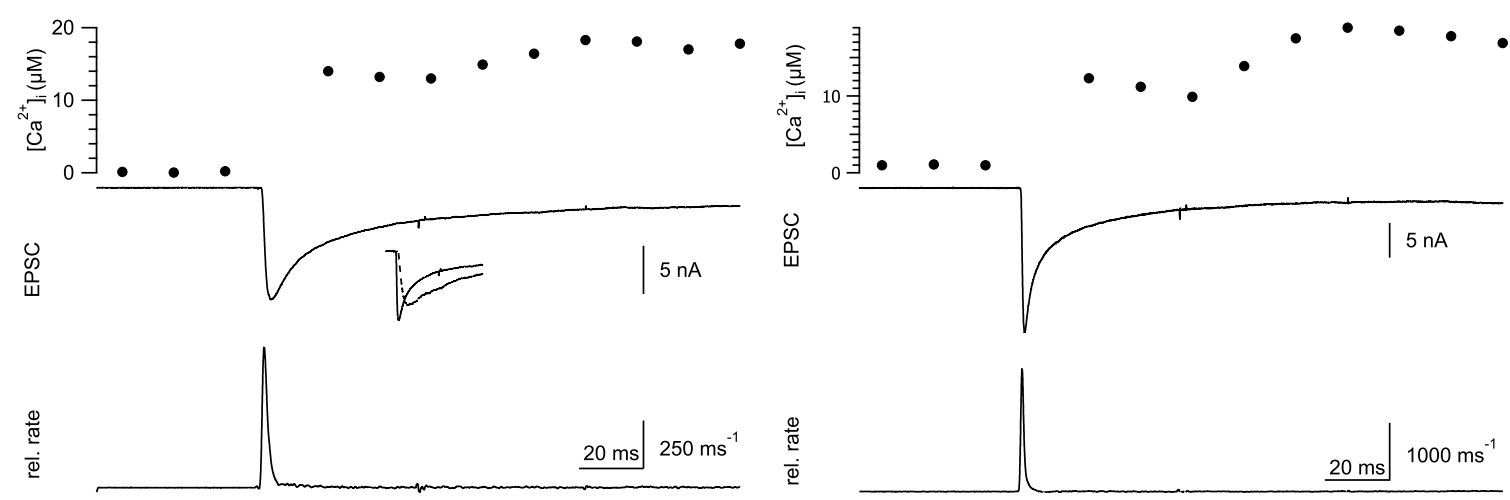

Figure 3.13: (a) Flash uncaging in a calyx of Held terminal infused with Rp3a(s650-669). Traces shown (from top to bottom): $\left[\mathrm{Ca}^{2+}\right]_{\mathrm{i}}$ derived from fura- $2 \mathrm{FF}$ measurement, presynaptic current, postsynaptic EPSC and release rate. The inset shows an overlay of the $\mathrm{Ca}^{2+}$ uncaging response (solid line) compared to an EPSC evoked by a $50 \mathrm{~ms}$ depolarization (dashed line) in the same cell. (b) is analogous to (a) but under control conditions.

specificity of the observed effect of Rp3a(650-669), a peptide from the homologous sequence in synaptotagmin-2 (thought to be the predominant synaptotagmin isoform at the calyx of Held, Sun et al (2007)) was used. Figures 3.12(b), (d) and (f) illustrate that the synaptotagmin peptide did not alter release significantly at the same concentration, comparable access resistance and time frame as the experiments with Rp3a(650-669).

To rule out that the net charge or number of hydrophobic amino acids alone mediates the effect seen with Rp3a(650-669), its scrambled variant (Rp3a(s650-669)) as described by Chung et al was introduced into the calyx terminal. Interestingly, Rp3a(s650-669) infusion resulted in a very fast and strong inactivation of the recorded $\mathrm{Ca}^{2+}$ currents. The inactivation was so severe, that proper 'template protocol' (see 2.4.1) or pool depleting stimuli recordings could not be conducted. However, the EPSC amplitudes recorded in the presence of $\mathrm{Rp} 3 \mathrm{a}(\mathrm{s} 650-669)$, though small, did not decrease over time. The effect on presynaptic $\mathrm{Ca}^{2+}$ currents was not described by Chung et al since they assayed the peptide effect by making use of radioactively labeled norepinephrin and digitonin to permeabalize the cells. The stability of EPSC amplitudes at the calyx of Held did however confirm that the scrambled peptide does not seem to affect vesicular release directly. 


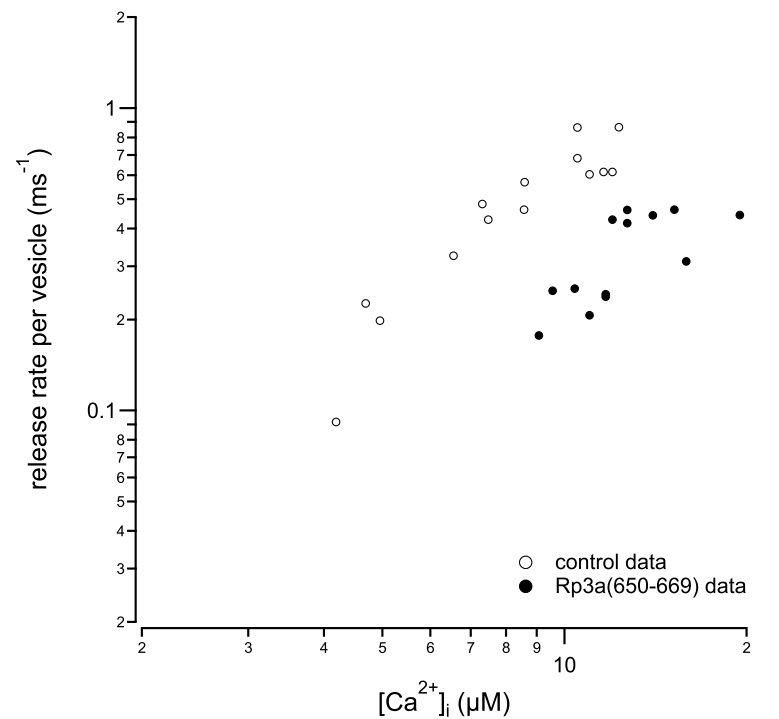

Figure 3.14: Summary plot of release rates per vesicle from flash uncaging experiments plotted against intracellular calcium. Closed circles show the data from recordings in cells that were infused with the Rp3a(650-669) peptide. Flashes were applied when the peptide had caused a 50-95\% reduction in EPSC amplitude. Open circles show recordings in control conditions.

To complete the characterization of the Rp3a(650-669) effect on release at the calyx of Held, flash uncaging experiments to $\left[\mathrm{Ca}^{2+}\right]_{\mathrm{i}}$ levels $>10 \mu \mathrm{M}$ were performed. Flash photolysis was induced when the peptide had reduced the initially observed EPSC amplitude to $50 \%$ or less. Figure 3.13 shows representative examples for both peptide and control condition. The inset in Fig. 3.13(a) indicates that the EPSC in the peptide experiment is somewhat slower compared to control, however, the peak release rate per vesicle was reduced only about 2-fold across all cell pairs. Figure 3.14 illustrates the dose-response relationship of peak release rate per vesicle to $\left[\mathrm{Ca}^{2+}\right]_{\mathrm{i}}$ for cells infused with Rp3a(650-669). Since the $\mathrm{Ca}^{2+}$ sensitivity of release seemed to be altered only little when depolarization induced EPSCs were strongly reduced in amplitude and presented slowed kinetics, Rp3a(650-669) does seem to interfere with the vesicle-release coupling at the calyx of Held. 


\section{Discussion}

Communication between neurons in neuronal networks predominantly relies on signal transmission via chemical synapses. These sites are, however, not merely relay stations for the signals that invade the presynaptic terminal, but highly dynamic in shaping the signal that eventually passes down to the processes of the postsynaptic cell. The proficiency at which a synapse operates is dependent on the history of its activity, both on long and short timeframes. Activity dependent changes in synapses that last, at the most, a few minutes, coined short-term synaptic plasticity, present themselves in either facilitation, depression or a mixture of both in virtually all synapses and have been recognized early on (reviewed in Zucker and Regehr, 2002).

The synaptic strength of a synapse can be described by the model introduced in the introduction (eq. 1.1), namely the parameters $N, p$ and $q$ that shape the postsynaptic response. Seemingly a simple model, a remarkable number of processes within the cell have been found to contribute to either one of these parameters. Special interest has been taken in the attempt to pinpoint a single, the predominant, process that shapes synaptic transmission at a given synapse.

The calyx of Held, a model glutamatergic synapse, depresses when stimulated with action potential (AP) trains and the depletion of vesicles from the readily releasable pool (RRP) is seen as the main cause of short-term synaptic depression at glutamatergic synapses such as the calyx of Held (Schneggenburger et al, 1999; Wu and Borst, 1999; Bollmann et al, 2000).

The situation at the calyx of Held is complicated by the fact that the RRP consists of two subpools that were identified based on their release kinetics and recovery rate (see 
Fig. 1.2, Sakaba and Neher (2001a)). The fast releasing vesicles among the RRP were released 10-fold faster than the slowly releasing vesicles under sustained depolarization of the terminal, yet took much longer to recover after depletion. These two subpools of vesicles were studied further in Sakaba (2006). It was found that synchronous release at the calyx of Held is mainly mediated by the fast releasing vesicles. Consequential, the depression observed during the synchronous phase of AP trains is a result of their depletion. The slowly releasing vesicles in turn contribute mainly to the asynchronous release phase during high frequency stimulation and are less prone to depression.

A heterogeneous RRP was also identified in glutamatergic hippocampal neurons in culture, where action potentials only drew a fifth of the vesicle pool released during sucrose application. Just as the calyx of Held, the remaining 'reluctant' vesicles could be forced to release by increasing the $\mathrm{Ca}^{2+}$ influx (Moulder and Mennerick, 2005), i.e. through higher frequency AP trains.

Investigating the nature of the slowly releasing or reluctant vesicles was attempted in this work. The comparison of fast and slow release then allows to clarify how fast release, responsible for AP-induced neurotransmitter release, is mediated.

It was shown that fast release could still be triggered by flash photolysis of caged $\mathrm{Ca}^{2+}$ which elevated $\left[\mathrm{Ca}^{2+}\right]_{\mathrm{i}}$ to levels above $10 \mu \mathrm{M}$ when AP evoked release was largely depressed (see Fig. 3.3(a)). A calcium concentration of roughly $10 \mu \mathrm{M}$ is thought to represent the amplitude of the average AP-induced $\mathrm{Ca}^{2+}$ transient that vesicles are exposed to. The vesicles remaining after a depolarizing pulse that depleted the fast releasing pool of vesicles (FRP) therefore were 'releasable' and the observed depression in AP-evoked release was not caused by a lack of fusion competence. Furthermore, quantitative analysis of the $\left[\mathrm{Ca}^{2+}\right]_{\mathrm{i}}$ dependence of release combined with a minimal model describing the kinetics of release revealed that the intrinsic sensitivity of reluctant vesicles to $\mathrm{Ca}^{2+}$ is reduced at most 2-fold. Intrinsic differences between vesicles should therefore only contribute little to the 10-fold difference in release kinetics observed in response to strong depolarization of the calyx of Held terminal. The 10-fold slower release kinetics of slowly releasing vesicles observed during a long depolarizing pulse (Sakaba and Neher, 2001a) can therefore be explained by a lower $\left[\mathrm{Ca}^{2+}\right]_{\mathrm{i}}$ that these vesicles are exposed to when the elevation in $\left[\mathrm{Ca}^{2+}\right]_{\mathrm{i}}$ is mediated by $\mathrm{Ca}^{2+}$ channels. It was estimated that slow vesicles 'see' an average $\mathrm{Ca}^{2+}$ transient peaking at $6-7 \mu \mathrm{M}$ 
whereas fast releasing vesicles are exposed to an average $\mathrm{Ca}^{2+}$ transient of $10-12 \mu \mathrm{M}$ (Wadel et al, 2007).

It has to be noted that a fraction of vesicles could not be released 'fast' as $16 \%$ of vesicles released slowly even when $\left[\mathrm{Ca}^{2+}\right]_{\mathrm{i}}$ was elevated uniformly via flash uncaging. However, intrinsically slow vesicles do not seem to be a major contributor to release under more physiological conditions since this should have presented itself when transient elevations of $\left[\mathrm{Ca}^{2+}\right]_{\mathrm{i}}$ were induced (Fig. 3.3). On average, the release rate per vesicle was reduced only $\sim 20 \%$ for transient flashes that followed partial pool depletion.

From this data it is reasonable to conclude that the slow vesicles are merely further away from sites were $\mathrm{Ca}^{2+}$ enters the cell, namely calcium channels or clusters thereof. This implies that the fusion competence of fast and slow releasing vesicles is similar. Distant vesicles will be exposed to lower $\mathrm{Ca}^{2+}$ concentrations due to the sharp spatial profile $\mathrm{Ca}^{2+}$ transients are assumed to possess (see 1.1.2). It is important to note that the slowness is indeed caused by the lowered local $\left[\mathrm{Ca}^{2+}\right]$ and not by a time delay imposed by diffusion from the channels' pores to a given vesicle. Due to the supralinear relationship of vesicle release to $\left[\mathrm{Ca}^{2+}\right]_{\mathrm{i}}$ at the calyx of Held (Fig. 3.4(d)), the difference of $6-7 \mu \mathrm{M}$ versus $10-12 \mu \mathrm{M}$ average local $\left[\mathrm{Ca}^{2+}\right]$ can readily account for the 10 -fold difference in kinetics observed for the two classes of vesicles.

It has to be noted that 'positional priming' of vesicles (the association of vesicles with $\mathrm{Ca}^{2+}$ channel clusters at the active zone) is different from the priming step in the vesicle cycle that is thought to involve proteins such as Munc13. Since the slow releasing pool of vesicles (SRP) can be released fast by homogeneous elevations of $\left[\mathrm{Ca}^{2+}\right]_{\mathrm{i}}$, vesicle docking and priming (a prerequisite for fusion to occur) do not seem to be the rate limiting steps in the exocytosis of 'slow' vesicles, but rather their positioning within the active zone and $\mathrm{Ca}^{2+}$ channel clusters. The remaining 2-fold difference in kinetics would then be explained by additional protein interactions ('superpriming', Schlüter et al (2004)).

The RRP contains an average of 3000 vesicles at the calyx of Held and is made up by about equal numbers of slow and fast vesicles (Sakaba and Neher, 2001a). About 500 active zones were identified by serial electron microscopy (EM) reconstruction of a p9 calyx of Held (Sätzler et al, 2002), so that on average three vesicles should be released fast and three slow at a given active zone. It was shown previously that the SRP recovers very quickly $(\tau=200 \mathrm{~ms}$ ), whereas the FRP recovers much slower (see Fig. 3.5, 
(a)

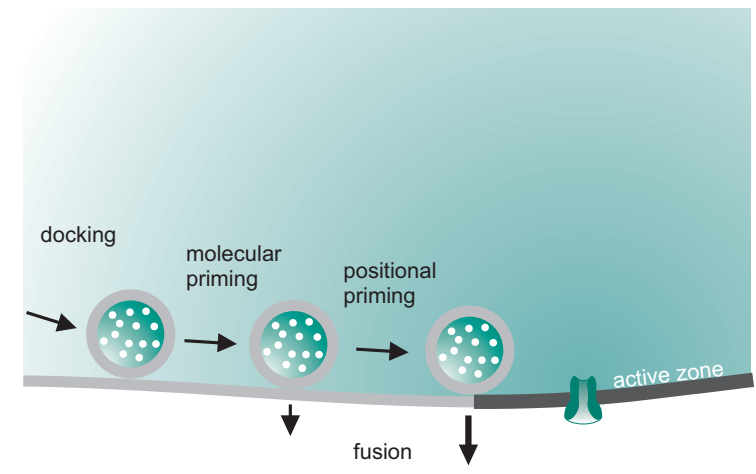

(b)

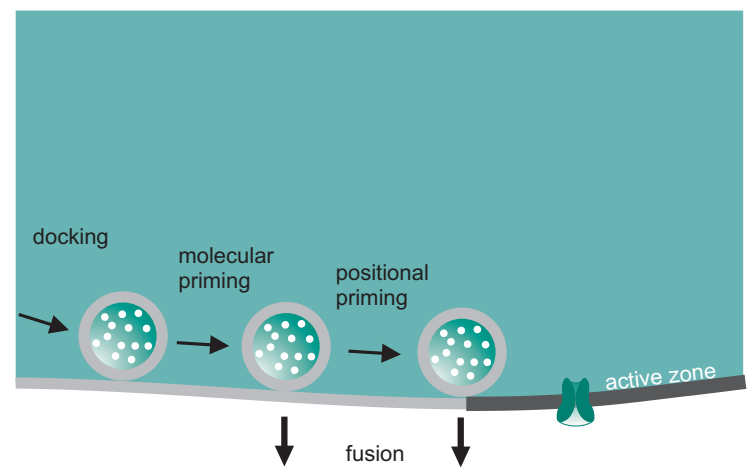

Figure 4.1: Illustration of the steps towards $\mathrm{Ca}^{2+}$-triggered exocytosis of synaptic vesicles when $\mathrm{Ca}^{2+}$ influx is mediated by $\mathrm{Ca}^{2+}$ channel opening (a) or when $\left[\mathrm{Ca}^{2+}\right]_{\mathrm{i}}$ is elevated uniformly via flash uncaging (b). In (a), vesicles that are close to $\mathrm{Ca}^{2+}$ channels release rapidly, whereas more distant vesicles are 'reluctant' to release. These vesicles are release competent and can be released rapidly in response to uniform elevations of $\left[\mathrm{Ca}^{2+}\right]_{\mathrm{i}}$ as shown in (b).

Sakaba and Neher (2001a)). It is plausible that these two pools recover sequentially so that the FRP draws from the SRP and that this 'maturation' involves the recruitment of vesicles into close proximity of $\mathrm{Ca}^{2+}$ channels. Naturally, trying to understand this maturation step involves the attempt to modulate it which can be achieved by both physiological and non-physiological means.

It was shown that the recovery of the fast releasing vesicles depends on $\mathrm{Ca}^{2+} / \mathrm{cal}$ modulin (Sakaba and Neher, 2001a) and cAMP (Sakaba and Neher, 2003a). The rate of recovery of the fast pool was described quantitatively by Hosoi et al (2007) who found a linear dependence on the global $\left[\mathrm{Ca}^{2+}\right]_{\mathrm{i}}$. Interestingly, the recovery of the SRP is rather robust and could only be slowed down by latrunculin A, causing actin depolymerization, and ATP- $\gamma \mathrm{S}$, a nonhydrolyzable analogue of ATP (Sakaba and Neher, 2003b).

Infusing the proline-rich N-terminal domain of synaptobrevin into the calyx terminal revealed a slowing of the recovery of the fast component, but did not interfere with recruitment of the slow releasing vesicles after depletion of the entire RRP (see Fig. 3.5). This indicates the involvement of the proline-rich domain of synaptobrevin in 'positional priming' of synaptic vesicles. The total amount of release, however, was not influenced by the peptide. This is in contrast to the action of tetanus neurotoxin (TeNT) which 


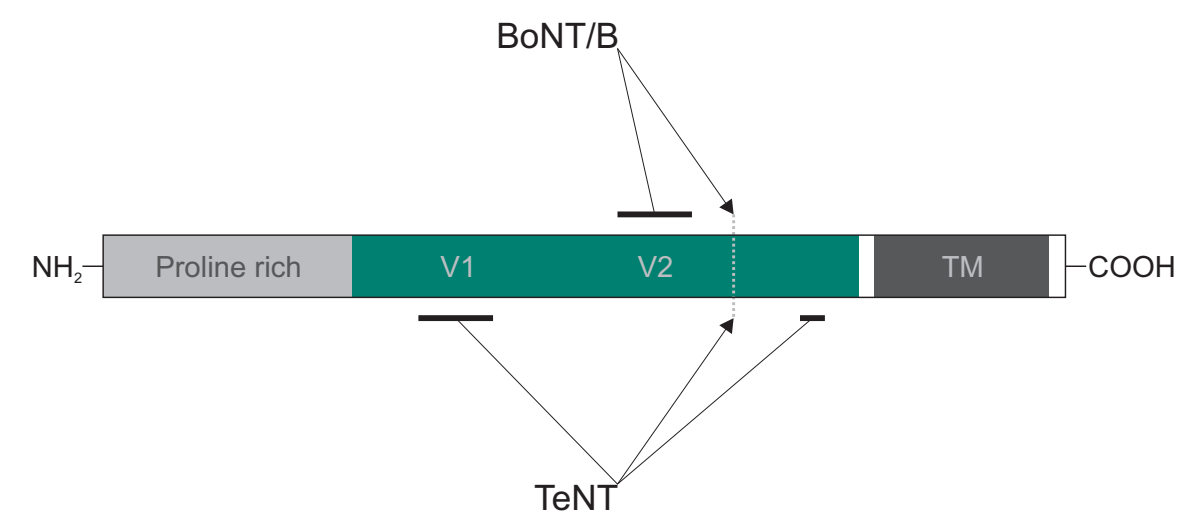

Figure 4.2: Schematic diagram of the synaptobrevin structure and its interaction with BoNT/B and TeNT. The proline-rich N-terminal domain is indicated in light gray. The coiled-coil homology domain (green) mediates the formation of the SNARE complex with syntaxin-1 and SNAP-25 and contains two copies of the SNARE motif (V1 and V2) with which the synaptobrevin-specific neurotoxins BoNT/B and TeNT selectively interact. The cleavage site for BoNT/B and TeNT is indicated by the dashed line (rat synaptobrevin-2 is cleaved at peptide bond GASQ ${ }^{76}$ FETS, whereas rat synaptobrevin-1 is not cleaved due to a variation in the cleavage site GASVFESS). The transmembrane domain (TM) of synaptobrevin is indicated in dark gray. Modified from Schiavo et al (2000).

cleaves both the proline-rich domain and the SNARE motives from synaptobrevin. At the calyx of Held, TeNT demonstrates an all-or-none effect which eventually leads to a complete block of release if sufficient time for toxin action is provided. During the early phase of toxin action, TeNT preferentially blocks the fast component of release, a first indication of synaptobrevin's role in mediating, at least partially, the incorporation of vesicles in the vicinity of $\mathrm{Ca}^{2+}$ channels. It is, however, not understood how the proline-rich domain mediates 'positional priming' in molecular terms.

Experiments that characterize the effect of BoNT/B on transmission at the calyx of Held confirmed the kinetic effect of synaptobrevin cleavage (see Fig. 3.7). The comparison of TeNT and BoNT/B allows interesting insights into the way the fusion machinery is assembled. Hua and Charlton (1999) made use of both toxins and studied their effect in crustacean neuromuscular junctions (NMJs). It was found that the efficiency of TeNT in cleaving synaptobrevin was greatly enhanced by nerve stimulation, whereas BoNT/B was effective even in a 'silent' synapse. Since TeNT and BoNT/B share the same cleavage site on synaptobrevin, the observed difference was accounted to the difference in the required toxin binding sites on synaptobrevin (see Fig. 4.2). 
TeNT requires the N-terminal SNARE motif for binding whereas BoNT/B needs the C-terminal one. Hua and Charlton concluded that a stable, partially assembled transSNARE complex shields the TeNT binding site but leaves the BoNT/B one accessible. BoNT/B would therefore even be able to exert its protease activity on vesicles that are docked, primed and available for fast $\mathrm{Ca}^{2+}$ driven exocytosis. It has to be noted that experiments that are based on comparing stimulated and non stimulated terminals cannot be reconciled with experiments in vertebrate neurons. At the calyx of Held, the rapid rate of docking and undocking as well as spontaneous release lead to sufficient 'cycling' of vesicles to open a time window for TeNT cleavage. Accordingly, botulinum neurotoxins were found to be efficient in blocking release in the absence of stimulation (T. Sakaba, personal communication).

However, BoNT/B did show an additional effect on the kinetics of release at the calyx of Held (see Fig. 3.11). When flash photolysis was used to trigger release at the calyx of Held after BoNT/B had caused more than $50 \%$ reduction in the RRP size, lower release rates per vesicle were observed at a given $\left[\mathrm{Ca}^{2+}\right]_{\mathrm{i}}$. The reduced $\mathrm{Ca}^{2+}$ sensitivity was evident at $\left[\mathrm{Ca}^{2+}\right]_{\mathrm{i}}>5 \mu \mathrm{M}$, but no differences could be identified at lower and resting levels of $\left[\mathrm{Ca}^{2+}\right]_{\mathrm{i}}$. Attempts to describe the observed effect by an allosteric kinetic model for vesicle fusion indicate that BoNT/B changes the calcium cooperativity of the release machinery. The contribution of SNAREs to calcium cooperativity was postulated for the Drosophila NMJ (Stewart et al, 2000) previously. Yet at the cerebellar basket cell terminal, BoNT/B cleavage of synaptobrevin led to a shift in $\mathrm{Ca}^{2+}$ sensitivity but no change in cooperativity was observed (Sakaba, 2008). However, spontaneous events were not analyzed in the latter study which makes it difficult to attribute the observed effect to changes in $K_{\mathrm{D}}, l_{+}$or the number of binding sites in the context of the model presented here. The data herein are compatible with a model of 'zippered' vesicle fusion, which allows BoNT/B to cleave synaptobrevin at a late stage of vesicle fusion, possibly the hemifusion state directly prior to $\mathrm{Ca}^{2+}$ triggered exocytosis.

In summary, BoNT/B mediated cleavage of synaptobrevin after molecular priming and before $\mathrm{Ca}^{2+}$ triggered exocytosis presents as a change in the $\mathrm{Ca}^{2+}$ sensitivity of the release machinery.

Clostridial neurotoxins are not the only agents that interfere with positional priming. In this work, it was shown that a peptide taken from the C-terminal end of rabphilin3a's $\mathrm{C}_{2} \mathrm{~B}$ domain (Rp3a(650-669)) also caused a pronounced block of neurotransmitter 


$\begin{array}{ll}\text { sp |P47709|RP3A_RAT/648-669 } & \text { Alpha 2 } \\ \text { sp|P21707|SYT1_RAT/380-401 } & \text { YNSTGAELRHWSDMLANPRRPI } \\ \text { sp|P29101|SYT2_RAT/381-402 } & \text { SNATGTELRHWSDMLANPRRPI } \\ \text { sp|Q925C0|SYT9_RAT/460-481 } & \text { NEAERLGRDHWSEMLSYPRKPI } \\ \text { sp|P70611|DOC2A_RAT/362-383 } & \text { PGARGEAQKHWRDCLHQPDTAV } \\ \text { sp|P70610|DOC2B_RAT/374-395 } & \text { INAKGERLKHWEDCLKNKDKRI } \\ & \text { Alpha 2 }\end{array}$

Figure 4.3: Sequence alignment of sequences containing the $\alpha$-helix that has been described as a conserved feature of $\mathrm{C}_{2} \mathrm{~B}$ domains. Conserved residues within the helix are highlighted in green. The residues corresponding to the peptides Rp3a(650-669) and Syt2(383-401) used in experiments are underlined. The corresponding sequences from synaptotagmin-1, -2 and -9 as well as Doc2A/B are shown for comparison. Modified from Ubach et al (1999).

release that initially presented as a loss of the fast component of release. Infusion of Rp3a(650-669) essentially mimics the TeNT phenotype at the calyx of Held. These kinds of experiments might suffer from non specific binding of the peptide. The effectiveness of Rp3a(650-669) in blocking release was therefore validated by a homologous peptide from synaptotagmin-2 (Syt2(383-401)) and a scrambled version of the rabphilin3a peptide (Rp3a(s650-669)), neither of which caused a block of release as observed with Rp3a(650-669).

$\mathrm{Rp3a}(650-669)$ contains the $\alpha$-helix that was described as a unique feature of $\mathrm{C}_{2} \mathrm{~B}$ domains and is thought to be involved in their $\mathrm{Ca}^{2+}$ independent interactions (Ubach et al, 1999). This helix is a conserved feature of $\mathrm{C}_{2} \mathrm{~B}$ domains and can hence not only be found in rabphilin3a, but also in the rat synaptotagmins and Doc2A/B. A later study identified this helix in rabphilin3a to mediate binding to SNAP-25 using NMR spectroscopy (Deák et al (2006), but see Tsuboi et al (2007)). The authors found an increased recovery from use-dependent synaptic depression in cultured neurons from rabphilin3a KO mice that was not described in previous work on synaptic transmission and plasticity in rabphilin3a deficient animals (Schlüter et al, 1999). The phenotypes described by Schlüter et al and Deák et al cannot be reconciled with results that were obtained by utilizing rabphilin3a in an 'overexpression' scheme (Chung et al, 1998; Burns et al, 1998; Tsuboi and Fukuda, 2005) and the results described herein.

Rather than interpreting the results obtained with Rp3a(650-669) at the calyx in the context of rabphilin3a's role in synaptic transmission, the focus should be set on 
its interaction partner. It is plausible that the observed block of release is caused by the interaction with SNAP-25 as described by Deák et al. In order to unify the results seen with Rp3a(650-669) and those of clostridial neurotoxins on fast neurotransmitter release at the calyx of Held, a collaborative effort is currently under way to see if and where Rp3a(650-669) binds to SNAP-25.

The work presented here served to investigate the kinetics of neurotransmitter release observed at the calyx of Held synapse. The heterogeneity in release probability, or in other words: the reluctance of a subpopulation of vesicles to be released by an AP invading the synaptic terminal was attributed to the spatial profile of vesicles within the terminal which in turn highlights the importance of $\left[\mathrm{Ca}^{2+}\right]_{\mathrm{i}}$ and the $\mathrm{Ca}^{2+}$ transients that trigger release and the long-standing interest of scientist in studying their role in synaptic transmission and plasticity.

It has to be noted that reluctant release of vesicles can be explained by alternative mechanisms that likely contribute to the mechanism that was described here. A study at the calyx of Held described differences in the intrinsic $\mathrm{Ca}^{2+}$ sensitivity of vesicles as the reason for heterogeneity in $p_{\text {ves }}$. The observed 'submaximal' release was interpreted mechanistically as an 'a posteriori' adaptation of the release apparatus to the $\mathrm{Ca}^{2+}$ signal (Wölfel et al, 2007). Other studies have highlighted the importance of small changes of the $\mathrm{Ca}^{2+}$ influx for short-term depression which were found to be specifically important at lower stimulation frequencies (Xu and $\mathrm{Wu}, 2005$ ).

As outlined, the recovery of vesicles for fast release can be modulated at many levels at the calyx of Held by both physiological and non physiological means. Conversely, the release machineries sensitivity to $\mathrm{Ca}^{2+}$ seems to be very robust so that changes are most easily induced by interfering directly with SNAREs (Sakaba et al, 2005) or the $\mathrm{Ca}^{2+}$ sensor (Sun et al, 2007).

Clearly, future work at the calyx of Held will attempt to unify biophysical concepts (such as 'positional priming') with those from biochemical ones ('molecular priming'). 


\section{Summary}

Fast and synchronous neurotransmitter release relies on the time course of calcium influx into the terminal, the availability of fusion competent vesicles and the proteins comprising the release machinery. Studies in glutamatergic synapses have identified a subpopulation of vesicles in the releasable pool that do not fuse in response to action potential (AP) driven calcium influx and release only slowly in response to sustained stimulation. The nature of these 'reluctant' vesicles, however, remained unclear.

This question was investigated at the calyx of Held, a large glutamatergic synapse in the auditory brainstem. By combining electrophysiological recordings of the preand postsynaptic compartments with calcium imaging and uncaging, it is shown that uniform elevations of the intracellular calcium concentration in the presynaptic terminal were able to elicit rapid release after the vesicles mediating fast and synchronous neurotransmitter release had been depleted. The calcium sensitivity of 'reluctant' vesicles was reduced only 2 -fold which is insufficient to explain the 10-fold slower release kinetics that is observed in response to sustained depolarizations of the presynaptic terminal. It is concluded, that 'reluctant' vesicles are indeed release competent, but that their distance to calcium channel clusters at the active zone prevents them to release in response to APs. This indicates that the incorporation of vesicles into the vicinity of calcium channels at the active zone (a 'positional priming' step) is rate-limiting in fast neurotransmitter release rather than acquiring fusion competence (a 'molecular priming' step).

The accessibility of the presynaptic terminal of the calyx of Held to patch-pipettes allows one to infuse toxins and peptides to further investigate the 'positional priming' 
step in exocytosis. Here, it is shown that the N-terminal of synaptobrevin is important for mediating this step, which has been indicated in a previous study based on the effect of tetanus neurotoxin (TeNT) on release at the calyx of Held. In contrast, it was found that BoNT/B, which shares the same cleavage site as TeNT but requires a different binding site on synaptobrevin, changes the intracellular calcium sensitivity of vesicles for fusion, likely by interfering with vesicle exocytosis at a step between calcium sensing and fusion.

'Positional priming' was also affected when a C-terminal peptide from rabphilin3a's $\mathrm{C}_{2} \mathrm{~B}$ domain was infused into the calyx of Held, which blocked synaptic transmission, potentially by interacting with SNAP-25. Its effect on the kinetics of release mimics that of TeNT as it preferentially blocked the fast component of release.

These results highlight the importance of calcium channel-vesicle coupling as well as the delicate interplay of multiple proteins of the release machinery in mediating fast neurotransmitter release. 


\section{Bibliography}

Adler, E. M., Augustine, G. J., Duffy, S. N., and Charlton, M. P. (1991). Alien intracellular calcium chelators attenuate neurotransmitter release at the squid giant synapse. J Neurosci, 11(6):1496-1507.

Augustine, G. J., Adler, E. M., and Charlton, M. P. (1991). The calcium signal for transmitter secretion from presynaptic nerve terminals. Ann NYAcad Sci, 635:365-381.

Awatramani, G. B., Turecek, R., and Trussell, L. O. (2004). Inhibitory control at a synaptic relay. J Neurosci, 24(11):2643-2647.

Banks, M. I. and Smith, P. H. (1992). Intracellular recordings from neurobiotin-labeled cells in brain slices of the rat medial nucleus of the trapezoid body. J Neurosci, 12(7):2819-2837.

Becherer, U., Moser, T., Stühmer, W., and Oheim, M. (2003). Calcium regulates exocytosis at the level of single vesicles. Nat Neurosci, 6(8):846-853.

Bollmann, J. H. (2001). Calcium sensitivity of neurotransmitter release in a glutamatergic synapse of the central nervous system. Ph.D. thesis, Rupertus Carola University of Heidelberg, Germany.

Bollmann, J. H. and Sakmann, B. (2005). Control of synaptic strength and timing by the release-site $\mathrm{Ca}^{2+}$ signal. Nat Neurosci, 8(4):426-434.

Bollmann, J. H., Sakmann, B., and Borst, J. G. (2000). Calcium sensitivity of glutamate release in a calyx-type terminal. Science, 289(5481):953-957.

Borst, J. G. and Sakmann, B. (1996). Calcium influx and transmitter release in a fast CNS synapse. Nature, 383(6599):431-434.

Borst, J. G. and Sakmann, B. (1998). Calcium current during a single action potential in a large presynaptic terminal of the rat brainstem. J Physiol, 506 ( Pt 1):143-157. 
Borst, J. G. and Sakmann, B. (1999). Effect of changes in action potential shape on calcium currents and transmitter release in a calyx-type synapse of the rat auditory brainstem. Philos Trans R Soc Lond B Biol Sci, 354(1381):347-355.

Borst, J. G., Helmchen, F., and Sakmann, B. (1995). Pre- and postsynaptic whole-cell recordings in the medial nucleus of the trapezoid body of the rat. J Physiol, 489 ( Pt 3):825-840.

Burns, M. E., Sasaki, T., Takai, Y., and Augustine, G. J. (1998). Rabphilin-3A: a multifunctional regulator of synaptic vesicle traffic. J Gen Physiol, 111(2):243-255.

Capogna, M., McKinney, R. A., O'Connor, V., Gähwiler, B. H., and Thompson, S. M. (1997). $\mathrm{Ca}^{2+}$ or $\mathrm{Sr}^{2+}$ partially rescues synaptic transmission in hippocampal cultures treated with botulinum toxin $\mathrm{A}$ and $\mathrm{C}$, but not tetanus toxin. J Neurosci, 17(19):7190-7202.

Changeux, J. P. and Edelstein, S. J. (1998). Allosteric receptors after 30 years. Neuron, 21(5):959-980.

Chung, S. H., Song, W. J., Kim, K., Bednarski, J. J., Chen, J., Prestwich, G. D., and Holz, R. W. (1998). The $\mathrm{C}_{2}$ domains of Rabphilin3A specifically bind phosphatidylinositol 4,5-bisphosphate containing vesicles in a $\mathrm{Ca}^{2+}$-dependent manner. In vitro characteristics and possible significance. J Biol Chem, 273(17):10240-10248.

Clements, J. D. and Bekkers, J. M. (1997). Detection of spontaneous synaptic events with an optimally scaled template. Biophys J, 73(1):220-229.

Cornille, F., Deloye, F., Fournié-Zaluski, M. C., Roques, B. P., and Poulain, B. (1995). Inhibition of neurotransmitter release by synthetic proline-rich peptides shows that the N-terminal domain of vesicle-associated membrane protein/synaptobrevin is critical for neuro-exocytosis. J Biol Chem, 270(28):16826-16832.

Deák, F., Shin, O.-H., Tang, J., Hanson, P., Ubach, J., Jahn, R., Rizo, J., Kavalali, E. T., and Südhof, T. C. (2006). Rabphilin regulates SNARE-dependent re-priming of synaptic vesicles for fusion. EMBO J, 25(12):2856-2866.

del Castillo, J. and Katz, B. (1954). Quantal components of the end-plate potential. J Physiol, 124(3):560-573.

Dittman, J. S. and Regehr, W. G. (1998). Calcium dependence and recovery kinetics of presynaptic depression at the climbing fiber to Purkinje cell synapse. J Neurosci, 18(16):6147-6162. 
Dobrunz, L. E. and Stevens, C. F. (1997). Heterogeneity of release probability, facilitation, and depletion at central synapses. Neuron, 18(6):995-1008.

Edwards, F. A., Konnerth, A., Sakmann, B., and Takahashi, T. (1989). A thin slice preparation for patch clamp recordings from neurones of the mammalian central nervous system. Pflugers Arch, 414(5):600-612.

Ellis-Davies, G. C. R. (2006). DM-nitrophen AM is caged magnesium. Cell Calcium, 39(6):471-473.

Ellis-Davies, G. C. R. (2007). Caged compounds: photorelease technology for control of cellular chemistry and physiology. Nat Methods, 4(8):619-628.

Ellis-Davies, G. C. R. (2008). Neurobiology with caged calcium. Chem Rev, 108(5):16031613.

Faas, G. C., Karacs, K., Vergara, J. L., and Mody, I. (2005). Kinetic properties of DM-nitrophen binding to calcium and magnesium. Biophys J, 88(6):4421-4433.

Foran, P., Shone, C. C., and Dolly, J. O. (1994). Differences in the protease activities of tetanus and botulinum B toxins revealed by the cleavage of vesicle-associated membrane protein and various sized fragments. Biochemistry, 33(51):15365-15374.

Forsythe, I. D. and Barnes-Davies, M. (1993a). The binaural auditory pathway: excitatory amino acid receptors mediate dual timecourse excitatory postsynaptic currents in the rat medial nucleus of the trapezoid body. Proc Biol Sci, 251(1331):151157.

Forsythe, I. D. and Barnes-Davies, M. (1993b). The binaural auditory pathway: membrane currents limiting multiple action potential generation in the rat medial nucleus of the trapezoid body. Proc Biol Sci, 251(1331):143-150.

Friauf, E. and Ostwald, J. (1988). Divergent projections of physiologically characterized rat ventral cochlear nucleus neurons as shown by intra-axonal injection of horseradish peroxidase. Exp Brain Res, 73(2):263-284.

Gansel, M., Penner, R., and Dreyer, F. (1987). Distinct sites of action of clostridial neurotoxins revealed by double-poisoning of mouse motor nerve terminals. Pflugers Arch, 409(4-5):533-539.

Gee, K. R., Archer, E. A., Lapham, L. A., Leonard, M. E., Zhou, Z. L., Bingham, J., and Diwu, Z. (2000). New ratiometric fluorescent calcium indicators with moderately attenuated binding affinities. Bioorg Med Chem Lett, 10(14):1515-1518. 
Grandes, P. and Streit, P. (1989). Glutamate-like immunoreactivity in calyces of Held. J Neurocytol, 18(5):685-693.

Grynkiewicz, G., Poenie, M., and Tsien, R. Y. (1985). A new generation of $\mathrm{Ca}^{2+}$ indicators with greatly improved fluorescence properties. J Biol Chem, 260(6):34403450 .

Hallermann, S., Pawlu, C., Jonas, P., and Heckmann, M. (2003). A large pool of releasable vesicles in a cortical glutamatergic synapse. Proc Natl Acad Sci USA, 100(15):8975-8980.

Harrison, J. M. and Irving, R. (1966). Ascending connections of the anterior ventral cochlear nucleus in the rat. J Comp Neurol, 126(1):51-63.

Heidelberger, R., Heinemann, C., Neher, E., and Matthews, G. (1994). Calcium dependence of the rate of exocytosis in a synaptic terminal. Nature, 371(6497):513515.

Helmchen, F., Borst, J. G., and Sakmann, B. (1997). Calcium dynamics associated with a single action potential in a CNS presynaptic terminal. Biophys J, 72(3):1458-1471.

Holt, M., Riedel, D., Stein, A., Schuette, C., and Jahn, R. (2008). Synaptic vesicles are constitutively active fusion machines that function independently of $\mathrm{Ca}^{2+}$. Curr Biol, 18(10):715-722.

Hosoi, N., Sakaba, T., and Neher, E. (2007). Quantitative analysis of calcium-dependent vesicle recruitment and its functional role at the calyx of Held synapse. J Neurosci, 27(52):14286-14298.

Hua, S. Y. and Charlton, M. P. (1999). Activity-dependent changes in partial VAMP complexes during neurotransmitter release. Nat Neurosci, 2(12):1078-1083.

Humeau, Y., Doussau, F., Grant, N. J., and Poulain, B. (2000). How botulinum and tetanus neurotoxins block neurotransmitter release. Biochimie, 82(5):427-446.

Inchauspe, C. G., Martini, F. J., Forsythe, I. D., and Uchitel, O. D. (2004). Functional compensation of $\mathrm{P} / \mathrm{Q}$ by N-type channels blocks short-term plasticity at the calyx of Held presynaptic terminal. J Neurosci, 24(46):10379-10383.

Ishikawa, T., Kaneko, M., Shin, H.-S., and Takahashi, T. (2005). Presynaptic N-type and $\mathrm{P} / \mathrm{Q}$-type $\mathrm{Ca}^{2+}$ channels mediating synaptic transmission at the calyx of Held of mice. J Physiol, 568(Pt 1):199-209. 
Iwasaki, S. and Takahashi, T. (1998). Developmental changes in calcium channel types mediating synaptic transmission in rat auditory brainstem. J Physiol, 509 ( Pt 2):419-423.

Iwasaki, S., Momiyama, A., Uchitel, O. D., and Takahashi, T. (2000). Developmental changes in calcium channel types mediating central synaptic transmission. J Neurosci, 20(1):59-65.

Jahn, R. and Scheller, R. H. (2006). SNAREs-engines for membrane fusion. Nat Rev Mol Cell Biol, 7(9):631-643.

Kandler, K. and Friauf, E. (1993). Pre- and postnatal development of efferent connections of the cochlear nucleus in the rat. J Comp Neurol, 328(2):161-184.

Kaplan, J. H. and Ellis-Davies, G. C. (1988). Photolabile chelators for the rapid photorelease of divalent cations. Proc Natl Acad Sci U S A, 85(17):6571-6575.

Kuwabara, N., DiCaprio, R. A., and Zook, J. M. (1991). Afferents to the medial nucleus of the trapezoid body and their collateral projections. J Comp Neurol, 314(4):684-706.

Lenn, N. J. and Reese, T. S. (1966). The fine structure of nerve endings in the nucleus of the trapezoid body and the ventral cochlear nucleus. Am J Anat, 118(2):375-389.

Leão, R. M., Kushmerick, C., Pinaud, R., Renden, R., Li, G.-L., Taschenberger, H., Spirou, G., Levinson, S. R., and von Gersdorff, H. (2005). Presynaptic Na ${ }^{+}$channels: locus, development, and recovery from inactivation at a high-fidelity synapse. $J$ Neurosci, 25(14):3724-3738.

Llinás, R., Sugimori, M., and Silver, R. B. (1992). Microdomains of high calcium concentration in a presynaptic terminal. Science, 256(5057):677-679.

London, R. E., Rhee, C. K., Murphy, E., Gabel, S., and Levy, L. A. (1994). NMRsensitive fluorinated and fluorescent intracellular calcium ion indicators with high dissociation constants. Am J Physiol, 266(5 Pt 1):C1313-C1322.

Lou, X., Scheuss, V., and Schneggenburger, R. (2005). Allosteric modulation of the presynaptic $\mathrm{Ca}^{2+}$ sensor for vesicle fusion. Nature, 435(7041):497-501.

Matthews, G. (2001). Calcium/calmodulin: a synaptic antidepressant? Neuron, $32(6): 962-963$.

Meinrenken, C. J., Borst, J. G. G., and Sakmann, B. (2002). Calcium secretion coupling at calyx of Held governed by nonuniform channel-vesicle topography. J Neurosci, 22(5):1648-1667. 
Meyer, A. C., Neher, E., and Schneggenburger, R. (2001). Estimation of quantal size and number of functional active zones at the calyx of Held synapse by nonstationary EPSC variance analysis. J Neurosci, 21(20):7889-7900.

Millar, A. G., Zucker, R. S., Ellis-Davies, G. C. R., Charlton, M. P., and Atwood, H. L. (2005). Calcium sensitivity of neurotransmitter release differs at phasic and tonic synapses. J Neurosci, 25(12):3113-3125.

Müller, M., Felmy, F., Schwaller, B., and Schneggenburger, R. (2007). Parvalbumin is a mobile presynaptic $\mathrm{Ca}^{2+}$ buffer in the calyx of Held that accelerates the decay of $\mathrm{Ca}^{2+}$ and short-term facilitation. J Neurosci, 27(9):2261-2271.

Morest, D. K. (1968). The growth of synaptic endings in the mammalian brain: a study of the calyces of the trapezoid body. Z Anat Entwicklungsgesch, 127(3):201-220.

Moulder, K. L. and Mennerick, S. (2005). Reluctant vesicles contribute to the total readily releasable pool in glutamatergic hippocampal neurons. J Neurosci, 25(15):38423850 .

Nakajima, Y. (1971). Fine structure of the medial nucleus of the trapezoid body of the bat with special reference to two types of synaptic endings. J Cell Biol, 50(1):121-134.

Naraghi, M. and Neher, E. (1997). Linearized buffered $\mathrm{Ca}^{2+}$ diffusion in microdomains and its implications for calculation of $\left[\mathrm{Ca}^{2+}\right]$ at the mouth of a calcium channel. $J$ Neurosci, 17(18):6961-6973.

Neher, E. (1998). Usefulness and limitations of linear approximations to the understanding of $\mathrm{Ca}^{2+}$ signals. Cell Calcium, 24(5-6):345-357.

Neher, E. (2008). Details of $\mathrm{Ca}^{2+}$ dynamics matter. J Physiol, 586(8):2031.

Neher, E. and Marty, A. (1982). Discrete changes of cell membrane capacitance observed under conditions of enhanced secretion in bovine adrenal chromaffin cells. Proc Natl Acad Sci U S A, 79(21):6712-6716.

Neher, E. and Sakaba, T. (2001). Combining deconvolution and noise analysis for the estimation of transmitter release rates at the calyx of Held. J Neurosci, 21(2):444-461.

Paxinos, G. and Watson, C. (1982). The rat brain in stereotaxic coordinates. Academic Press.

Pellizzari, R., Rossetto, O., Lozzi, L., Giovedi', S., Johnson, E., Shone, C. C., and Montecucco, C. (1996). Structural determinants of the specificity for synaptic vesicleassociated membrane protein/synaptobrevin of tetanus and botulinum type B and $\mathrm{G}$ neurotoxins. J Biol Chem, 271(34):20353-20358. 
Rizo, J. and Rosenmund, C. (2008). Synaptic vesicle fusion. Nat Struct Mol Biol, 15(7):665-674.

Rosenmund, C. and Stevens, C. F. (1996). Definition of the readily releasable pool of vesicles at hippocampal synapses. Neuron, 16(6):1197-1207.

Rosenmund, C., Clements, J. D., and Westbrook, G. L. (1993). Nonuniform probability of glutamate release at a hippocampal synapse. Science, 262(5134):754-757.

Rowland, K. C., Irby, N. K., and Spirou, G. A. (2000). Specialized synapse-associated structures within the calyx of Held. J Neurosci, 20(24):9135-9144.

Sakaba, T. (2006). Roles of the fast-releasing and the slowly releasing vesicles in synaptic transmission at the calyx of Held. J Neurosci, 26(22):5863-5871.

Sakaba, T. (2008). Two $\mathrm{Ca}^{2+}$-dependent steps controlling synaptic vesicle fusion and replenishment at the cerebellar basket cell terminal. Neuron, 57(3):406-419.

Sakaba, T. and Neher, E. (2001a). Calmodulin mediates rapid recruitment of fastreleasing synaptic vesicles at a calyx-type synapse. Neuron, 32(6):1119-1131.

Sakaba, T. and Neher, E. (2001b). Quantitative relationship between transmitter release and calcium current at the calyx of Held synapse. J Neurosci, 21(2):462-476.

Sakaba, T. and Neher, E. (2003a). Direct modulation of synaptic vesicle priming by $\mathrm{GABA}_{\mathrm{B}}$ receptor activation at a glutamatergic synapse. Nature, 424(6950):775-778.

Sakaba, T. and Neher, E. (2003b). Involvement of actin polymerization in vesicle recruitment at the calyx of Held synapse. J Neurosci, 23(3):837-846.

Sakaba, T., Stein, A., Jahn, R., and Neher, E. (2005). Distinct kinetic changes in neurotransmitter release after SNARE protein cleavage. Science, 309(5733):491-494.

Scheuss, V., Schneggenburger, R., and Neher, E. (2002). Separation of presynaptic and postsynaptic contributions to depression by covariance analysis of successive EPSCs at the calyx of Held synapse. J Neurosci, 22(3):728-739.

Schiavo, G., Matteoli, M., and Montecucco, C. (2000). Neurotoxins affecting neuroexocytosis. Physiol Rev, 80(2):717-766.

Schlüter, O. M., Schnell, E., Verhage, M., Tzonopoulos, T., Nicoll, R. A., Janz, R., Malenka, R. C., Geppert, M., and Südhof, T. C. (1999). Rabphilin knock-out mice reveal that rabphilin is not required for rab3 function in regulating neurotransmitter release. J Neurosci, 19(14):5834-5846. 
Schlüter, O. M., Schmitz, F., Jahn, R., Rosenmund, C., and Südhof, T. C. (2004). A complete genetic analysis of neuronal Rab3 function. J Neurosci, 24(29):6629-6637.

Schneggenburger, R. (2005). $\mathrm{Ca}^{2+}$ uncaging in nerve terminals. In R. Yuste and A. Konnerth, editors, Imaging in neuroscience and development - A laboratory manual, chapter 53, pages 415-419. Cold Spring Harbor Laboratory Press.

Schneggenburger, R. and Forsythe, I. D. (2006). The calyx of Held. Cell Tissue Res, 326(2):311-337.

Schneggenburger, R. and Neher, E. (2000). Intracellular calcium dependence of transmitter release rates at a fast central synapse. Nature, 406(6798):889-893.

Schneggenburger, R., Meyer, A. C., and Neher, E. (1999). Released fraction and total size of a pool of immediately available transmitter quanta at a calyx synapse. Neuron, 23(2):399-409.

Schneggenburger, R., Sakaba, T., and Neher, E. (2002). Vesicle pools and short-term synaptic depression: lessons from a large synapse. Trends Neurosci, 25(4):206-212.

Stanley, E. F. (1991). Single calcium channels on a cholinergic presynaptic nerve terminal. Neuron, 7(4):585-591.

Stein, A., Radhakrishnan, A., Riedel, D., Fasshauer, D., and Jahn, R. (2007). Synaptotagmin activates membrane fusion through a $\mathrm{Ca}^{2+}$-dependent trans interaction with phospholipids. Nat Struct Mol Biol, 14(10):904-911.

Stewart, B. A., Mohtashami, M., Trimble, W. S., and Boulianne, G. L. (2000). SNARE proteins contribute to calcium cooperativity of synaptic transmission. Proc Natl Acad Sci U S A, 97(25):13955-13960.

Sätzler, K., Söhl, L. F., Bollmann, J. H., Borst, J. G. G., Frotscher, M., Sakmann, B., and Lübke, J. H. R. (2002). Three-dimensional reconstruction of a calyx of Held and its postsynaptic principal neuron in the medial nucleus of the trapezoid body. $J$ Neurosci, 22(24):10567-10579.

Sun, J., Pang, Z. P., Qin, D., Fahim, A. T., Adachi, R., and Südhof, T. C. (2007). A dual- $\mathrm{Ca}^{2+}$-sensor model for neurotransmitter release in a central synapse. Nature, 450(7170):676-682.

Sun, J. Y. and Wu, L. G. (2001). Fast kinetics of exocytosis revealed by simultaneous measurements of presynaptic capacitance and postsynaptic currents at a central synapse. Neuron, 30(1):171-182. 
Takahashi, A., Camacho, P., Lechleiter, J. D., and Herman, B. (1999). Measurement of intracellular calcium. Physiol Rev, 79(4):1089-1125.

Traynelis, S. F. (1998). Software-based correction of single compartment series resistance errors. J Neurosci Methods, 86(1):25-34.

Tsuboi, T. and Fukuda, M. (2005). The C2B domain of rabphilin directly interacts with SNAP-25 and regulates the docking step of dense core vesicle exocytosis in PC12 cells. J Biol Chem, 280(47):39253-39259.

Tsuboi, T., Kanno, E., and Fukuda, M. (2007). The polybasic sequence in the C2B domain of rabphilin is required for the vesicle docking step in PC12 cells. J Neurochem, 100(3):770-779.

Ubach, J., García, J., Nittler, M. P., Südhof, T. C., and Rizo, J. (1999). Structure of the Janus-faced $\mathrm{C}_{2} \mathrm{~B}$ domain of rabphilin. Nat Cell Biol, 1(2):106-112.

Verhage, M., Maia, A. S., Plomp, J. J., Brussaard, A. B., Heeroma, J. H., Vermeer, H., Toonen, R. F., Hammer, R. E., van den Berg, T. K., Missler, M., Geuze, H. J., and Südhof, T. C. (2000). Synaptic assembly of the brain in the absence of neurotransmitter secretion. Science, 287(5454):864-869.

von Gersdorff, H. and Borst, J. G. G. (2002). Short-term plasticity at the calyx of Held. Nat Rev Neurosci, 3(1):53-64.

von Gersdorff, H., Schneggenburger, R., Weis, S., and Neher, E. (1997). Presynaptic depression at a calyx synapse: the small contribution of metabotropic glutamate receptors. J Neurosci, 17(21):8137-8146.

Wadel, K., Neher, E., and Sakaba, T. (2007). The coupling between synaptic vesicles and $\mathrm{Ca}^{2+}$ channels determines fast neurotransmitter release. Neuron, 53(4):563-575.

Weis, Schneggenburger, and Neher (1999). Properties of a model of $\mathrm{Ca}^{2+}$-dependent vesicle pool dynamics and short term synaptic depression. Biophys J, 77(5):2418-2429.

Wimmer, V. C., Horstmann, H., Groh, A., and Kuner, T. (2006). Donut-like topology of synaptic vesicles with a central cluster of mitochondria wrapped into membrane protrusions: a novel structure-function module of the adult calyx of Held. J Neurosci, 26(1):109-116.

Wölfel, M., Lou, X., and Schneggenburger, R. (2007). A mechanism intrinsic to the vesicle fusion machinery determines fast and slow transmitter release at a large CNS synapse. J Neurosci, 27(12):3198-3210. 
Wu, L. G. and Borst, J. G. (1999). The reduced release probability of releasable vesicles during recovery from short-term synaptic depression. Neuron, 23(4):821-832.

Wu, L. G., Westenbroek, R. E., Borst, J. G., Catterall, W. A., and Sakmann, B. (1999). Calcium channel types with distinct presynaptic localization couple differentially to transmitter release in single calyx-type synapses. J Neurosci, 19(2):726-736.

$\mathrm{Xu}$, J. and Wu, L.-G. (2005). The decrease in the presynaptic calcium current is a major cause of short-term depression at a calyx-type synapse. Neuron, 46(4):633-645.

Xu, J., Mashimo, T., and Südhof, T. C. (2007). Synaptotagmin-1, -2, and -9: $\mathrm{Ca}^{2+}$ sensors for fast release that specify distinct presynaptic properties in subsets of neurons. Neuron, 54(4):567-581.

Xu, T., Naraghi, M., Kang, H., and Neher, E. (1997). Kinetic studies of Ca2+ binding and Ca2+ clearance in the cytosol of adrenal chromaffin cells. Biophys J, 73(1):532545 .

Zenisek, D., Davila, V., Wan, L., and Almers, W. (2003). Imaging calcium entry sites and ribbon structures in two presynaptic cells. J Neurosci, 23(7):2538-2548.

Zucker, R. S. (1973). Changes in the statistics of transmitter release during facilitation. J Physiol, 229(3):787-810.

Zucker, R. S. and Regehr, W. G. (2002). Short-term synaptic plasticity. Annu Rev Physiol, 64:355-405. 


\section{Appendix}

\section{A.1 Abbreviations}

aCSF artificial cerebrospinal fluid

AMPA $\quad \alpha$-Amino-3-hydroxy-5-methyl-4-isoxazolepropionic acid

AP action potential

APW action potential waveform

aVCN anterior ventral cochlear nucleus

AZ active zone

BAPTA 1,2-Bis(2-aminophenoxy)ethane-N,N,N',N'-tetraacetic acid

BoNT botulinum neurotoxin

BoNT/B botulinum neurotoxin serotype B

CTZ cyclothiazide

D-AP5 D(-)-2-amino-5-phosphonopentanoic acid

DGC Dodt gradient contrast

DIC differential interference contrast

DMn DM-nitrophen (1-(2-Nitro-4,5-dimethoxyphenyl)-

N,N,N',N'-tetrakis[(oxycarbonyl)methyl]-1,2-ethanediamine)

EGTA Ethylene glycol-bis(2-aminoethylether)-N,N,N',N'-tetraacetic acid

EM electron microscopy

EPSC excitatory postsynaptic current

FRP fast releasing pool of vesicles (a subpool of the readily releasable pool)

FWHM full width of half maximum

GBC globular bushy cell

gDGG $\quad \gamma$-D-glutamylglycine

IR infrared

IPSC inhibitory postsynaptic current

ISI interstimulus interval

Kyn kynurenic acid 
mEPP miniature endplate potential

mEPSC miniature excitatory postsynaptic current

MNTB medial nucleus of the trapezoid body

Nd:YAG neodymium-doped yttrium aluminum garnet

NMDA N-methyl-D-aspartic acid

NMJ neuromuscular junction

NSF N-ethylmaleimide sensitive factor

OGB-5N Oregon Green BAPTA-5N

RRP readily releasable pool (defined as the number of docked and fusion competent vesicles that can be released by strong depolarizing pulses or $\mathrm{Ca}^{2+}$ uncaging at the calyx of Held)

RT room temperature

SEM standard error of the mean

SNAP soluble NSF attachment protein

SNAP-25 synaptosomal associated protein of $25 \mathrm{kDa}$

SNARE SNAP receptor

SRP slow releasing pool of vesicles (a subpool of the readily releasable pool)

TEA tetraethylammonium

TeNT tetanus neurotoxin

TTX tetrodotoxin

UV ultraviolet 


\section{Acknowledgment}

First and foremost, I would like to thank my supervisor Dr. Takeshi Sakaba for giving me the opportunity to conduct my $\mathrm{PhD}$ studies in his group, for the patience he took in teaching me to patch and for being a role model scientist of both tremendous skill and knowledge.

I am grateful to the members of my PhD committee, Prof. Erwin Neher, Prof. Reinhard Jahn and Prof. Tobias Moser for their ongoing support throughout my PhD years.

I would like to thank all members of the department for membrane biophysics as well as all members of the research group for biophysics of synaptic transmission for their assistance, discussions and a working atmosphere that made every minute of work worth the while.

Dr. Nobutake Hosoi and Lijun Yao deserve a special 'thanks' as great desk neighbors, snack suppliers and for sharing setups with me. I would also like to thank Dr. Samuel Young for challenging me, day in and day out, leaving me with the conclusion that science is a competitive sport...

Dr. Holger Taschenberger and Frank Würriehausen were invaluable in providing their expertise in programming. Also, I would like to thank Frank Köhne and Sigrid Schmidt for excellent technical assistance. Special thanks go to Dr. Alexander Stein for providing the BoNT/B and support with preparing the synthetic peptides and to Prof. Bert Sakmann and Dr. Gert Rapp for providing the UV laser systems used in this study.

I would like to express my gratitude to the faculty members of the MSc/ $\mathrm{PhD}$ program for Neurosciences for giving me the opportunity to study in this exciting field and within the wonderful scientific community in Göttingen. Additionally, I would like to thank Prof. Hörner and Sandra Drube for managing and organizing the Neuroscience program, as well as my 'generation' of neuroscience (Alexander, Anjana, Annette, Aycan, Barbara, Eva, Ioanna, John, Thorsten and Yunyun) and molecular biology students for the great time during class, in the lab(s) and especially during non-scientific hours.

Last but not least, I would like to thank my parents and my girlfriend for all the love and support they gave me throughout my student years. 


\section{Curriculum Vitae}

\section{Personal Data}

$\begin{aligned} \text { Name: } & \text { Kristian Wadel } \\ \text { Gender: } & \text { Male } \\ \text { Date of birth: } & 20.08 .1980 \\ \text { Place of birth: } & \text { Friedberg, Germany } \\ \text { Present Citizenship: } & \text { German }\end{aligned}$

\section{Education}

2001-2004:

2004-2005:

2005-2008:
B.Sc. in Molecular Biotechnology Ruprecht-Karls-University Heidelberg, Germany

International Max Planck Research School for Neurosciences (first segment)

Georg August-University Göttingen, Germany

PhD thesis in the research group for biophysics of synaptic transmission at the Max Planck Institute for Biophysical Chemistry, Göttingen, Germany in the framework of the

International Max Planck Research School for Neurosciences (second segment, PhD program)

Georg August-University Göttingen, Germany 


\section{Publication list}

Wadel, K., Neher, E., and Sakaba, T. (2007). The coupling between synaptic vesicles and $\mathrm{Ca}^{2+}$ channels determines fast neurotransmitter release. Neuron, 53(4):563-575. 